\author{
WILDLIFE PROGRAMMATIC \\ ENVIRONMENTAL IMPACT STATEMENT
}

\title{
NOTIFICATION OF THE
}

ACCEPTANCE OF THE DRAFT WILDLIFE

PROGRAMMATIC EIS

AND SUPPLEMENT TO THAT DRAFT AS THE

\section{FINAL EIS}

NOVEMBER 1998

:HE DUTM:"ITS CMILEGTION

\section{3}


MONTANA STATE LIBRARY

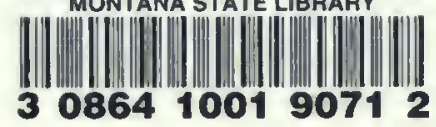




\section{(6) OMontana Fish,}

November 30, 1998

\section{NOTIFICATION OF THE ACCEPTANCE OF THE DRAFT \\ WILDLIFE PROGRAMMATIC EIS AND SUPPLEMENT TO THAT DRAFT \\ AS THE FINAL EIS}

\section{TO ALL INTERESTED PARTIES:}

This is to notify you that, with the concurrence of the Fish, Wildlife \& Parks Commission, I have made a decision to adopt the Wildlife Draft EIS and Supplement to the Draft EIS as the Final EIS, and to accept Alternative 6 as the Preferred Alternative. After careful examination of public comment on both documents, FWP found no new information to indicate that the preparation of a final EIS is necessary to analyze the consequences of this action.

The preferred alternative, as described in the Supplement to the Draft EIS, if implemented, would replace the current program as described in the Draft EIS under Alternative 1. The Preferred Alternative would continue most current actions and policies, reaffirming the effectiveness of our current wildlife program. It also provides for needed changes to the program through the incorporation of actions proposed under the other alternatives, primarily Alternative 3.

In offering this alternative, FWP believes that the factors that currently influence our operating environment will continue, including increases in the cost of delivering the present level of services. FWP also assumes that a growing human population and increased demand for services and opportunities to enjoy Montana's wildlife resources will place additional pressure on FWP to protect those resources. FWP also believes there will be an increased demand for new services that go beyond the traditional activities of hunting and trapping. More resources will be required to address the needs of species to prevent listings under the federal Endangered Species Act and there will be impacts on management, recreational opportunity and land use for species which are listed.

In response FWP proposes to seek ways to decrease the burden on hunters and anglers to fund wildlife-related programs that benefit all citizens. For example, FWP would continue to seek funding for work on federal endangered species, preventing the listing of vulnerable species and for wildlife recreation not related to hunting and trapping. This alternative also provides direction for the wildlife program to develop partnerships and increased local involvement to increase hunter access. It calls for expanded educational programs that emphasize Montana's hunting heritage, hunter behavior and the role of hunting and trapping in wildlife management. It would expand FWP's collaborative efforts with other entities such as the Montana Agricultural Extension Service and private enterprises to help deal with urban and nuisance wildlife problems and take a more active role in providing land use planners information on methods to reduce the potential for human/wildlife conflicts. 


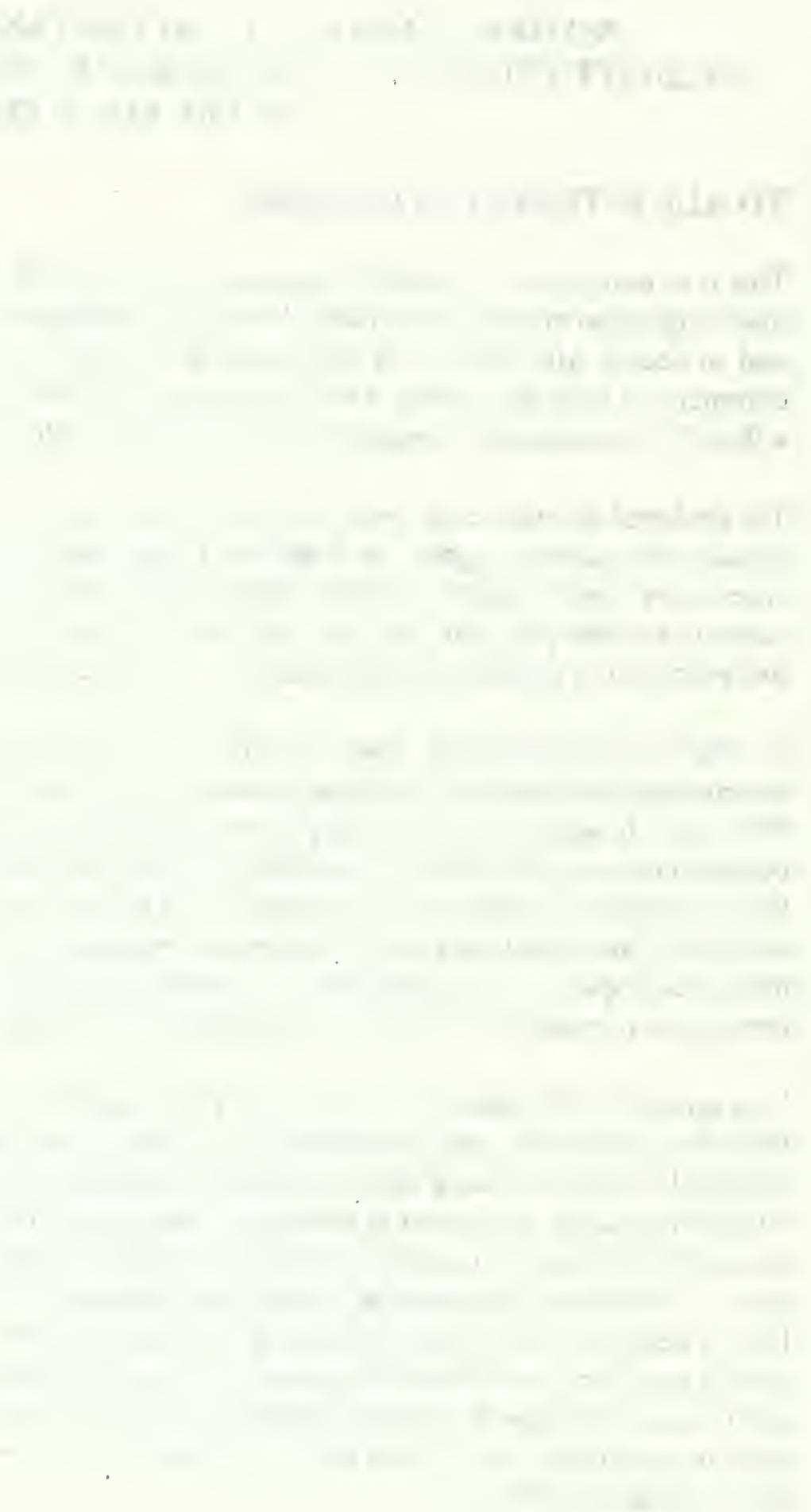


FWP believes this blend of alternatives would move the wildlife program toward a more comprehensive approach to resource stewardship, would decrease the burden on hunters and anglers to fund all wildlife-related programs, provides FWP the direction that nontraditional programs be supported by alternative funding, and identifies services for which collaborative or private sector effort will best meet public needs and expectations.

FWP also believes that the range of alternatives and our analysis of the probable consequences of implementing each alternative as described in the Draft EIS and Supplement have adequately addressed the important issues relevant to managing the state's wildlife resources. No new issues were raised though the final phase of public involvement. Additionally, public comment on the Draft EIS and Supplement focused primarily on actions and policies proposed under the analyzed alternatives and did not indicate that our analysis of environmental consequences was incomplete or inadequate. Thus FWP's decision is to forego publication of a Final EIS and to adopt the Draft EIS and Supplement to the Draft as the Final EIS.

For your information in this packet we are enclosing the Preferred Alternative, the environmental analysis of that alternative and a summary of public comment received on the Draft EIS and Supplement.

This notice of decision will be followed by a published Record of Decision (ROD) that will provide the legal and administrative rationale for the decision. Please send any inquiries to: Wildlife Division, POB 200701, Helena, MT 59620-0701.

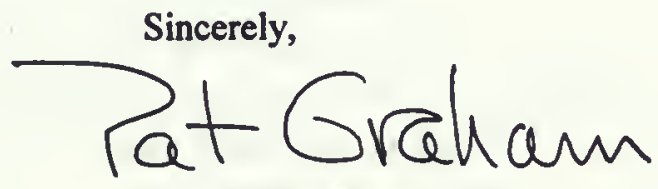

Patrick J. Graham

Director 



\section{TABLE OF CONTENTS}

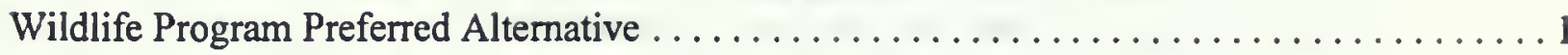

Matrix for Developing a Preferred Alternative from the Wildlife Draft EIS $\ldots \ldots \ldots \ldots \ldots 2$

Environmental Effects analysis of the Preferred Alternative $\ldots \ldots \ldots \ldots \ldots \ldots \ldots \ldots$

Issue:

Access/Effects on Wildlife ................................... 17

Recreational Opportunity/Effects on Wildlife .................... 18

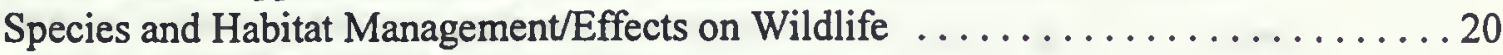

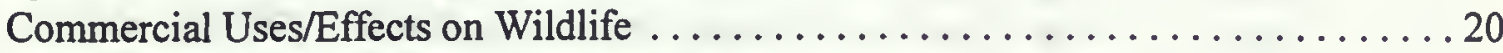

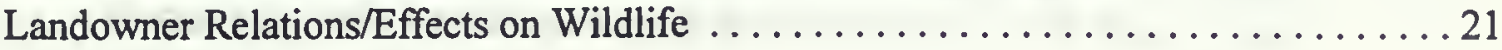

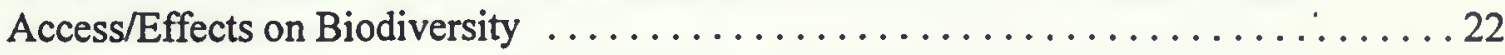

Recreational Opportunity/Effects on Biodiversity ................... 22

Species and Habitat Management/Effects on Biodiversity $\ldots \ldots \ldots \ldots \ldots \ldots \ldots 23$

Commercial Uses/effects on Biodiversity . . . . . . . . . . . . . . . . . 24

Landowner Relations/Effects on Biodiversity . . . . . . . . . . . . . . . 24

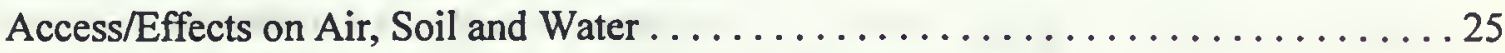

Recreational Opportunity/Effects on Air, Soil and Water ............... 25

Species and Habitat Management/Effects on Air, Soil and Water . . . . . . . . . . 26

Commercial Uses/Effects on Air, Soil and Water .................... 26

Landowner Relations/Effects on Air, Soil and Water ................... 26

Access/Effects on Recreational Opportunity ....................... 27

Recreational Opportunity/Effects on Recreational Opportunity ............. 28

Species and Habitat Management/Effects on Recreational Opportunity . . . . . . . . . . 29

Commercial Uses/Effects on Recreational Opportunity ................. 30

Landowner Relations/Effects on Recreational Opportunity ................. 30

Access/Effects on Archaeological and Historical Resources . . . . . . . . . . . . 30

Recreational Opportunity/Effects on Archaeological and Historical Resources . . . . . 31

Species \& Habitat Management/Effects on Archaeological and Historical Resources . . 31

Commercial Uses/Effects on Archaeological and Historical Resources ........... 32

Landowner Relations/Effects on Archaeological and Historical Resources . . . . . . 32

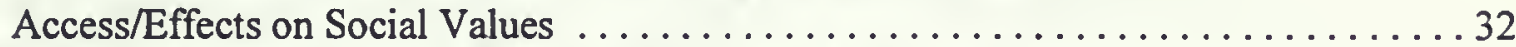

Recreational Opportunity/Effects on Social Values ................... 34

Species and Habitat Management/Effects on Social Values ................ 36

Commercial Uses/Effects on Social Values . . . . . . . . . . . . . . . . . . 37

Landowner Relations/Effects on Social Values ...................... 37

Access/Effects on Economic Values . ........................... 38

Recreational Opportunity/Effects on Economic Values .................... 39

Species and Habitat Management/Effects on Economic Values ............. 40

Commercial Uses/Effects on Economic Values . . . . . . . . . . . . . . . 41

Landowner Relations/Effects on Economic Values ................... 41

Access/Effect on Other Agencies and Staff . .................... 42

Recreational Opportunity/Effect on Other Agencies and Staff ..............43 
Species and Habitat Management/Effect on Other Agencies and Staff . . . . . . . . 44

Commercial Uses/Effect on Other Agencies and Staff ................. 45

Landowner Relations/Effect on Other Agencies and Staff . . . . . . . . . . 45

Access/Effects on Priorities, Funding and Staffing .................. 46

Recreational Opportunity/Effects on Priorities, Funding and Staffing .......... 47

Species and Habitat Management/Effects on Priorities, Funding and Staffing . . . . . . 48

Commercial Uses/Effects on Priorities, Funding and Staffing '. . . . . . . . . . . . . 49

Landowner Relations/Effects on Priorities, Funding and Staffing $\ldots \ldots \ldots \ldots . \ldots 49$

Access/Effect on Licensing, Regulations and Enforcement ............... 50

Recreational Opportunity/Effect on Licensing, Regulations and Enforcement .... . . 5 51

Species \& Habitat Management/Effect on Licensing, Regulations and Enforcement . . . 51

Commercial Uses/Effect on Licensing, Regulations and Enforcement . . . . . . . . . 52

Landowner Relations/Effect on Licensing, Regulations and Enforcement ........ 52

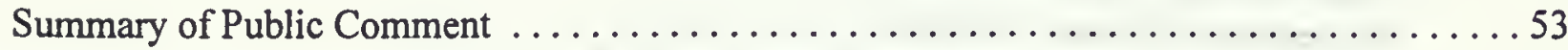

Samples of Comments Received on Draft EIS and FWP's Response $\ldots . \ldots \ldots \ldots \ldots . \ldots 55$

Summary of Public Response to the Preferred Alternative (Draft Supplement) . . . . . . . 75

Appendices

Appendix A. Organizations, Groups or Individuals that Reviewed and Responded to the

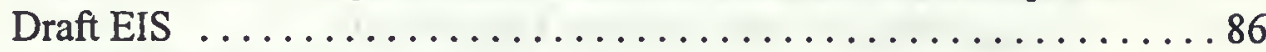

Appendix B. Wildlife EIS Response Form .................... 90

Appendix C. Organizations, Groups or Individuals that Reviewed and Responded to the

Draft Supplement ...........................91

Appendix D. Summary of Questions from Response Form $\quad$. $\quad$. . . . . . . . 92

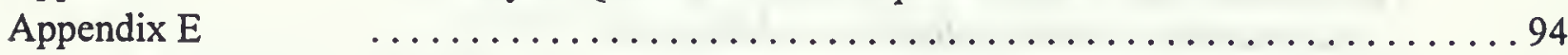

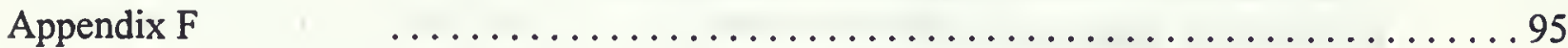




\section{WILDLIFE PROGRAM PREFERRED ALTERNATIVE}

\section{NOVEMBER 30, 1998}

After giving careful consideration to public comment on the five alternatives analyzed in the draft EIS, FWP offers a sixth alternative that it believes to be the most reasonable integration of public expectations and sound wildlife stewardship. FWP recognizes that its current package of actions and policies is not "broken," but there remain opportunities for improvement. These opportunities have been highlighted through both public comment and internal dialogue. While this alternative will not go far enough to satisfy the expectations of some individuals and groups, all comments and suggestions were given full consideration. What has become apparent through the process of examining FWP's wildlife programs is that Montana residents take their wildlife resource very seriously.

\section{Proposed Action}

FWP proposes to implement a long-term wildlife management program that will provide direction over the next ten years, consider all its collective actions related to wildlife, and meet its legal mandate in a manner that allows FWP to adapt to a changing future.

\section{Alternative 6 (Preferred alternative)}

This alternative will continue many of the actions and policies cited under alternative 1 in the draft EIS and incorporate others, primarily from alternative 3 and to a lesser extent from alternative 5 .

In offering this alternative, FWP assumes that forces influencing its operating environment will continue, including increases in the cost of delivering the present level of services. FWP also assumed that a growing human population and increased demand for services and opportunities to enjoy the resource will place increasing pressure on FWP to protect Montana's rich wildlife resources. These forces will also bring an increased demand for new services that go beyond the traditional activities of hunting and trapping. FWP believes this blend of alternatives, while continuing to retain much of our current program, will move the wildlife program toward the more comprehensive approach to resource stewardship that was embodied in alternative 3 . It would also seek to decrease the burden on hunters and anglers to fund all wildlife-related programs by seeking new funding for some programs, while identifying some in which collaborative or private sector effort would best meet public expectations, as proposed under alternatives 4 and 5 . 


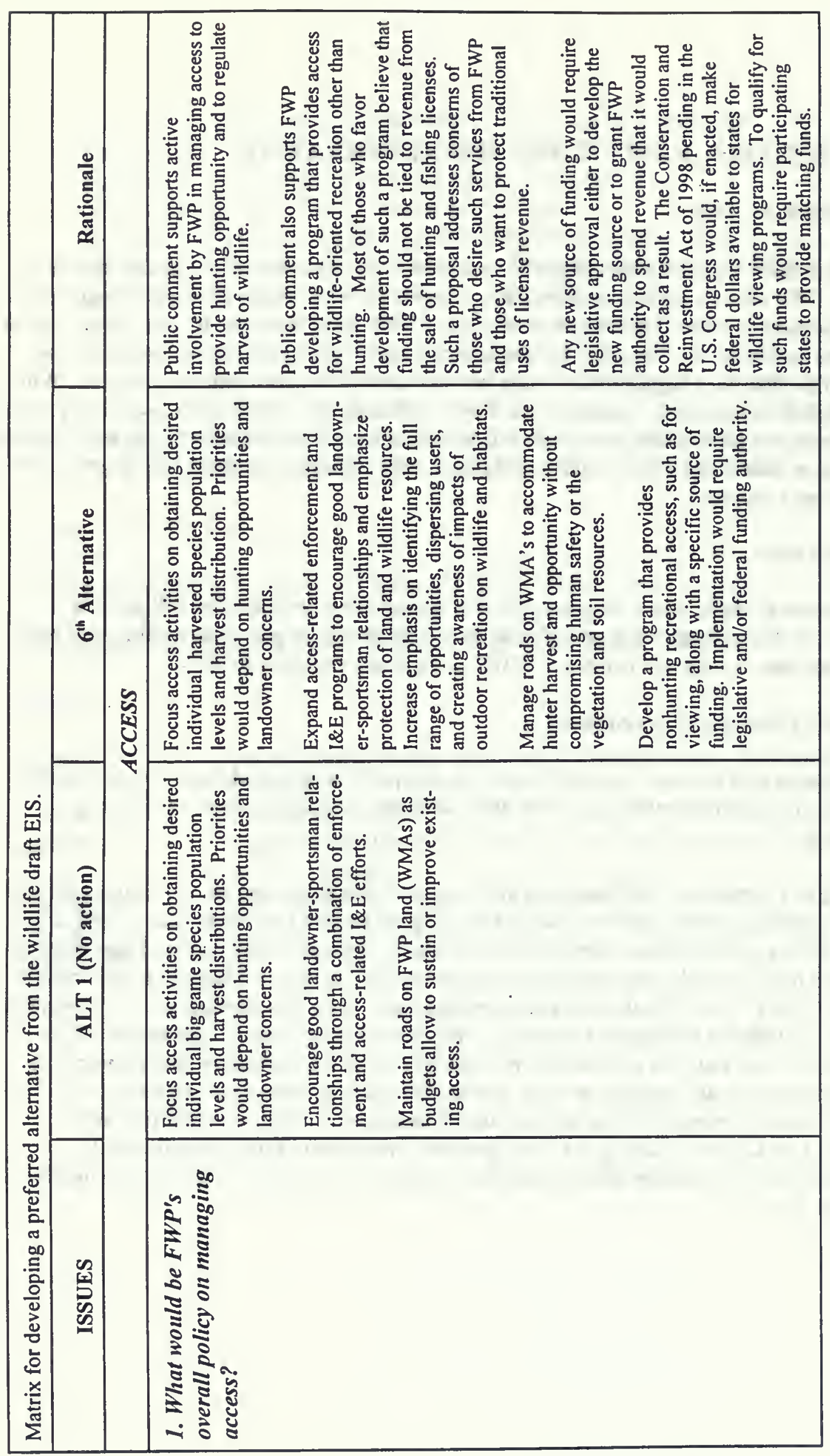




\begin{tabular}{|c|c|c|c|c|}
\hline 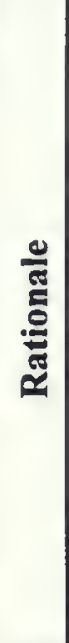 & 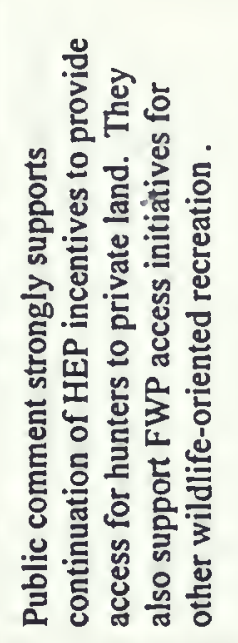 & 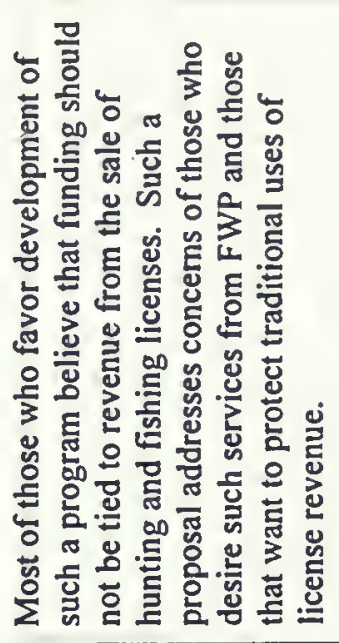 & 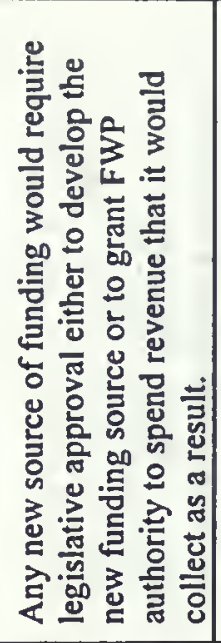 & 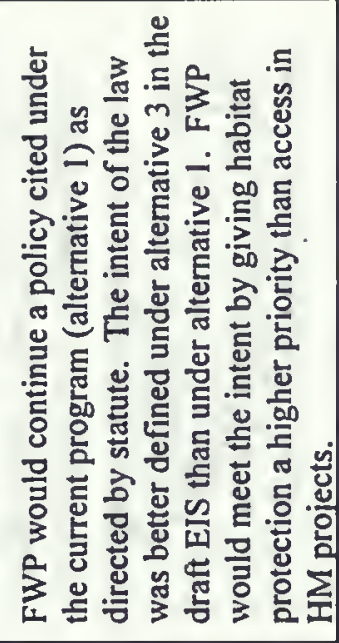 \\
\hline 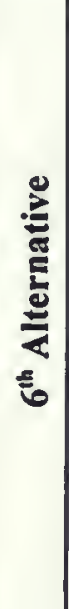 & 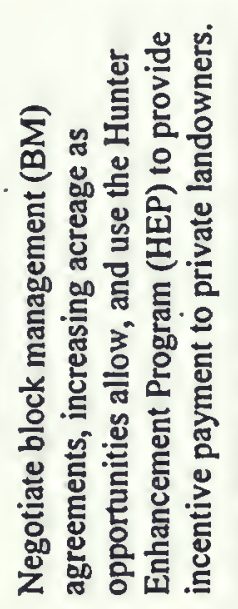 & 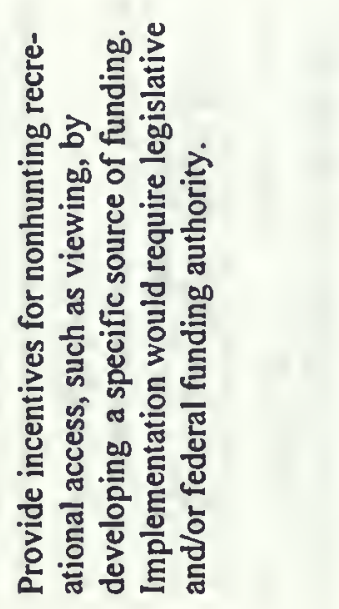 & & 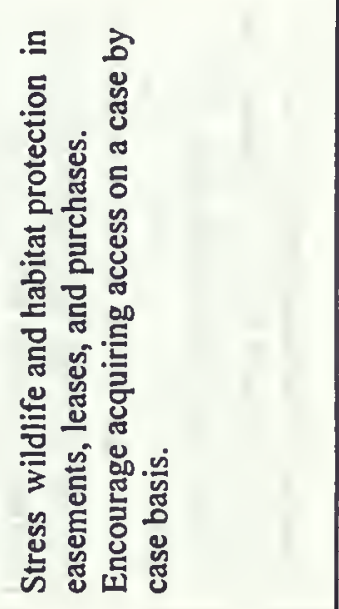 \\
\hline 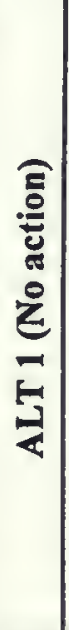 & 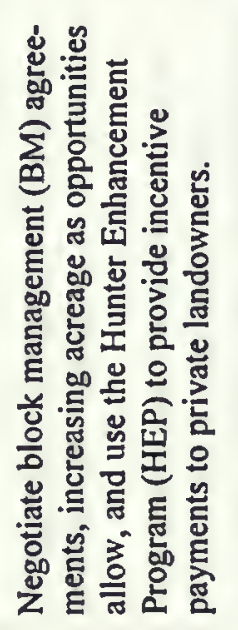 & & $x$ & 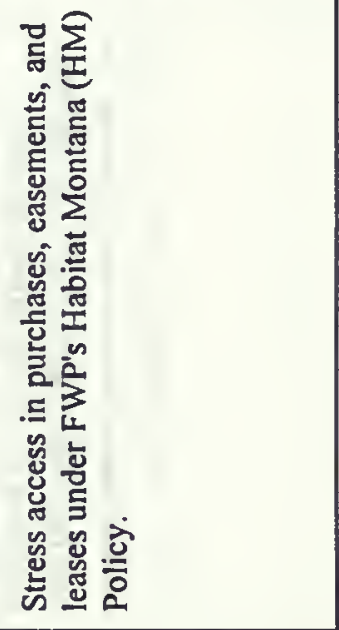 \\
\hline 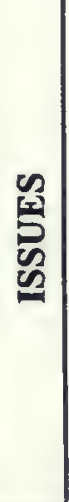 & 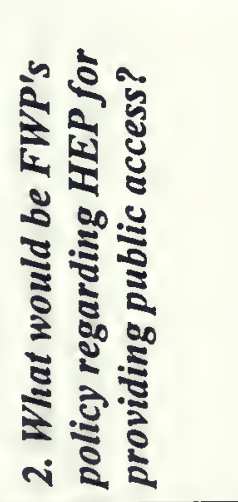 & & - & 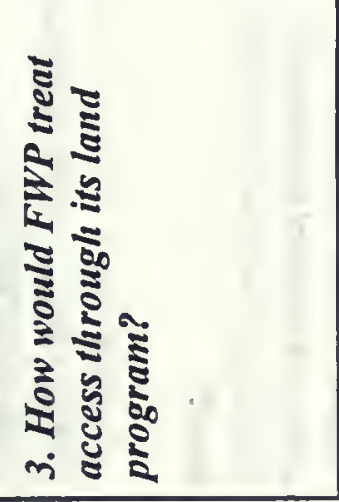 \\
\hline
\end{tabular}




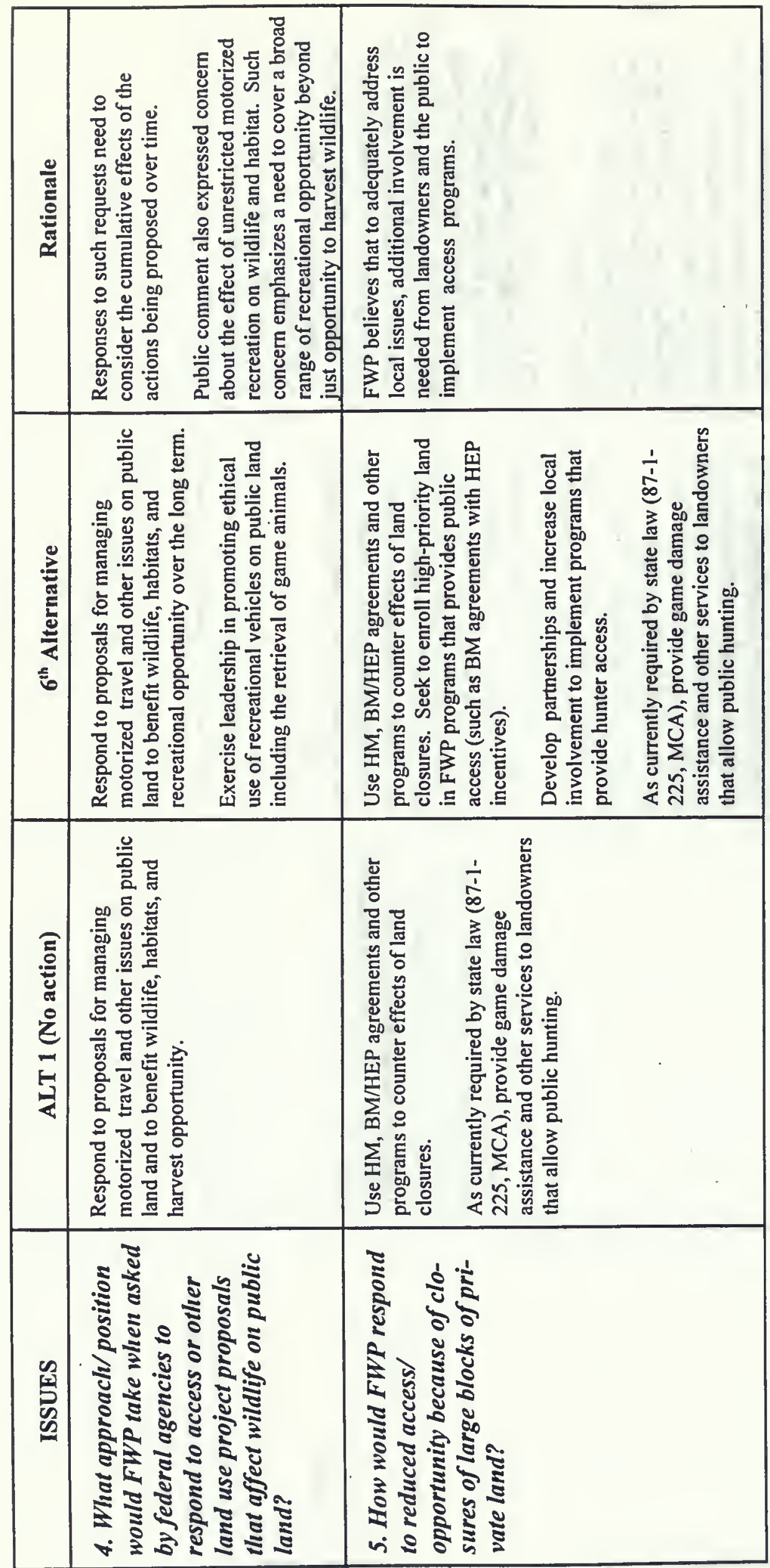




\begin{tabular}{|c|c|c|c|c|c|c|c|}
\hline \multirow[t]{2}{*}{ 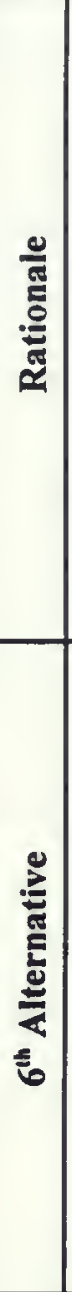 } & \multicolumn{3}{|l|}{ 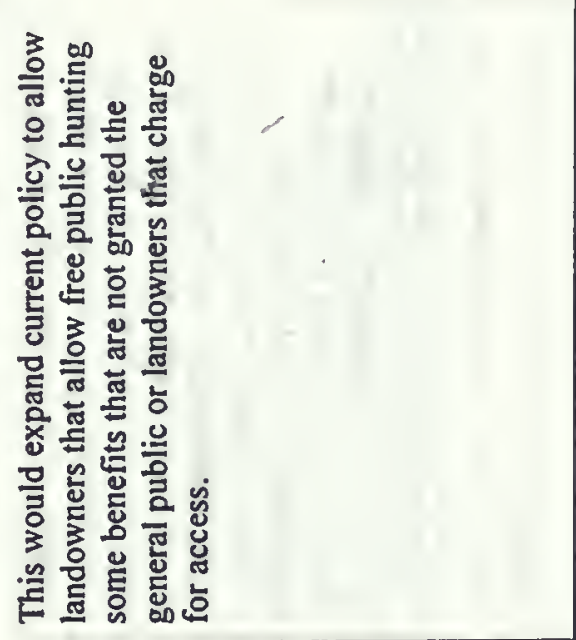 } & & \multicolumn{3}{|c|}{ 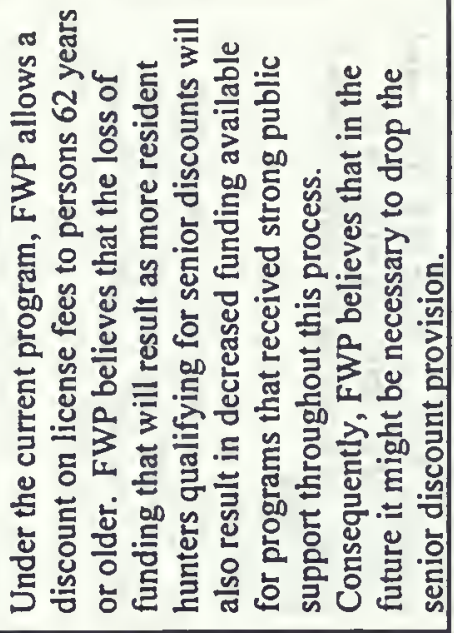 } \\
\hline & 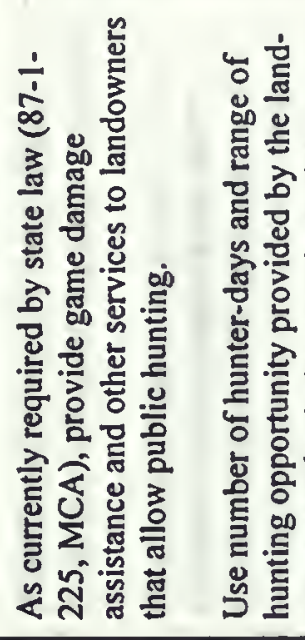 & & 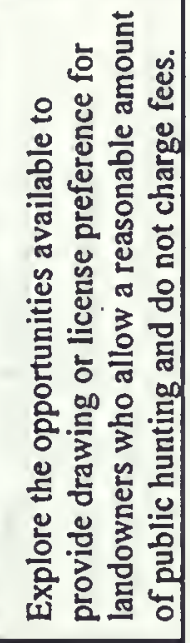 & 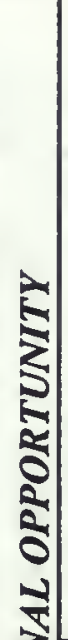 & 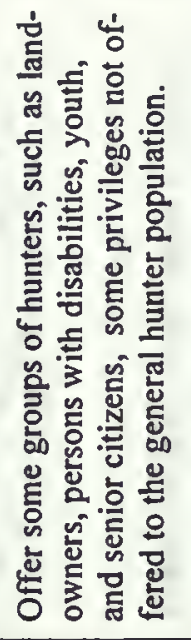 & 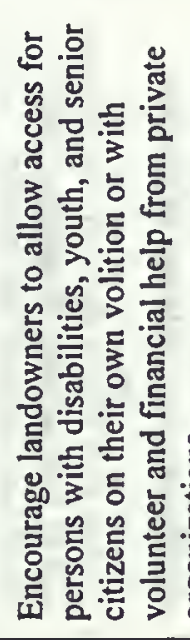 & \\
\hline 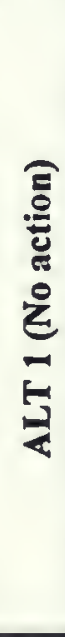 & 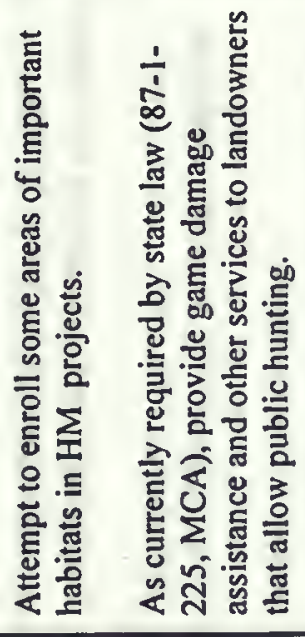 & & 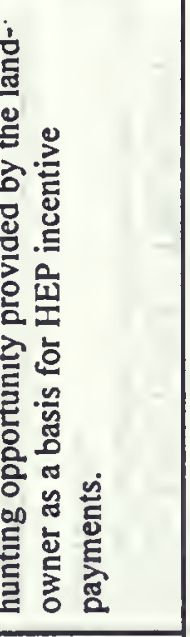 & 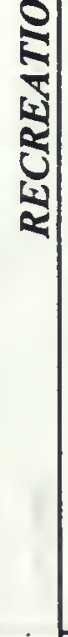 & 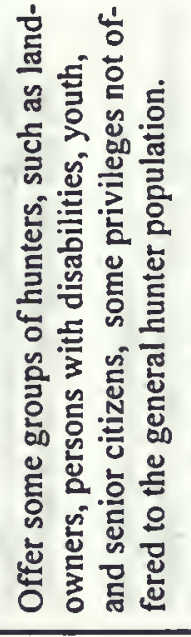 & 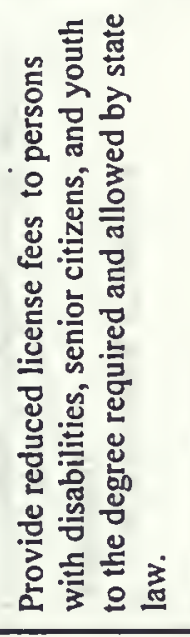 & \\
\hline 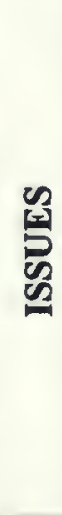 & 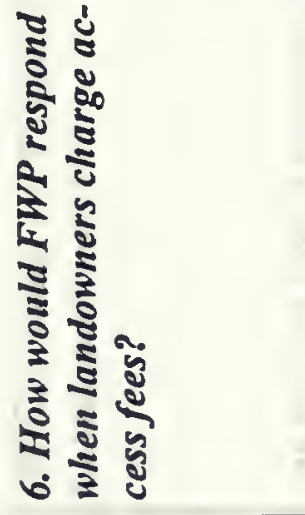 & & & & 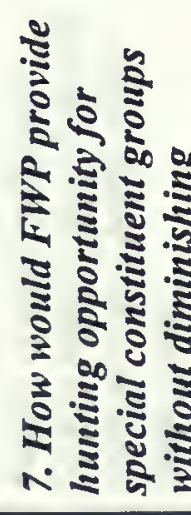 & 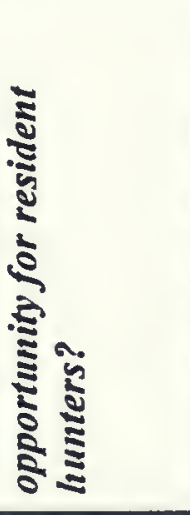 & 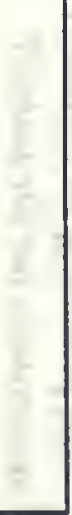 \\
\hline
\end{tabular}




\begin{tabular}{|c|c|c|c|c|c|c|c|c|}
\hline 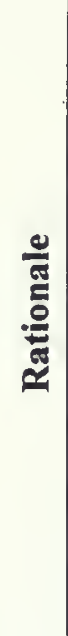 & \multicolumn{2}{|c|}{ 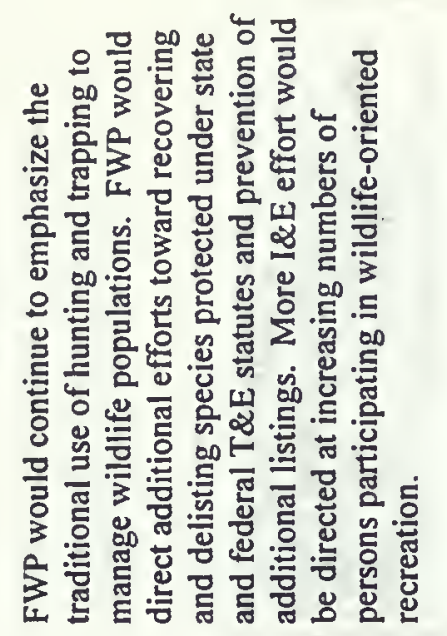 } & - & & & \multicolumn{3}{|c|}{ 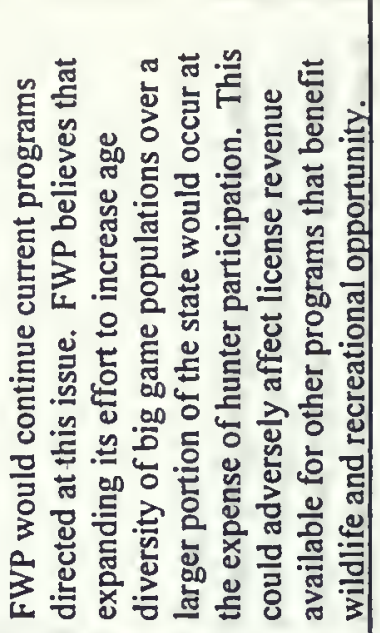 } \\
\hline 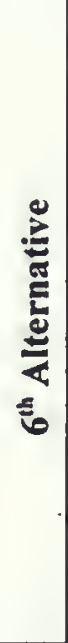 & 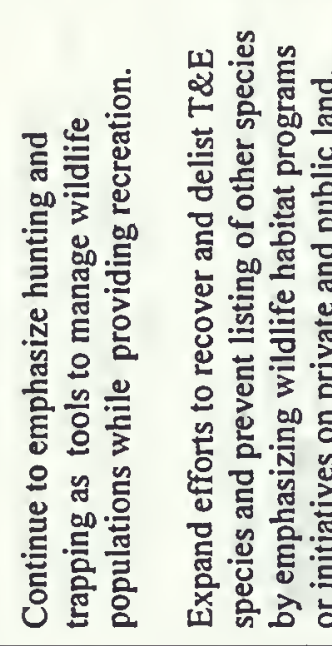 & 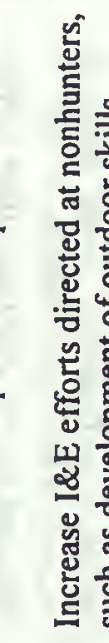 & 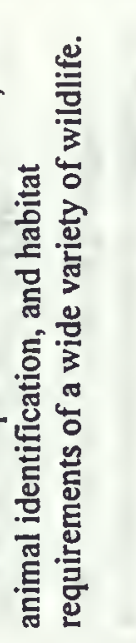 & & & 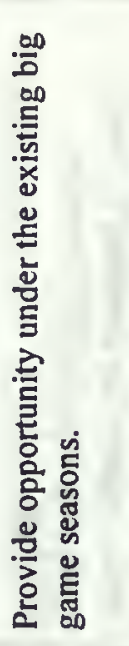 & 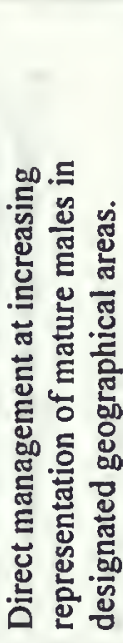 & 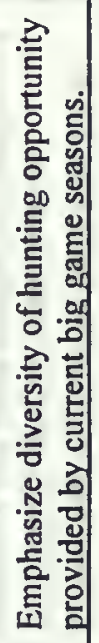 \\
\hline 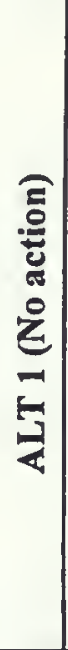 & 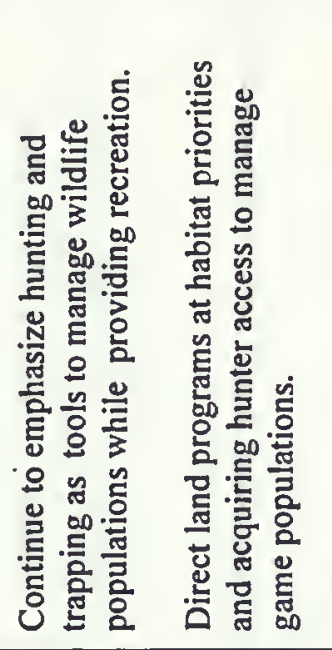 & 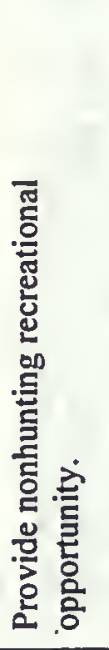 & 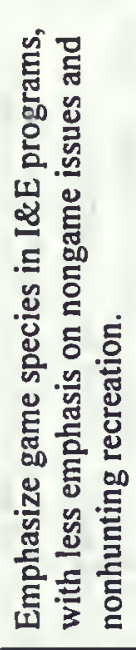 & 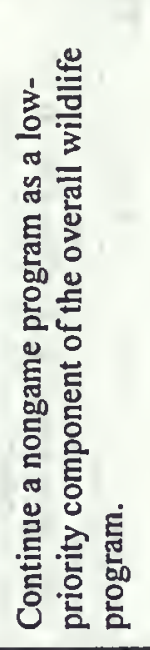 & 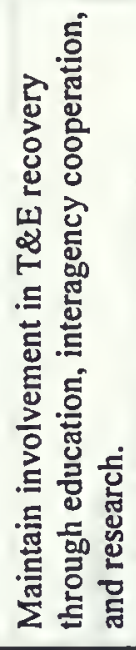 & 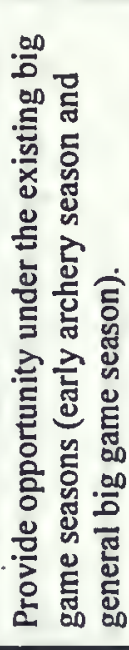 & 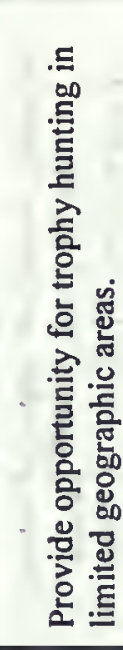 & 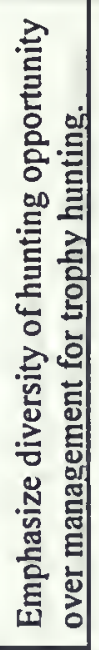 \\
\hline 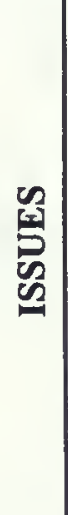 & 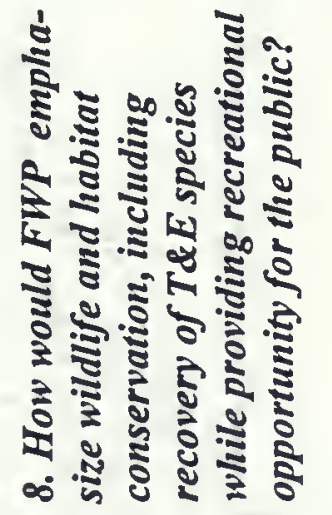 & & & & & 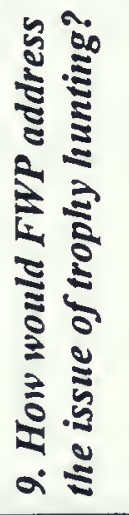 & & \\
\hline
\end{tabular}




\begin{tabular}{|c|c|c|c|c|c|c|c|c|}
\hline 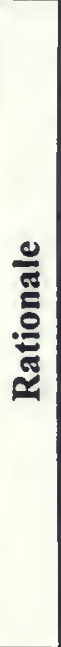 & \multicolumn{4}{|c|}{ 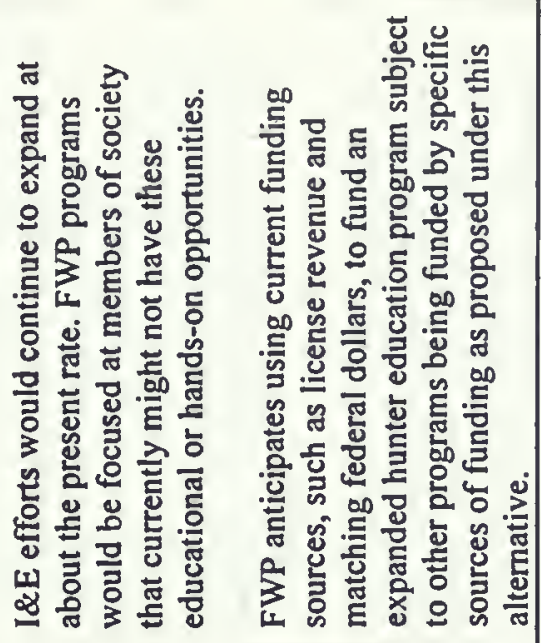 } & \multicolumn{2}{|c|}{ 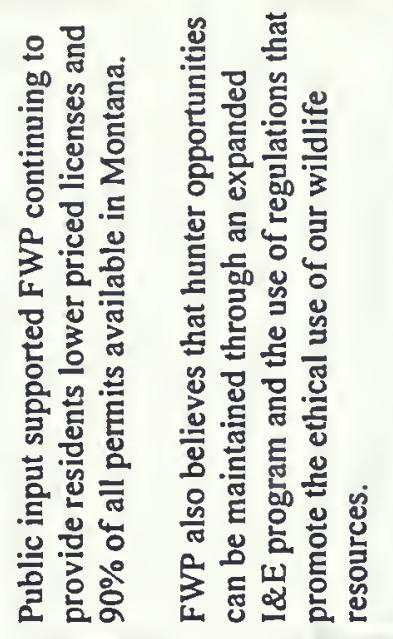 } & & 7 \\
\hline 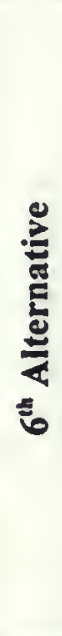 & 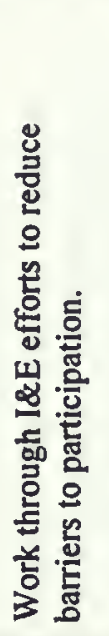 & 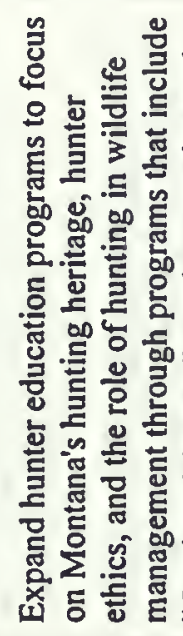 & 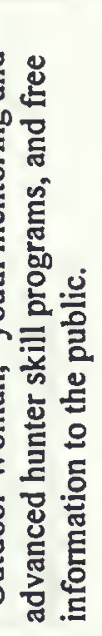 & 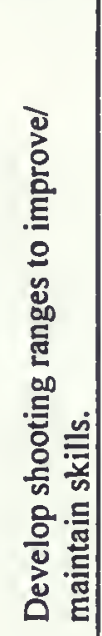 & 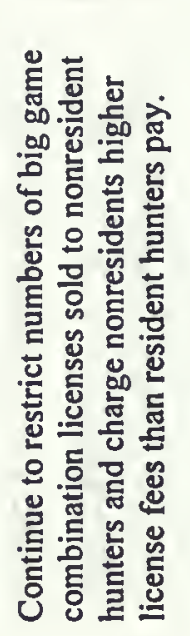 & 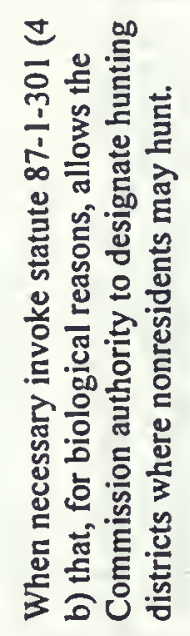 & 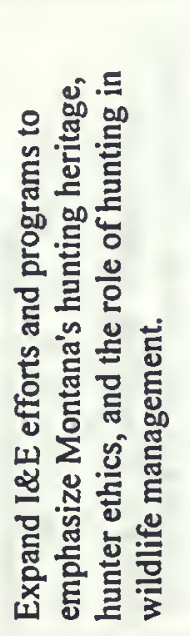 & 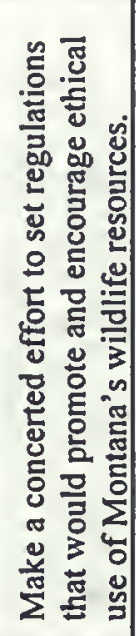 \\
\hline 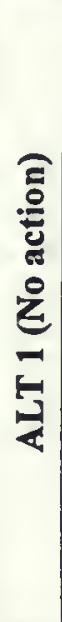 & 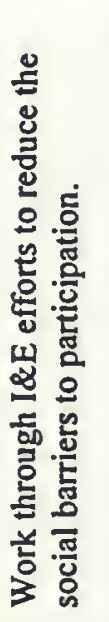 & 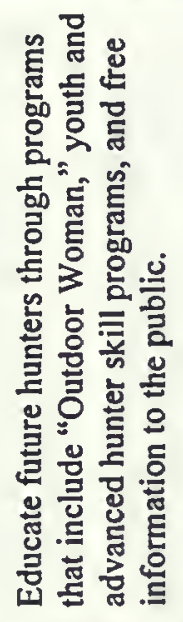 & 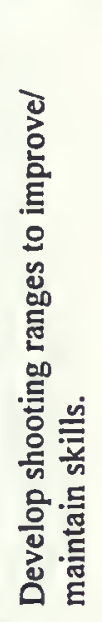 & & 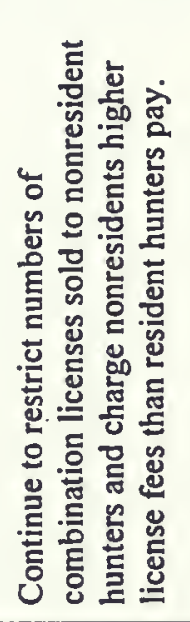 & 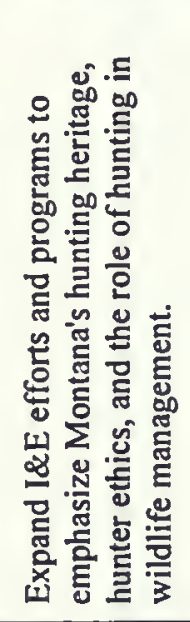 & & \\
\hline 嗂 & 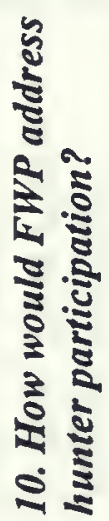 & & & & 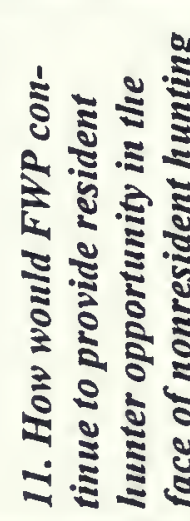 & 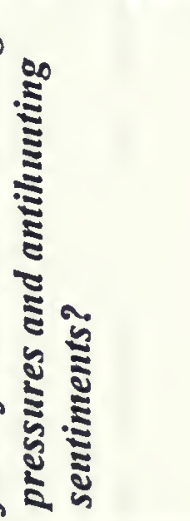 & & - \\
\hline
\end{tabular}




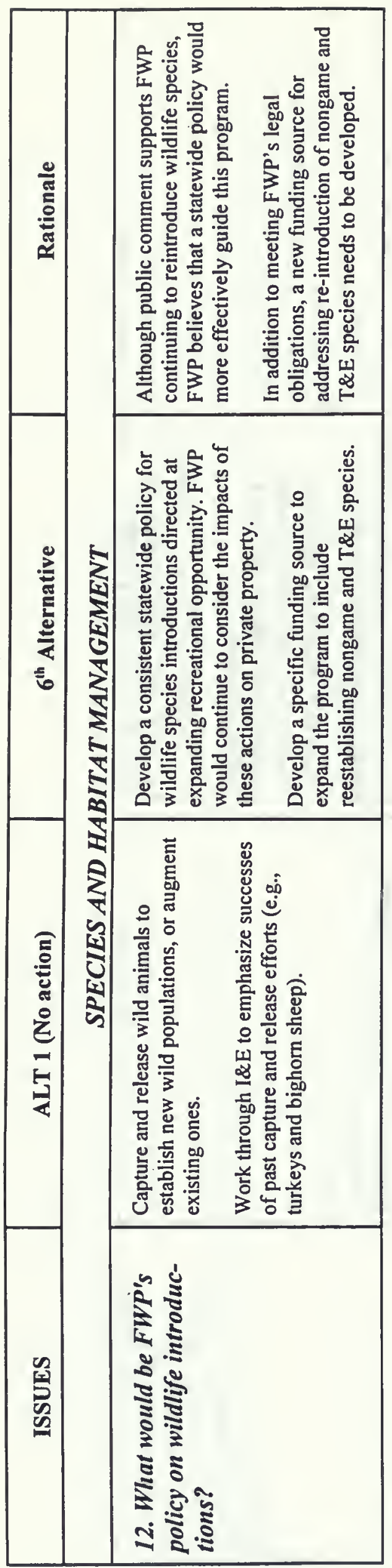




\begin{tabular}{|c|c|c|c|c|c|c|c|}
\hline 总 & 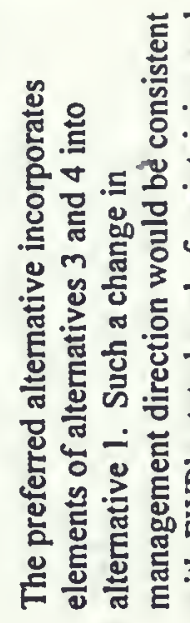 & 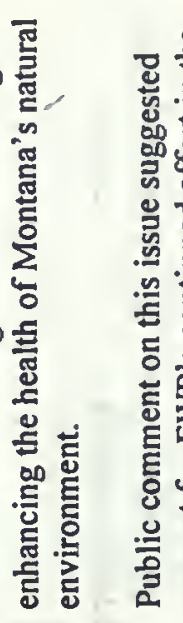 & 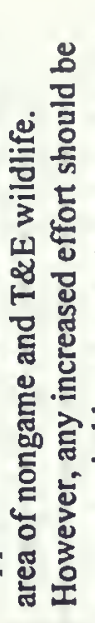 & & & 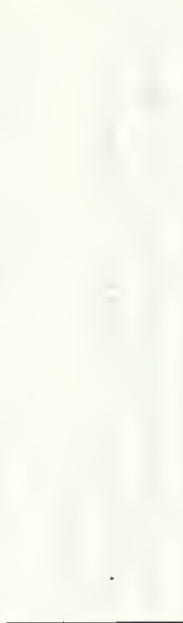 & \\
\hline 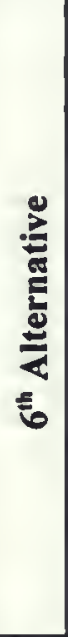 & 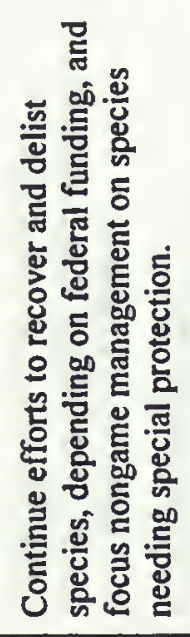 & 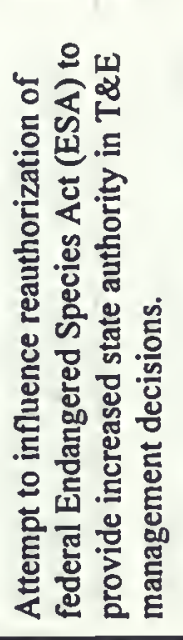 & 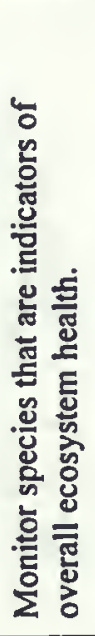 & 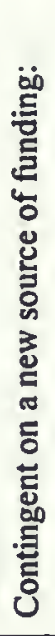 & 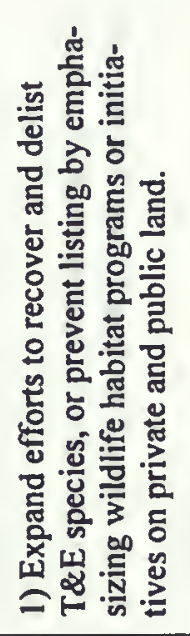 & 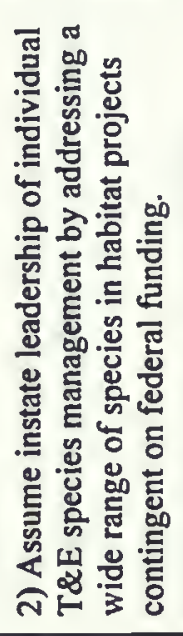 & 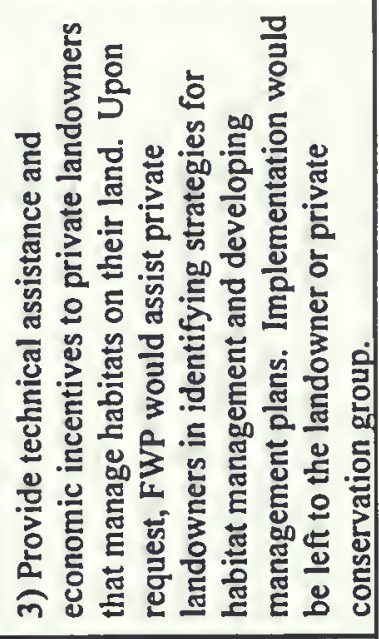 \\
\hline 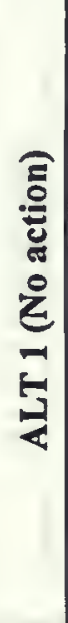 & 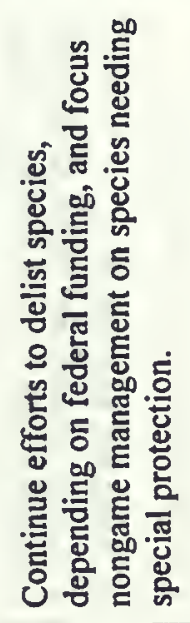 & 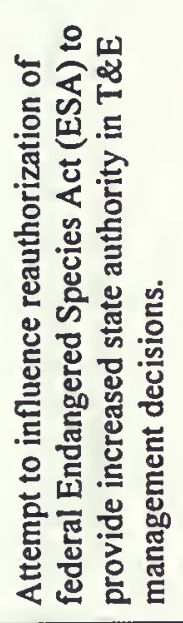 & 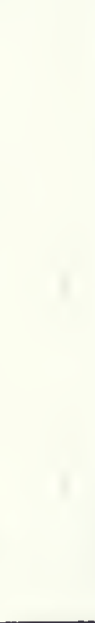 & & & 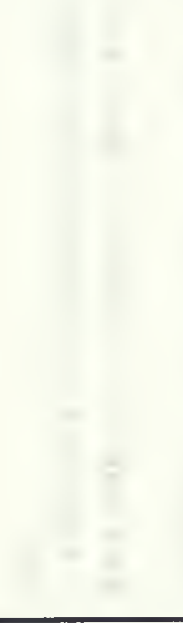 & 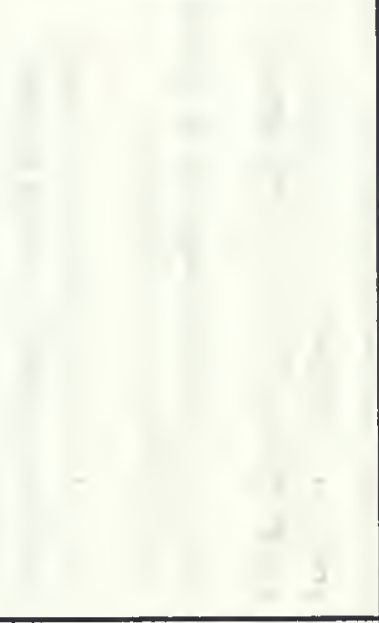 \\
\hline $\begin{array}{l}\mathscr{W} \\
5 \\
\widetilde{\sigma} \\
\mathbb{E}\end{array}$ & 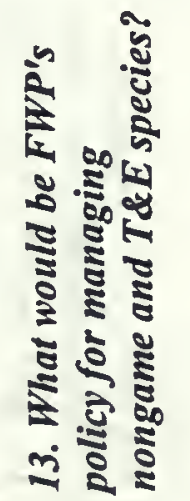 & & -2 & . & & & $\cdots$ \\
\hline
\end{tabular}




\begin{tabular}{|c|c|c|c|c|c|}
\hline & 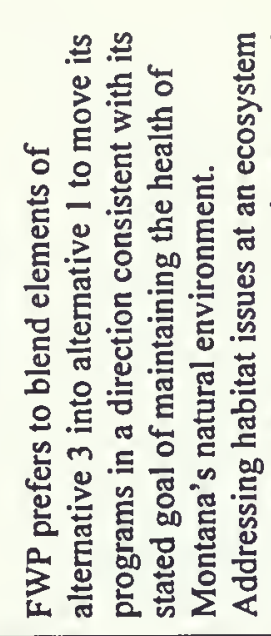 & 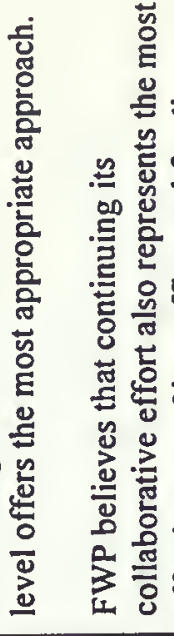 & 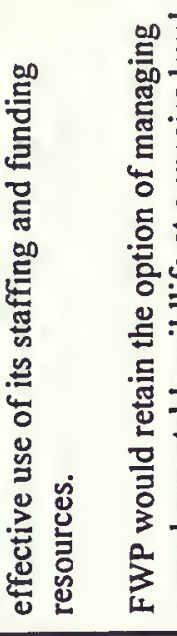 & 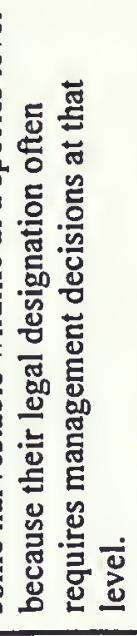 & 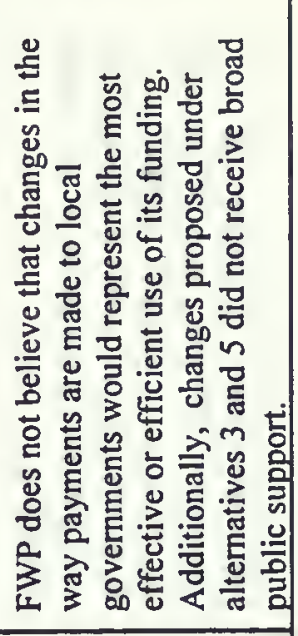 \\
\hline 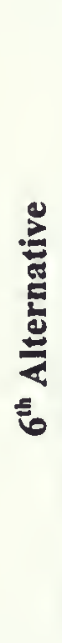 & 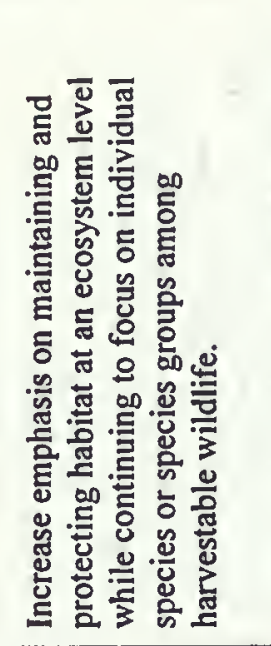 & 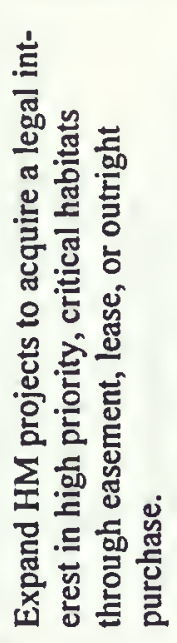 & 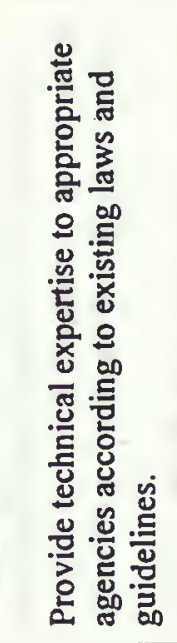 & 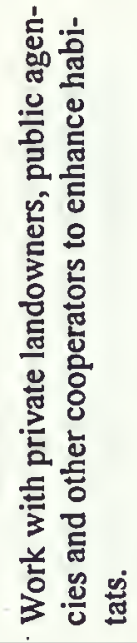 & 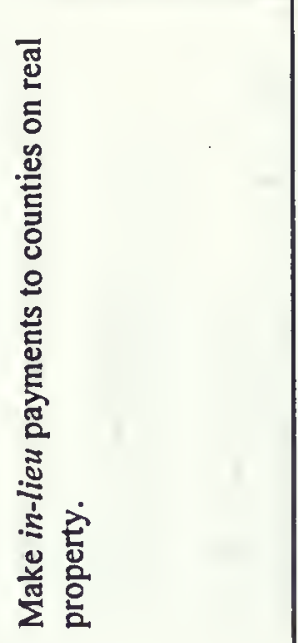 \\
\hline 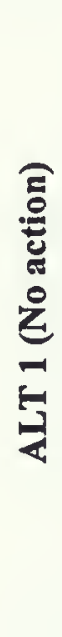 & 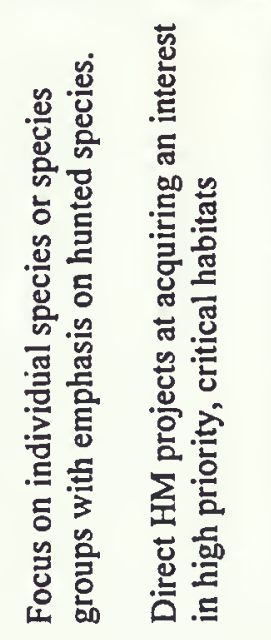 & 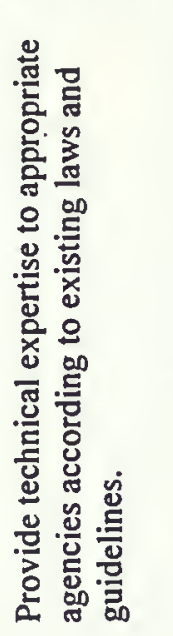 & 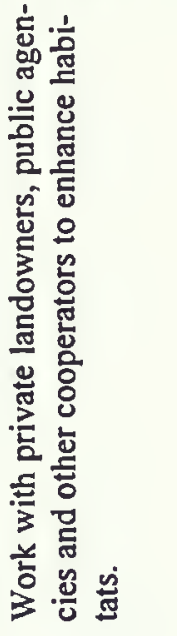 & & 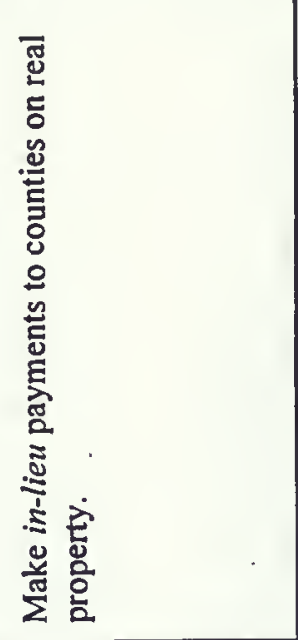 \\
\hline 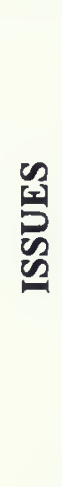 & 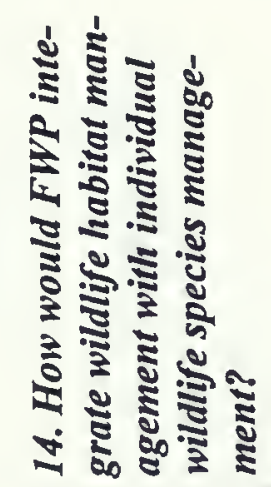 & & & & 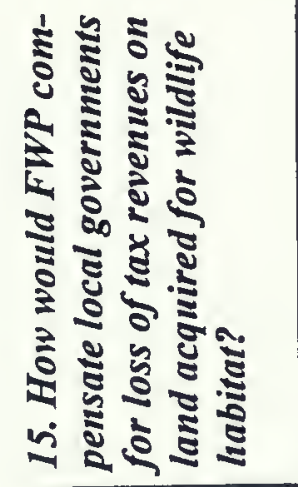 \\
\hline
\end{tabular}




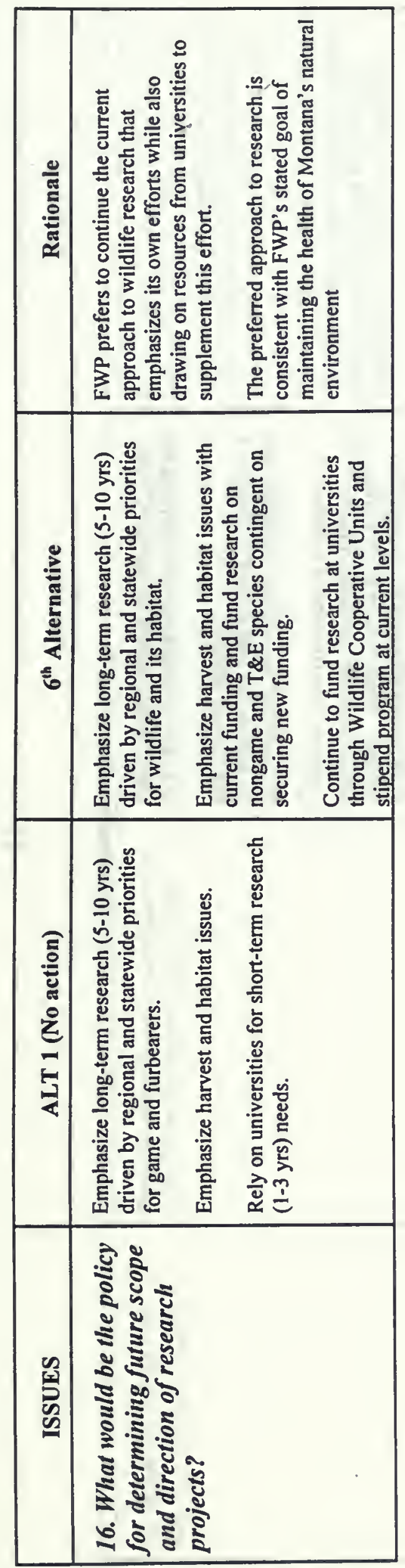




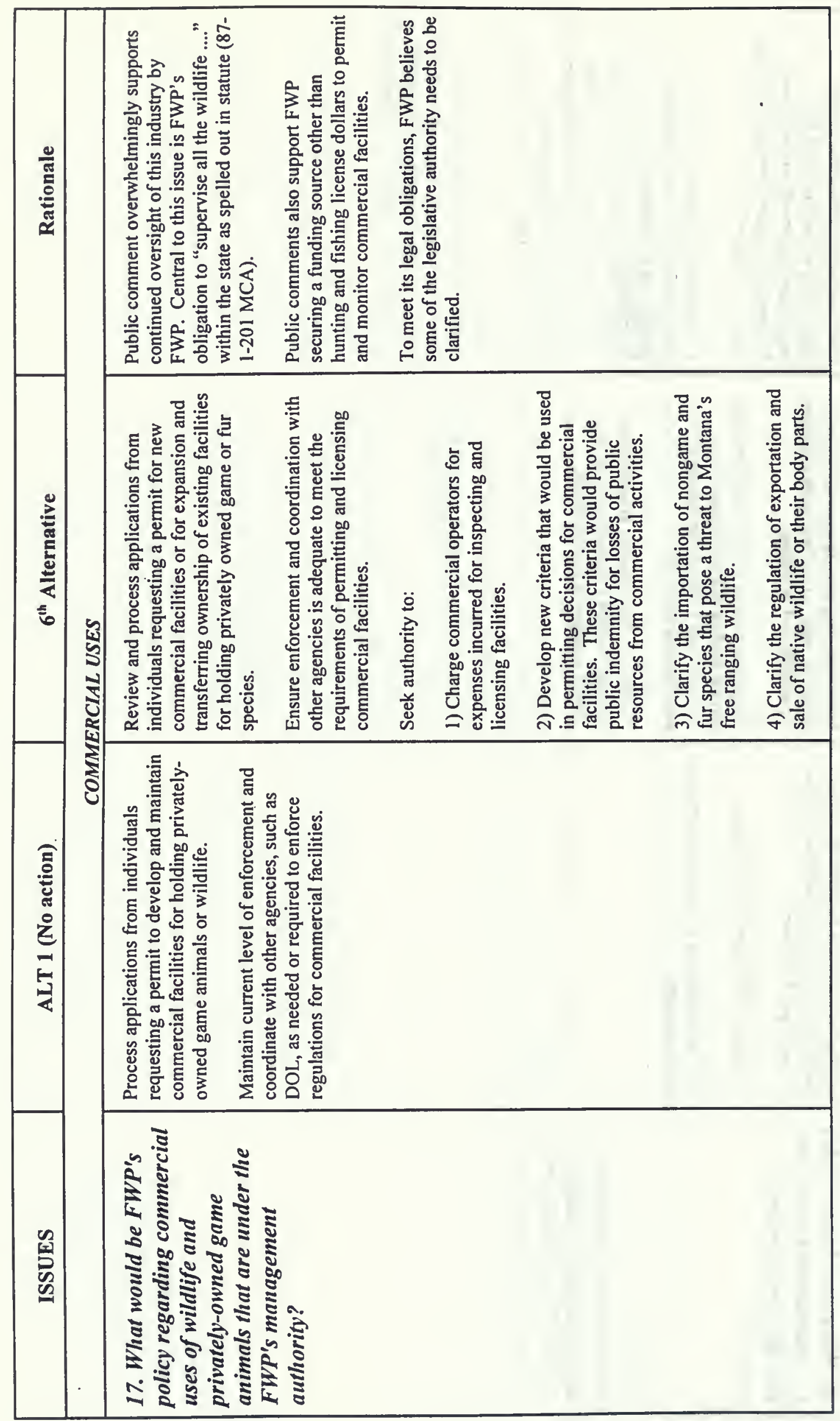




\begin{tabular}{|c|c|c|c|c|}
\hline 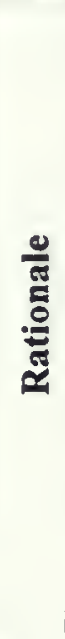 & & \multicolumn{2}{|c|}{ 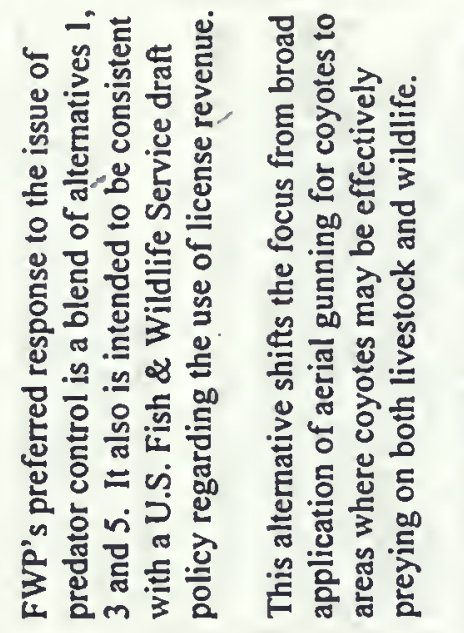 } & 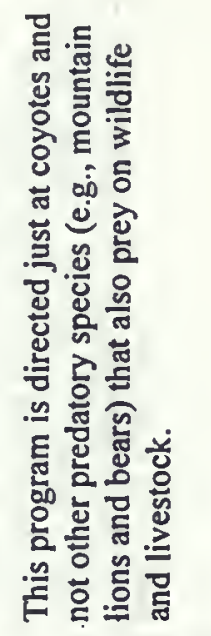 \\
\hline 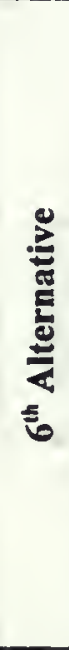 & 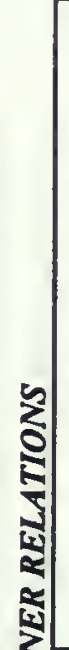 & 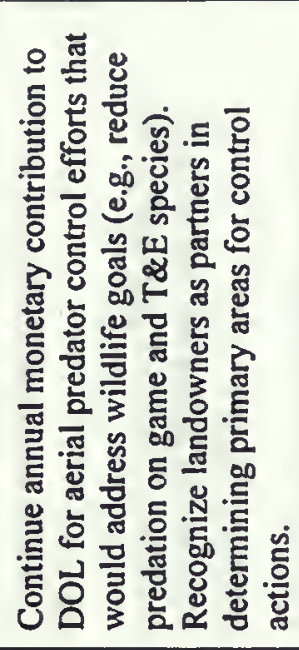 & 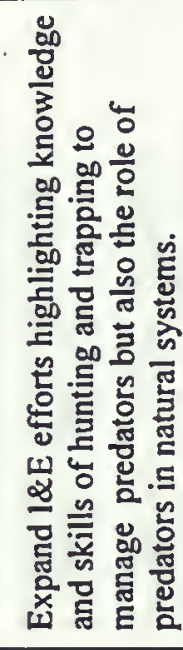 & 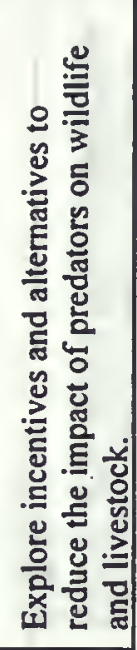 \\
\hline 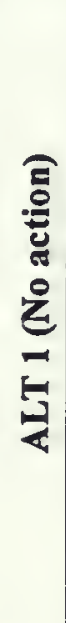 & $\begin{array}{l}\overrightarrow{0} \\
\vdots \\
3\end{array}$ & 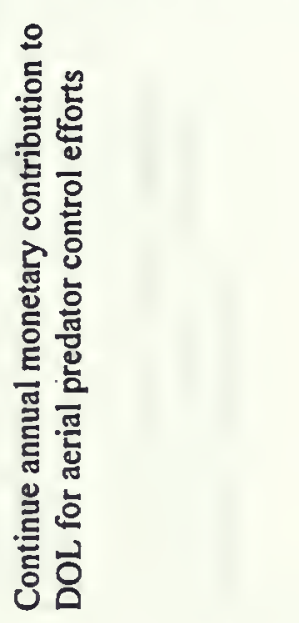 & & \\
\hline $\begin{array}{l}\mathscr{w} \\
\text { 点 } \\
\text { 心 }\end{array}$ & & 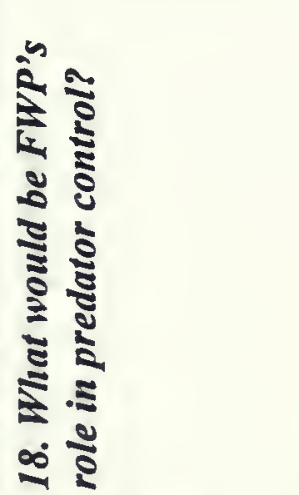 & & $t$ \\
\hline
\end{tabular}




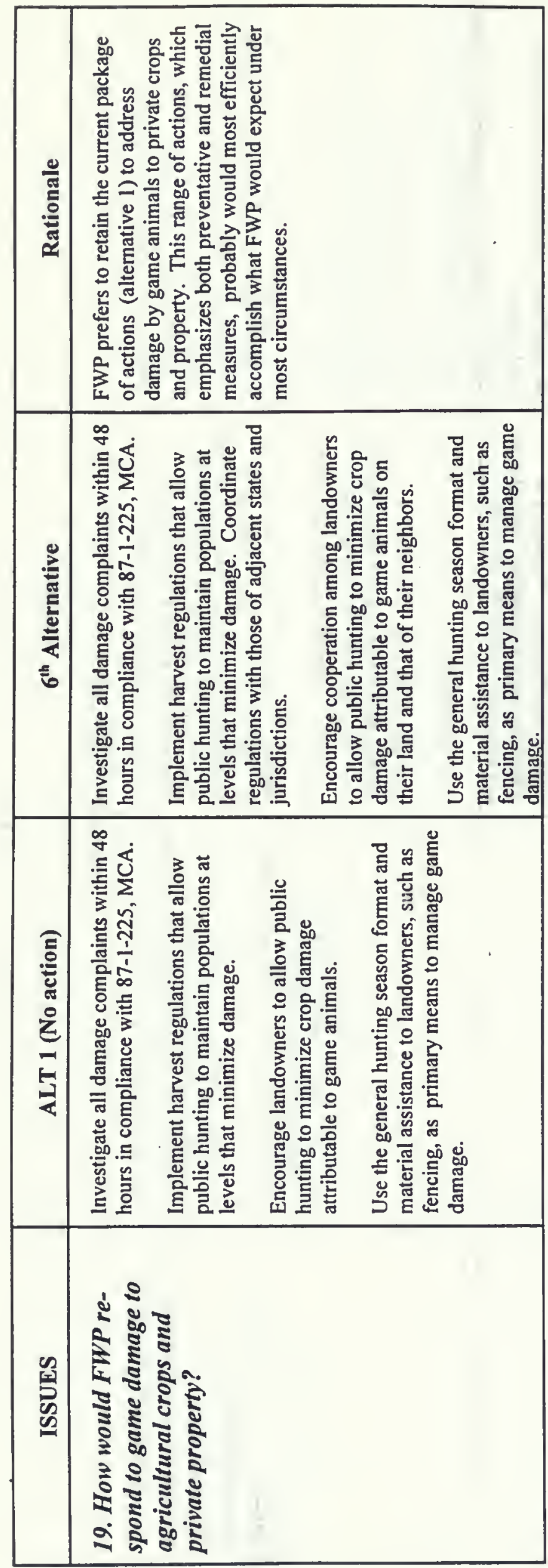




\begin{tabular}{|c|c|c|c|c|c|c|}
\hline 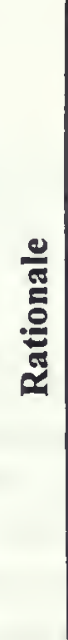 & \multicolumn{5}{|c|}{ 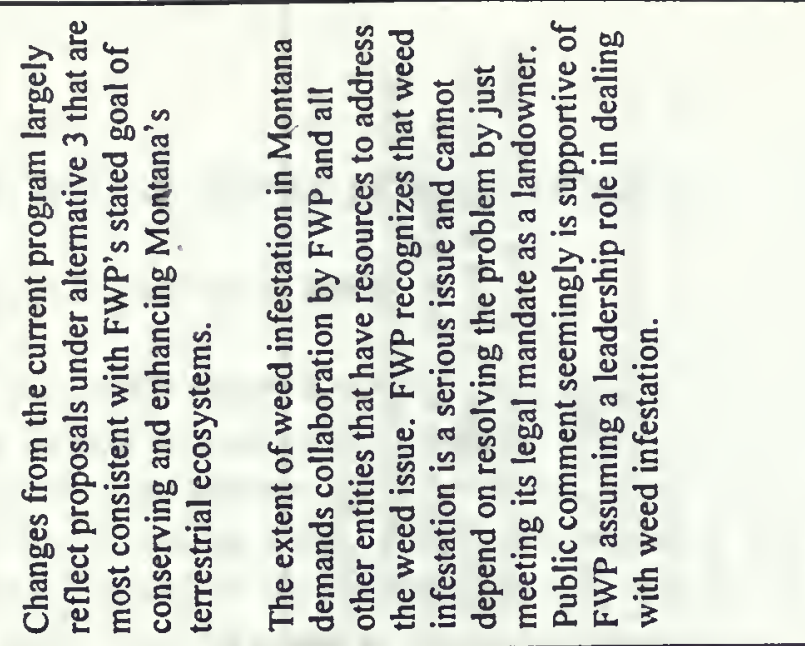 } & \multirow[b]{2}{*}{ 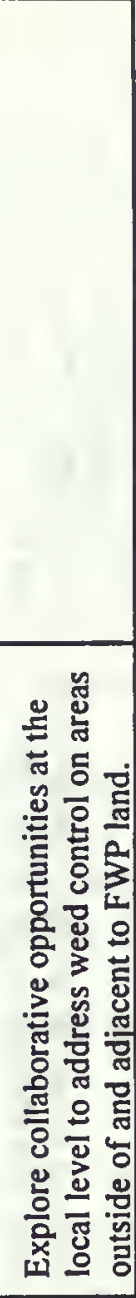 } \\
\hline 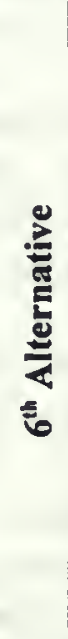 & 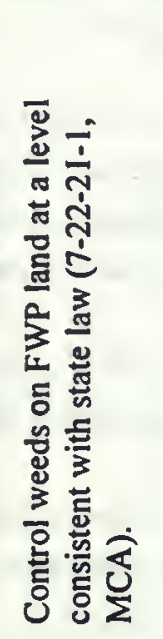 & 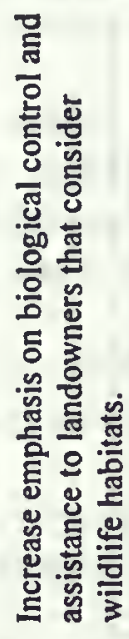 & 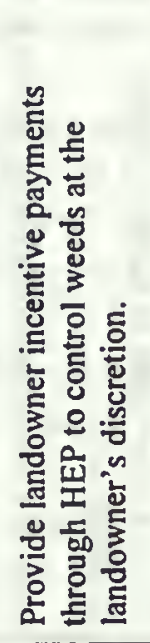 & 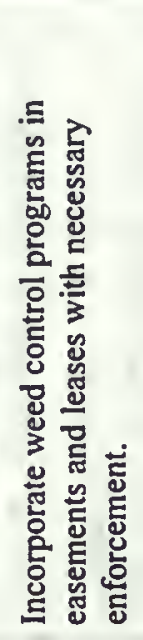 & 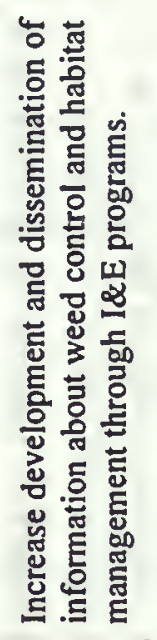 & \\
\hline 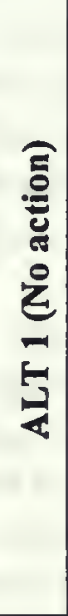 & 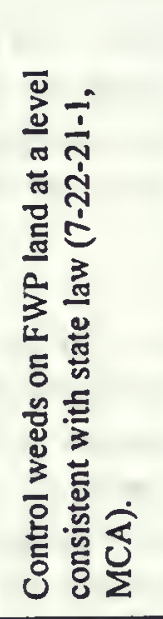 & 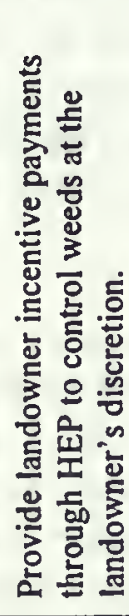 & & & & \\
\hline 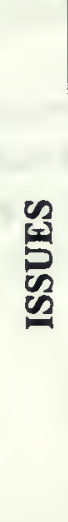 & 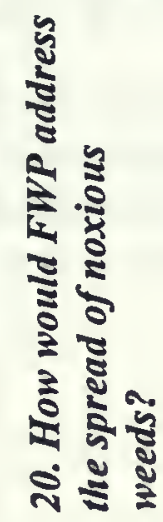 & & & & & \\
\hline
\end{tabular}









\section{ENVIRONMENTAL EFFECTS ANALYSIS OF THE PREFERRED ALTERNATIVE}

\section{Issue: Access /Effects on Wildlife}

Overall Access--FWP assists hunters in obtaining access to private land through negotiated access agreements, habitat enhancement projects, and game damage assistance to private landowners. By encouraging access to private land hunters and harvest are distributed over a larger area.

Development of a funding source for nonhunting recreation access and increased I\&E efforts would increase overall access for wildlife recreation from alternative 1 . Increased administration of recreational access would also result in additional protection of wildlife resources. Concentrations of hunters in highly accessible areas could still result in reductions of local populations.

Increased access for nonhunting recreation above that of alternative 1 could affect wildlife in a variety of ways. For example, disturbance of big game on winter ranges by recreationists could increase mortality, or increase the potential for game damage on adjacent private land. However, FWP would expect expanded I\&E and enforcement to reduce potential for these impacts.

Expansion of FWP's access-related actions would not be expected to have long term negative impacts on statewide population levels of harvested species.

Block Management Policy--As under alternative 1, FWP would expect acreage under Block Management/Hunter Enhancement (BM/HEP) agreements to increase over time. This also would increase the distribution of hunters and harvest and affect big game somewhat more than upland game species. Populations of predators could be reduced indirectly through reduction of local prey populations but would not affect populations on a statewide basis. Increased access might increase the potential for taking of nontarget species, including T\&E species. The overall effect on predators and other nontarget species would be insignificant statewide because of the small percentage of total acreage enrolled in BM/HEP agreements. Education and enforcement efforts would address this concern.

Access Through Lease, Purchase, or Easement--Recreational access would be examined on a case by case basis under this alternative. Habitat Montana is a program that by statute emphasizes resource protection over access. Consequently it may result in access restrictions on some land where FWP acquires management of some or all of the resources of that land. Emphasizing resource protection over access in Habitat Montana (HM) projects would reduce vulnerability of wildlife to hunting or disturbance by dispersing recreational use and could expand access over the long term. Concentration of recreational use would vary with the level of restrictions established on a case by case basis.

Interaction with Other Agencies--Under this alternative, FWP would continue collaborating with public land managers to optimize access on other public land. FWP would continue responding to land use proposals for public land based on local priorities and the long term needs of wildlife, habitat, and public recreational opportunity. A response from FWP could lead other agencies to 
decisions affecting year-long distribution of recreationists and other users, including motorized travel. FWP primarily would look to benefit wildlife by protecting important habitats.

Closure of Large Private Blocks--Closure of large tracts of private land to public hunting would concentrate hunters on public land and tracts of private land open for public hunting. This concentrated use by hunters could lead to excessive harvest and temporary displacement of game animals from this land. Closures might allow game populations to increase to levels that create a potential for game damage both on closed land and land that is open to public hunting.

This alternative's aggressive application of incentives under BM/HEP, and the current policy requiring landowners to allow public hunting to be eligible for game damage assistance, could improve distribution of hunters and harvests of game. Local increases in game harvest might reduce those populations, but such reductions would not measurably affect their distribution and abundance statewide.

Considering access on a case by case basis through HM projects might somewhat reduce the effectiveness of harvests in keeping local game populations at desired levels. Increased public access to private land also might force some game animals to land that remains closed to hunting, limiting the overall effectiveness of hunting in reducing populations.

Access Fees--The acreage of private land where landowners charge hunters fees for access would not appreciably change from that expected under alternative 1 . As a consequence, FWP would continue to expect a lower harvest of game and more game damage complaints on private land where fees limit access than where the public can obtain access through FWP programs.

Increased access and reduction of populations in response to game damage would be only temporary if the affected land closes again after resolution of damage problems. Redistribution of game animals from land open to public hunting to land that remains closed could limit the effectiveness of hunting to reduce game damage. Any decreased emphasis on access in HM projects might enhance habitat security for wildlife on land with FWP oversight but could aggravate game damage on adjoining private land.

\section{Issue: Recreational Opportunity /Effects on Wildlife}

Providing Hunter Opportunities--FWP would continue offering services for special constituent groups under this alternative. Increased access for hunters resulting from landowner preferences might locally increase harvests of both big game and upland game. Increased motorized access for persons with disabilities could reduce habitat security and temporarily shift distribution of harvested wildlife away from roads. Levels of motorized traffic and densities of open roads affect harvest rates and distribution of big game. Still, the overall effect on wildlife would be minor statewide as long as 
only a small percentage of all hunters would be afforded special privileges. Landowner preferences might persuade landowners to protect wildlife habitats on their land.

Emphasizing Conservation While Providing Recreation--FWP would continue emphasizing hunting and trapping to manage wildlife populations but increase opportunity for nonhunting recreation. Emphasis on conservation of harvested wildlife (big game, upland game, migratory waterfowl, and furbearers) would maintain populations of these species at levels supporting sustainable harvests while maintaining populations at levels compatible with other land uses.

Greater emphasis on habitat protection for a broader range of species than under alternative 1 could increase numbers of some nongame species. However, it is difficult to predict overall population trends because of natural factors, such as disease, weather, and predation that also influence population numbers.

This alternative would increase emphasis on recovery of T\&E species above that of alternative 1 and could aid in their recovery. Additional education, habitat protection, interagency cooperation, and research could reduce human-caused mortality and the number of species needing protection under endangered species statutes.

Trophy Hunting--Under this alternative, FWP would continue to apply regulations in designated geographical areas to limit harvest of males of some species of big game, such as deer and elk. FWP would expect age diversity of males in these populations to increase as under alternative 1. A younger age structure among males could result where such regulations were not applied with fewer males surviving long enough to attain maximum body and/or antler size. These impacts would vary geographically with legal and physical access. Species for which FWP regulates harvest by quotas and drawn permits would continue to be less affected than species for which sale of licenses to resident hunters is unlimited.

Hunter Participation--Educational efforts directed at reducing barriers to participation, along with an expanded hunter education program under this alternative, might increase participation in wildliferelated recreation from alternative 1. Increased participation in recreation could increase disturbance or temporary displacement of wildlife and increase potential for T\&E species to be taken through misidentification. FWP would expect education and enforcement efforts to adequately mitigate this concern and would not expect a small increase in numbers of hunters to markedly affect wildlife on a statewide scale.

Resident Hunter Opportunity--This alternative's provision of invoking Montana statute 87-1-301 (4) (b), which gives the Commission rulemaking authority to regulate harvest by holders of nonresident combination big game licenses could also increase FWP's ability to manage distribution of big game harvests. Using this rule, the commission can restrict harvests by nonresidents in areas with population declines while directing additional nonresident hunting pressure to other areas of the state. 


\section{Issue: Species and Habitat Management /Effects on Wildlife}

Wildlife Introductions--Development of a consistent statewide policy for capture and release of wildlife under this alternative could increase populations and distribution of designated species. The number of species involved might increase from alternative 1. Releases of wild-trapped animals would continue to minimize the time required to establish new populations compared with natural dispersal of animals from existing populations. Moving animals from existing wild populations within or around Montana also would reduce the risk of transmitting or introducing diseases and would maintain genetic integrity of wildlife in the state.

Expanded education efforts could increase public acceptance of wildlife introductions and lead to increased introductions on a statewide scale.

Nongame and T\&E Species--Under this alternative, FWP would continue to devote effort to identifying nongame species in need of special management and collaborate with other agencies and groups in managing nongame and T\&E species. Increasing emphasis on overall habitat quality for native species could decrease recovery time for some T\&E species from alternative 1 or preclude the need for protection under endangered species laws for other species.

FWP could increase effectiveness of habitat programs on private land from alternative 1 through technical assistance and incentives to private landowners.

Integrating Habitat Management with Species Management--FWP proposals under this alternative would continue to emphasize individual game species in its programs but consider a broader range of wildlife in its habitat programs. FWP would continue to maintain big game populations at levels acceptable to both landowners and recreationists. Increased emphasis on habitat issues under this alternative could benefit a broad range of wildlife by acquiring priority habitats and applying technical expertise across the varied land ownerships.

\section{Compensating Local Governments for Lost Tax Revenue--No effect.}

Setting Future Research Agenda--Both long-term and short-term research under this alternative would continue to address resource management needs such as generating new knowledge to enhance management of habitats and populations. Research would directly affect wildlife by providing a basis for making policy decisions.

\section{Issue: Commercial Uses /Effects on Wildlife}

This alternative would increase FWP's role in the stewardship and protection of free-ranging wildlife and their habitats through increased monitoring of importation of wildlife into the state and sale and exportation of animal parts. Actions proposed under this alternative would provide monitoring and enforcement to preclude commercial operations from adversely affecting wildlife populations on a 
statewide scale. Development of new criteria for licensing commercial facilities could increase FWP's effectiveness in maintaining the quality of the state's wildlife and habitats.

\section{Issue: Landowner Relations /Effects on Wildlife}

Predator Control--Actions proposed under this alternative would broaden the scope of aerial gunning of coyotes from alternative 1. FWP funds would continue to address depredations by coyotes on livestock as under alternative 1, but also would address predation on wildlife. Predator control activities might result in increased survival of some wildlife in control areas as long as control efforts continue.

Aerial gunning of coyotes would minimize taking nontarget wildlife species that might be taken by alternate methods, such as poisoning. FWP's contribution to DOL for predator control would not measurably affect wildlife statewide and would not threaten the existence of coyote populations in Montana.

Game Damage--Under this alternative, FWP would continue to implement harvest regulations to minimize game damage over broad areas as described for alternative 1 . This would maintain big game populations at levels lower than might otherwise occur. This broad-based approach on private land and adjoining public land would have greater impact on game populations than a more localized response, such as hunters removing problem animals on individual ranches. Special damage hunts that address individual problems would result in temporary reductions in game populations although such actions would carry a low priority under this alternative.

Weed Control--By increasing reliance on biological control, providing landowner incentives, broadening control efforts to include leases and easements, and collaborative efforts at the local level as proposed under this alternative, FWP could help reduce infestation of noxious weeds on some private land. Increased dependence on biological control would reduce the potential for adverse effects of chemicals on wildlife. Integration of control techniques in sensitive areas could better preserve native vegetation and integrity of wildlife habitats than if options were more restricted to the use of herbicides as in alternative 1. This alternative would increase FWP's overall effectiveness in maintaining the quality of wildlife habitats across the state.

Urban Wildlife--FWP would continue responding to urban wildlife issues through direct intervention in conflicts to maintain public safety and providing comment on proposed subdivisions to local decision makers in a timely manner. Capturing and translocating nuisance animals, such as bears, probably would continue to reduce local populations, as described for alternative 1 , although informational brochures such as "Living with Grizzlies" or "Living with Lions" could reduce some of these conflicts.

Timely response to proposed subdivisions by FWP under this alternative could lead to local decisions that minimize habitat loss and reduce human/ wildlife conflicts. Increased reliance on other entities 
to address some human/wildlife conflicts and providing technical services at the local level might more effectively resolve conflicts on the urban interface.

\section{Issue: Access /Effects on Biodiversity}

Overall Access--FWP would expect the effects of overall access under this alternative to remain unchanged from alternative 1 . Impacts to biodiversity would be in proportion to any change in total access. A small increase in hunter access could reduce biodiversity although FWP expects these impacts to be negligible.

Block Management Policy--This alternative would increase the acreage of private land accessible to recreationists from that anticipated under alternative 1 . The impacts to biodiversity, such as the effect of hunting on sex and age structure of some game species, would remain negligible as under alternative 1 .

Access Through Lease, Purchase, or Easement--Protecting wildlife habitat through land acquisitions by easement, purchase, or lease would favor conservation of biodiversity on that land under all alternatives. Protection might vary among alternatives depending on the extent to which FWP could disperse overall recreational use and hunter harvest across a broader base of land ownership.

Interaction with Other Agencies--In responding to other agencies' requests for comment on motorized access and other land use proposals on public land, FWP would offer recommendations for protecting habitats that consider cumulative effects of agency decisions. If implemented, such recommendations would favor conservation of biodiversity. Any action relative to FWP's recommendations would be at the discretion of the requesting agency.

Closure of Large Private Blocks--FWP's response to closures of private land under this alternative would change very little from alternative 1. Any impacts to biodiversity would result from effects of hunter access on sex and age structure of local game populations. If this alternative increased overall access from alternative 1 by discouraging closure of private land and improving distribution of hunters and harvest, the benefit to biodiversity could slightly increase.

Access Fees--Under this alternative, FWP would continue to apply its habitat and access programs, game damage assistance, and a landowner preference system to discourage landowners from charging access fees. Increasing access to private land could benefit conservation of biodiversity by dispersing hunters and harvest and reduce local disturbance to wildlife and damage to vegetation that would occur if the same number of recreationists were confined to a smaller land base.

\section{Issue: Recreational Opportunity /Effects on Biodiversity}

Providing Hunter Opportunities--FWP regulations can affect sex and age structure of harvestable wildlife through hunting, but no effects on biodiversity have been documented. Effects on wildlife populations from granting access exemptions to persons with disabilities or landowner preference for 
licenses would be small under any alternative. Increased landowner commitment to maintaining habitats on private land influenced by landowner preference for licenses might benefit conservation of biodiversity.

Emphasizing Conservation While Providing Recreation--Increased emphasis on recovery of T\&E species could increase rates of recovery of protected species and reduce the need to list other species, thereby benefitting biodiversity.

Trophy Hunting--Harvest regulations applied in designated geographical areas (e.g., antler point restrictions or quotas and permits) as proposed under this alternative could increase representation of mature males and thereby further reduce the effects of hunting on the male segment of the population in those areas. FWP maintains that any purported long-term implications for biodiversity, such as the argument that emphasis on managing big game is at the expense of reduced diversity of other species, are speculative and inconclusive.

Hunter Participation--Expanded hunter education efforts under this alternative could increase the support base between hunters and nonhunters interested in wildlife-related recreation. Programs aimed at adults would increase their appreciation of wildlife and the role regulations play in wildlife protection and maintenance of biodiversity.

Resident Hunter Opportunity--No effect.

\section{Issue: Species and Habitat Management /Effects on Biodiversity}

Wildlife Introductions--Introductions and natural dispersal of wildlife affect biodiversity by influencing local wildlife populations and genetic diversity within species. By expanding the range of species affected to include nongame and T\&E species and administered through a consistent statewide policy, FWP could benefit biodiversity in the state.

Nongame and T\&E Species--This alternative could increase benefits to biodiversity over those under alternative 1 by more intensively monitoring game and nongame wildlife, emphasizing ecosystem structure and function in habitat projects, and more aggressive oversight of T\&E species on both private and public land. This could reduce the rate of listing species in Montana for endangered species protection.

Integrating Habitat Management with Species Management--By increasing habitat protection under this alternative, FWP could address habitat fragmentation, which is often associated with loss of biodiversity, better than under alternative 1. FWP actions would not be expected to reverse the trend toward habitat fragmentation, but could mitigate some effects through specific acquisitions and habitat enhancement projects. These projects would help provide linkage between fragmented habitat patches.

Compensating Local Governments for Lost Tax Revenue--No effect. 
Setting Future Research Agenda--This alternative would broaden the focus of research from that under alternative 1 by expanding the overall effort to include nongame and T\&E wildlife. Such a focus would benefit biodiversity by providing the decision maker with scientific knowledge to increase predictability of outcomes.

\section{Issue: Commercial Uses /Effects on Biodiversity}

Commercial uses of game animals on private land favors species with high market value over others and can adversely affect biodiversity through competition with native species, habitat loss, genetic degradation, or introduction of disease. Regulations and enforcement imposing strict standards on facilities holding game animals brought into the state, stringent health inspection of imported animals, and limits on importation of certain species would continue to minimize these risks. Under no alternative would FWP advocate that the level of regulations affecting importation or sale of game or exotic species be lowered from current standards.

\section{Issue: Landowner Relations /Effects on Biodiversity}

Predator Control--Predator control efforts would continue to focus on coyotes but, as under alternative 1, would remain controversial. FWP's contribution to predator control through DOL under this alternative would be directed at protecting domestic livestock and wildlife. Predator control could increase survival among some local wildlife populations while control efforts are conducted. Reductions of coyotes would not threaten the continued existence of the species in Montana although control might affect sex and age composition of local populations of coyotes.

Limiting lethal techniques to aerial gunning would appreciably reduce the risk of taking nontarget wildlife such as birds of prey or other small predatory animals. Given all factors that affect survival and distribution of wildlife, FWP's contribution to predator control probably would have a negligible effect on biodiversity under any alternative.

Game Damage--Through hunting, FWP would continue to affect sex and age structure of some game populations. Efforts directed at reducing game damage on private land under this alternative would focus primarily on the female (or antlerless) segment of big game populations to effectively reduce total numbers of animals over large areas. These efforts also would affect sex and age composition and reproductive potential in some big game populations. Any effect on biodiversity probably would be negligible over the short term (e.g., less than $50 \mathrm{yrs}$ ).

Weed Control--While invasions of noxious weeds reduce biological diversity, actions to control weeds, which includes application of chemicals, would locally affect biodiversity by altering or removing vegetation. The level of effects would depend on the extent to which chemical control is used. These effects also would vary with the level of manual or biological control methods integrated into overall control efforts. 
Urban Wildlife--FWP's effect on biodiversity from a response to urban wildlife issues would be small under any alternative, and the effect would not differ from that under alternative 1. FWP's influence would be limited to providing information and recommendations to local governments, maintaining public safety, and informing the public how to live with wildlife.

\section{Issue: Access /Effects on Air, Soil and Water}

Overall Access--The overall effect on air, water, and soil probably would be minimal. However, minor increases in soil erosion, compaction, and in-stream sedimentation probably would occur in proportion to any expansion of motorized access.

Block Management Program--Minor increases in soil erosion, compaction, and in-stream sedimentation would occur in proportion to any increase in total motorized access to private land by recreationists.

Access Through Lease, Purchase, or Easement--This alternative would increase emphasis on resource protection above what would occur under alternative 1. Minor decreases in soil erosion, compaction, and in-stream sedimentation might occur with increased restriction of recreational use on land that FWP controls though easement, lease, or purchase. The extent to which FWP can disperse recreational use through HEP enrollments and other cooperative agreements also would reduce adverse impacts to air, soil, and water.

Interaction with Other Agencies--FWP would respond to public agencies requesting comment on potential impacts of travel management and habitat alteration on wildlife habitat and motorized recreation. A response would focus on actions by other agencies that potentially affect wildlife habitat and wildlife-related recreation but would not obligate the agency to any action.

Closure of Large Private Blocks--FWP could increase access to private land under this alternative through more aggressive application of access initiatives, increasing local involvement in access issues, and continuing to provide game damage assistance. Soil erosion, compaction, and in-stream sedimentation could decrease from alternative 1 by dispersing recreational use.

Access Fees--FWP would not expect a net decrease in the quality on air, soil, and water from current levels under any alternative because access fees would not measurably affect numbers of hunters. However, changes in hunter distribution resulting from an FWP effort to discourage access fees could locally affect the quality of air, soil, and water.

\section{Issue: Recreational Opportunity/Effects on Air, Soil and Water}

Providing Hunter Opportunities--A very small increase from alternative 1 in soil erosion, compaction, and in-stream sedimentation might occur from granting motorized access exemptions by FWP and private landowners to persons with disabilities under this alternative. 
Emphasizing Conservation While Providing Recreation--FWP does not expect the overall effect on air, water, and soil to be substantial under any alternative. However, minor changes in soil erosion, compaction, and in-stream sedimentation could result from any recreational opportunity affecting the level and distribution of access. Any adverse effects would be reduced by FWP efforts to protect habitats.

Trophy Hunting--No effect.

Hunter Participation--The potential for impacts to air, water and soil would correspond directly to numbers of vehicles and people on the land. If total numbers of people were to increase, potential for soil compaction and erosion would increase. Erosion generated by wildlife-related recreation would be negligible under any alternative.

Resident Hunter Opportunity--Minor changes in soil erosion, compaction, and in-stream sedimentation could occur with changes in access or recreational use.

Issue: Species and Habitat Management /Effects on Air, Soil and Water

Wildlife Introductions--No effect.

Nongame and T\&E Species--Management of nongame and T\&E probably would not measurably affect air, water, or soil. Actions would be directed at conservation rather than recreation, and rehabilitation of soil and water would remain outside FWP's mission and technical capability across all alternatives.

Integrating Habitat Management with Species Management--Emphasizing individual game species and their habitats as separate entities would not measurably affect air, water, and soil.

Compensating Local Governments for Lost Tax Revenue--No effect.

Setting Future Research Agenda--No effect.

\section{Issue: Commercial Uses /Effects on Air, Soil and Water}

Increased regulatory authority under this alternative could increase soil stability and water and air quality from levels under alternative 1.

\section{Issue: Landowner Relations /Effects on Air, Soil and Water}

Predator Control--No effect.

Game Damage--Actions to minimize game damage to agricultural crops probably would not measurably impact air, water, and soil under any alternative. However, any increased hunter 
access to address game damage might have a small impact on these resources because of increased motorized travel.

Weed Control--Chemical treatment methods might temporarily affect air quality when chemical particles are suspended in the atmosphere. Accumulation of chemical residues could result from chemical application (Mont. Fish, Wildl. and Parks 1994). Herbicides could affect groundwater through point source discharges (e.g., accidental spills) and might contaminate surface water through runoff. These risks would be the same across all alternatives but the magnitude of these effects would depend on the degree to which chemicals were used.

Biological weed control would not affect air quality. Manual and cultural methods, including mowing and burning, could temporarily increase particulate matter in the air. Soil loss and reduction in site productivity could result from manual control of noxious weeds (Mont. Fish, Wildl. and Parks 1994). Over the long term, controlling the spread of noxious weeds could maintain or improve the quality of air, water, and soil by maintaining soil stability.

Urban Wildlife--No effect.

\section{Issue: Access /Effects on Recreational Opportunity}

Overall Access--Access activities directed at population management of some wildlife species would continue at the current level. However, this alternative's reliance on expanded I\&E efforts to maintain access to public and private land could maintain or increase the acreage available for public recreation from alternative 1. Increased emphasis on habitat integrity alone might not increase hunter access but might increase the quality of the experience, particularly for viewers. If a new funding source is developed to provide access to private land for nonhunting recreation, opportunities for these activities would increase from alternative 1.

Block Management Program--The number of BM/HEP agreements probably would increase at the present rate along with opportunity for hunting on private land. If this alternative's proposal to develop a source of funding to provide incentives to private landowners for nonhunting recreation is successful, opportunities for the public would increase from alternative 1.

Access Through Lease, Purchase, or Easement-This alternative's emphasis on resource protection over access in HM projects might not significantly increase access to land under FWP's control. However, such actions might increase quality of recreation over the long term both through increased protection of habitat and a stable or increasing addition of land to the program. The degree to which FWP can disperse users through management of acquisitions and cooperative agreements on private land would correspondingly increase quality of recreational opportunity.

Interaction with Other Agencies--FWP would continue to collaborate with public land managers under this alternative to optimize access on other public land. Response to issues related to travel management and habitat alteration projects would focus on actions by other agencies that potentially 
affect habitats and opportunities to harvest or view wildlife. FWP's response might discourage actions that adversely affect recreational opportunity over the long term.

Closure of Large Private Blocks--FWP programs would work to expand public access and recreational opportunity on private land as proposed under alternative 1 . Under this alternative, however, the mix of opportunity on private land would change with increased emphasis on wildlife viewing. This alternative's increased emphasis on partnerships and local involvement in access issues could reduce the rate at which lands accessible to the public are lost as a result of closures and leasing to outfitters.

Access Fees--On a statewide basis, access provided through FWP programs under this alternative might not completely offset acreage lost to the public as a result of landowners charging fees to hunt on their land. The mix of opportunity for hunting, trapping, and viewing on private land probably would not significantly change from that of alternative 1 although some landowners might not charge access fees to remain eligible for landowner preference for some types of licenses.

\section{Issue: Recreational Opportunity /Effects on Recreational Opportunity}

Providing Hunter Opportunities--The current hunting season framework would continue to offer a range of hunting opportunities for many user groups, including special constituent groups. Special privileges offered to persons with disabilities, senior citizens, and youth might provide some parity with the general hunter population as under alternative 1. Exemptions for persons with disabilities might sometimes conflict with motorized travel restrictions that apply to the general hunter population.

Granting landowners preference for some types of big game licenses might predispose them to allow hunters access to their land and thus, maintain or improve quantity and quality of recreational opportunity for the general hunter population.

Emphasizing Conservation While Providing Recreation--Increased emphasis on T\&E recovery, habitat protection and expanded I\&E programs under this alternative could maintain or increase opportunity for hunting above what would occur under alternative 1. Nonhunting opportunities for the public would increase under this alternative through expanded education programs.

Trophy Hunting--A policy under this alternative to increase representation of mature males in big game populations in designated geographical areas might increase opportunities to harvest or view mature animals. However, harvest regulations in those areas would reduce overall hunting opportunity. Opportunities for viewers and other nonhunting recreationists might be less restricted in these areas than for hunters.

Continued emphasis on diversity of hunting opportunity throughout the remainder of the state might result in fewer large mature males available to hunters and viewers, which also would occur under 
alternative 1. However, opportunity to participate would remain less restricted than in areas managed to increase representation of mature males.

Hunter Participation--An expanded hunter education program under this alternative, which would also target adults, probably would maintain participation by resident hunters at current levels. At the same time, these programs might increase appreciation for nonhunting recreation such as viewing, feeding, or photographing. If participation in hunting increases substantially, overall quality of hunting opportunity could decline because of increased competition among hunters. Expanded habitat and access programs could mitigate these impacts.

Resident Hunter Opportunity--This alternative's provision of invoking Montana statute 87-1-301 (4)(b), which gives the Commission authority to regulate harvest by nonresident hunters, at times would limit opportunity for holders of nonresident big game combination licenses. Invoking such rules would not directly impact opportunity for resident hunters. An allocation method for nonresident licenses consistent with biological goals for managing big game would sustain opportunity for hunting, viewing and other wildlife-related recreation.

\section{Issue: Species and Habitat Management /Effects on Recreational Opportunity}

Wildlife Introductions--Increasing both numbers and distribution of species through a consistent statewide policy, over time, could increase opportunities for many forms of wildlife-related recreation.

Nongame and T\&E Species--This alternative's integration of management of nongame and T\&E species into habitat programs could increase opportunity for nonhunting wildlife recreation. This alternative's aggressive approach to managing nongame and T\&E species could ease access restrictions on some public land over the long term and thereby increase opportunity for wildliferelated recreation. This could be accomplished both through successful recovery of some species and through preventing others from needing special protection.

Integrating Habitat Management with Species Management--Increased emphasis on habitat protection from that proposed under alternative 1 could increase opportunity for all forms of wildliferelated recreation.

Compensating Local Governments for Lost Tax Revenue--Continuing payments to counties in lieu of taxes on real property, as proposed under alternative 1, would increase the likelihood that FWP land acquisitions would be acceptable to local governments and might result in a net increase in the opportunity afforded outdoor recreationists.

Setting Future Research Agenda--Research under this alternative would emphasize harvest and habitat issues, but with an expanded funding base, would expand effort to develop new knowledge to manage nongame and T\&E wildlife for public enjoyment. Knowledge generated through FWP research projects would provide a basis for policy decisions that allocate recreational opportunity. 
affect habitats and opportunities to harvest or view wildlife. FWP's response might discourage actions that adversely affect recreational opportunity over the long term.

Closure of Large Private Blocks--FWP programs would work to expand public access and recreational opportunity on private land as proposed under alternative 1 . Under this alternative, however, the mix of opportunity on private land would change with increased emphasis on wildlife viewing. This alternative's increased emphasis on partnerships and local involvement in access issues could reduce the rate at which lands accessible to the public are lost as a result of closures and leasing to outfitters.

Access Fees--On a statewide basis, access provided through FWP programs under this alternative might not completely offset acreage lost to the public as a result of landowners charging fees to hunt on their land. The mix of opportunity for hunting, trapping, and viewing on private land probably would not significantly change from that of alternative 1 although some landowners might not charge access fees to remain eligible for landowner preference for some types of licenses.

\section{Issue: Recreational Opportunity /Effects on Recreational Opportunity}

Providing Hunter Opportunities--The current hunting season framework would continue to offer a range of hunting opportunities for many user groups, including special constituent groups. Special privileges offered to persons with disabilities, senior citizens, and youth might provide some parity with the general hunter population as under alternative 1. Exemptions for persons with disabilities might sometimes conflict with motorized travel restrictions that apply to the general hunter population.

Granting landowners preference for some types of big game licenses might predispose them to allow hunters access to their land and thus, maintain or improve quantity and quality of recreational opportunity for the general hunter population.

Emphasizing Conservation While Providing Recreation--Increased emphasis on T\&E recovery, habitat protection and expanded I\&E programs under this alternative could maintain or increase opportunity for hunting above what would occur under alternative 1. Nonhunting opportunities for the public would increase under this alternative through expanded education programs.

Trophy Hunting--A policy under this alternative to increase representation of mature males in big game populations in designated geographical areas might increase opportunities to harvest or view mature animals. However, harvest regulations in those areas would reduce overall hunting opportunity. Opportunities for viewers and other nonhunting recreationists might be less restricted in these areas than for hunters.

Continued emphasis on diversity of hunting opportunity throughout the remainder of the state might result in fewer large mature males available to hunters and viewers, which also would occur under 
alternative 1. However, opportunity to participate would remain less restricted than in areas managed to increase representation of mature males.

Hunter Participation--An expanded hunter education program under this alternative, which would also target adults, probably would maintain participation by resident hunters at current levels. At the same time, these programs might increase appreciation for nonhunting recreation such as viewing, feeding, or photographing. If participation in hunting increases substantially, overall quality of hunting opportunity could decline because of increased competition among hunters. Expanded habitat and access programs could mitigate these impacts.

Resident Hunter Opportunity--This alternative's provision of invoking Montana statute 87-1-301 (4)(b), which gives the Commission authority to regulate harvest by nonresident hunters, at times would limit opportunity for holders of nonresident big game combination licenses. Invoking such rules would not directly impact opportunity for resident hunters. An allocation method for nonresident licenses consistent with biological goals for managing big game would sustain opportunity for hunting, viewing and other wildlife-related recreation.

\section{Issue: Species and Habitat Management /Effects on Recreational Opportunity}

Wildlife Introductions--Increasing both numbers and distribution of species through a consistent statewide policy, over time, could increase opportunities for many forms of wildlife-related recreation.

Nongame and T\&E Species--This alternative's integration of management of nongame and T\&E species into habitat programs could increase opportunity for nonhunting wildlife recreation. This alternative's aggressive approach to managing nongame and T\&E species could ease access restrictions on some public land over the long term and thereby increase opportunity for wildliferelated recreation. This could be accomplished both through successful recovery of some species and through preventing others from needing special protection.

Integrating Habitat Management with Species Management--Increased emphasis on habitat protection from that proposed under alternative 1 could increase opportunity for all forms of wildliferelated recreation.

Compensating Local Governments for Lost Tax Revenue--Continuing payments to counties in lieu of taxes on real property, as proposed under alternative 1, would increase the likelihood that FWP land acquisitions would be acceptable to local governments and might result in a net increase in the opportunity afforded outdoor recreationists.

Setting Future Research Agenda--Research under this alternative would emphasize harvest and habitat issues, but with an expanded funding base, would expand effort to develop new knowledge to manage nongame and T\&E wildlife for public enjoyment. Knowledge generated through FWP research projects would provide a basis for policy decisions that allocate recreational opportunity. 


\section{Issue: Commercial Uses /Effects on Recreational Opportunity}

FWP's response to applications for game farms and other commercial operations under this alternative, such as charging applicants fees for processing applications, might result in no net impact on recreational opportunity. FWP would oversee commercial activities to protect current benefits and reduce any detrimental effects on the resources that provide recreational opportunities to the public. Potential for conflict exists with landowners who intend to expand their agricultural operations to include game farms or shooting preserves.

\section{Issue: Landowner Relations /Effects on Recreational Opportunity}

Predator Control--This alternative would continue to address depredations on livestock but also address wildlife goals. Expanded I\&E efforts that emphasize skills of hunting and trapping and the role of predators in natural systems could increase interest and opportunities in both hunting and viewing.

Game Damage--FWP's policy for addressing game damage would remain essentially unchanged from alternative 1. Game damage would continue to be addressed through setting of hunting seasons and providing landowners with materials, such as fencing. This would benefit hunting opportunity on private land and adjoining public land. General hunting seasons that address game damage through liberal regulations might seasonally reduce opportunities for nonhunting recreation related to big game because they directly reduce numbers of animals and affect behavior of remaining animals.

Weed Control--The effect of weed control efforts on recreational opportunity under any alternative would depend on the success of control effort to maintain habitat integrity. For example, control of noxious weeds could improve recreational opportunity by increasing the amount of available habitats and thus animal numbers and species diversity. The impacts could vary with the type of treatment and type of recreation (Mont. Fish, Wildl. and Parks 1994).

Urban Wildlife--Opportunities for hunting would be extremely limited in and around urban and rural residential areas under any alternative. Limited opportunities for hunting would require restrictions on weapon types. Urban and rural residential areas might serve as refuge for hunted species. This could increase opportunity for viewing and other nonhunting recreational uses. Actions proposed under this alternative that emphasize coexistence with wildlife and maintaining public safety would increase opportunities for public enjoyment of wildlife on the urban interface.

\section{Issue: Access /Effects on Archaeological and Historical Resources}

Overall Access--FWP staff would be alert to possible discovery of historical or archaeological resources on private land but would not become directly involved in historical resource management on private land. Initial acquisition of land would not require a cultural resource survey. Subsequent development would require a systematic site survey, and FWP would evaluate and protect sites as required by law (22-3-424, MCA, and associated FWP Policy 12.8.501) under any alternative. 
Block Management Program--FWP staff would be alert to possible discovery of historical or archaeological resources on private land under BM/HEP agreement under any alternative but would not become directly involved in management of such resources on private land.

Access Through Lease, Purchase, or Easement--Under any access management policy, initial acquisition would not require a cultural resource survey of an area. Any development would require a systematic site survey, and FWP would evaluate and protect sites as required by law (22-3-424, MCA, and associated FWP Policy 12.8.501).

Interaction with Other Agencies--FWP normally would not advise other agencies regarding archaeological or historical resources because the managing agencies are required to satisfy public laws that protect these resources.

Closure of Large Private Blocks--FWP proposes no ground disturbing actions that would affect access to private land. Historical and archaeological sites would remain unaffected under any alternative but would remain subject to incidental surface disturbance. A shift in use from private to public land could increase the potential for disturbance of historical and archaeological sites on public land. FWP would work with the appropriate land management agency to reduce any potential impact, and take whatever action is necessary to protect sites on FWP land.

Access Fees--No effect.

\section{Issue: Recreational Opportunity /Effects on Archaeological and Historical Resources}

Providing Hunter Opportunities--Archaeological and historical sites would remain unaffected under any alternative but would be subject to incidental surface disturbance associated with wildlife-related recreation. FWP would protect archaeological and historical sites on its own land as required by law (22-3-424, MCA, and associated FWP Policy 12.8.501).

Emphasizing Conservation While Providing Recreation--No effect.

Trophy Hunting--No effect.

Hunter Participation--No effect.

Issue: Species and Habitat Management /Effects on Archaeological and Historical Resources Wildlife Introductions--No effect.

Nongame and T\&E Species--No effect.

Integrating Habitat Management with Species Management--No effect. 
Compensating Local Governments for Lost Tax Revenue--No effect.

Setting Future Research Agenda--No effect.

Issue: Commercial Uses /Effects on Archaeological and Historical Resources

No effect.

Issue: Landowner Relations /Effects on Archaeological and Historical Resources

Predator Control--No effect.

Game Damage--No effect.

Weed Control--Weed treatments under any alternative could affect archaeological and historical resources. Of the treatments used, only burning has the potential for adverse effects. As appropriate, FWP would consult with the Montana State Historic Preservation Officer to ensure protection of archaeological and historical resources.

Urban Wildlife--No effect.

\section{Issue: Access /Effects on Social Values}

Overall Access--Total available access within the state depends on the willingness of landowners to grant hunters and other recreationists access to their land. Many people consider FWP's legally mandated programs dealing with public access as beneficial in preserving hunting traditions. FWP's continued direct involvement in public access to private land would help maintain a working relationship between FWP and private landowners in addressing mutual concerns.

This alternative's expanded enforcement and educational programs would continue to emphasize landowner/sportsman relationships but also would emphasize resource protection. Hunters and trappers would continue to benefit more from FWP's access programs, but this alternative also could improve FWP's working relationships with nonhunting conservationists. Considering habitat integrity in an overall access policy would show FWP's commitment to a broader management role than under alternative 1.

Block Management Policy--Continued emphasis on hunting access with FWP oversight under this alternative would be consistent with Montana tradition. Incentive payments to landowners through $\mathrm{BM} / \mathrm{HEP}$ agreements and a new initiative for nonhunting access would facilitate access to private land and many people would perceive this as preserving hunting traditions and broadening of FWP's constituency base. 
Relationships between landowners and sportsmen would remain unchanged. New relationships between landowners and nonhunting recreationists would result from expanded access. The net effect would be increased interaction of landowners and the public. Access agreements would not affect private property rights. Landowners allowing access to the public would continue to be seen as benefactors of wildlife recreation.

Access Through Lease, Purchase, or Easement--This alternative's proposal to encourage access in HM projects on a case by case basis would provide for continued hunting and nonhunting opportunities on land under FWP's management control. The relationship between hunters and FWP would remain unchanged. Nonhunters who enjoy wildlife also would continue to benefit from access to FWP land.

This program would affect landowners to the extent that landowners choose to participate.

Participation in FWP's habitat programs would remain voluntary and private property rights would not be directly affected.

Large purchases of land for wildlife might affect communities by polarizing public opinion. Some people would favor continued private ownership and that this land remains primarily in agricultural production or be open for development; others might favor protection of wildlife and recreational values through public ownership or involvement.

Interaction with Other Agencies--FWP's response to land management proposals on public land managed by other agencies would continue to be a part of FWP's management responsibility and would be favorably perceived by hunters as helping to maintain game populations and hunter opportunities. Nonhunting recreationists, such as wildlife viewers, might not believe they are receiving adequate benefits from FWP actions.

Responses to other agencies' proposed management actions on public land under this alternative would affect relations among FWP, landowners, and local communities about the same as under alternative 1. Landowners might welcome FWP's influence on land management decisions that lessen the potential for damage. On the other hand, landowners might perceive FWP's involvement as a threat to private property rights if management decisions were to increase the potential for game damage.

Local communities could perceive working relationships between FWP and land management agencies as benefitting land use decisions, unless such decisions were unpopular. In that case, cooperation between agencies could be seen as jeopardizing the ability of local people to influence resource decisions in their area.

Closure of Large Private Blocks--FWP would use incentive programs to gain hunter access to some private land previously closed to hunting. Although there could still be a net loss of land open for hunting, hunters would perceive FWP as acting in their interest. Other wildlife recreationists would see less benefit than hunters from these programs. 
Access would remain the prerogative of the landowner under any alternative though FWP programs available for landowner participation might vary among alternatives. Thus, private property rights would remain protected and outside the management authority of FWP. Relationships between FWP and landowners choosing to keep their land closed to hunting might be strained where game damage is an issue.

Private landowners would have the choice of allowing public access without any FWP involvement, participate in FWP programs, close their land to all hunting, or charge hunters an access fee. In some cases, landowners might charge fees to hunt some types of game while allowing free access to other hunters for other types. Groups of adjacent landowners might act in concert to open or close their land to hunters.

Incentives provided through FWP programs could benefit relationships between communities and landowners by allowing local residents to hunt on private land and providing a hunter clientele for businesses.

Access Fees--FWP would use game damage assistance and incentive payments through BM/HEP programs to maintain public access to private land where landowners might otherwise limit access to those paying a fee. As under alternative 1, hunters would perceive FWP as acting in their interest to protect social values associated with hunting.

Landowners would retain the choice to allow free public access, participate in FWP programs that provide access, or limit access to hunters paying an access fee. Some landowners might not charge access fees to remain eligible for preference for some types of licenses if such a system were developed. Relationships between landowners who charge for hunting and those who do not might become strained. Relationships also might deteriorate between local sportsmen and landowners who charge access fees for hunting (Swenson 1983 - see bibliography in Draft EIS). Traditional opposition to access fees among resident hunters is demonstrated by legislative action to fund access initiatives, such as BM/HEP, and reluctance by the Legislature to defer these costs to resident hunters through their license fees.

Private property rights would remain protected and outside the management authority of FWP. Relationships between FWP and landowners who choose to charge an access fee for hunting might be strained where game damage is an issue. Incentives provided through FWP programs could benefit relationships between communities and landowners by providing recreational opportunity to local residents and a hunter clientele for local businesses.

\section{Issue: Recreational Opportunity /Effects on Social Values}

Providing Hunter Opportunities--FWP would maintain opportunities for hunting and the socializing that goes with it while achieving some parity in opportunity for special groups of hunters as proposed under alternative 1. Granting preferences to landowners for some types of licenses could improve 
relationships between FWP and landowners, provide additional access for sportsmen, and reinforce the landowner's role as a neighbor in the community.

FWP would encourage increased landowner involvement in providing opportunities for hunting and associated socializing for persons with disabilities, youth and senior citizens. The general public might view this as equitable, but some hunters might contend that this would reduce their opportunities.

Emphasizing Conservation While Providing Recreation--Continued emphasis on hunting and trapping as tools to manage wildlife would maintain the current relationships between FWP and a traditional constituency. Increased I\&E efforts directed at nonhunters could broaden FWP's constituency base from that under alternative 1 and increase support for its wildlife programs.

Increased emphasis from alternative 1 on T\&E species conservation and recovery could improve a relationship between T\&E advocates and FWP. Individuals and groups adamantly opposed to the goals of the Endangered Species Act, however, might view FWP actions as a threat to their lifestyle. Some landowners with this opinion might deny access to hunters as a backlash against FWP.

Trophy Hunting--Maintaining diversity of hunting opportunity under this alternative, which includes opportunity to harvest mature animals, has evolved through public involvement. The general hunter population would continue to favor such diversity over specific types of hunts and would view this as a beneficial influence on social opportunities and traditions associated with hunting. FWP would expect participation in hunting by Montana residents to continue at a rate higher than the nation as whole (USDI Fish and Wildl. Serv. 1997b - see bibliography in Draft EIS). Among Montana deer hunters, less than 25 percent cite the opportunity to bag a trophy animal as their primary motivation for hunting (Duffield and Neher 1990, Anderson 1995).

Most animal rights groups oppose trophy hunting. Any expansion of trophy hunting opportunities might draw increasing attention to the state.

Hunter Participation--Many Montana residents would continue to view programs involving women and youth in hunting as fostering family-oriented traditions and broadening the hunter constituency. This alternative's provision of programs to develop or improve skills, mentoring, and opportunities for first-time hunters would help remove social barriers to participation in hunting beyond what could be accomplished under alternative 1 . Some nonhunters might view these actions as serving the traditional hunter constituency while limiting emphasis on other wildlife-oriented recreation and values.

Resident Hunter Opportunity--The current license and fee structure favoring resident over nonresident hunters and providing opportunities for residents to hunt would remain essentially unchanged from alternative 1. Emphasis under this alternative would continue to provide benefits to both residents and nonresidents associated with hunting, although at a higher cost for nonresidents. 
Although resident hunters might favor this alternative's emphasis on the Commission invoking Montana statute 87-1-301 (4) (b), which would allocate hunter opportunity for biological reasons, nonresident hunters might view it as further restricting their opportunity to hunt in Montana. Resident hunters also would continue to have more influence on the process of establishing hunting seasons and regulations than nonresidents. This would allow residents to influence the aspects of hunting that they value.

Harvesting wildlife would continue to present a fundamental clash of values between most Montana residents and advocates of animal rights. None of the alternatives analyzed in the draft EIS would eliminate that conflict.

\section{Issue: Species and Habitat Management /Effects on Social Values}

Wildlife Introductions--Many Montanans might favor the expanded program of wildlife introductions under this alternative because of increased potential for recreation. Many hunters would perceive introductions of game animals as a means of preserving the social traditions of hunting. While maintaining its relationship with hunters, FWP would improve its image among nonhunters.

Private landowners with a potential to experience game damage or transmission of diseases from wildlife to domestic livestock might oppose introductions. Some might view introductions as a threat to private property rights. These opposing views could strain relationships between FWP and agricultural producers. The overall effect of wildlife introductions on FWP/landowner relationships probably would be small under this alternative.

Nongame and T\&E Species--This alternative's increased emphasis on T\&E species conservation and recovery would improve the relationship between conservation organizations and FWP. Both conservationists and states' rights advocates would support FWP asserting a leadership role in managing T\&E wildlife.

Landowners might support this alternative's emphasis on economic incentives and technical assistance for habitat protection. Some landowners and local communities opposed to T\&E legislation, however, might still view FWP's involvement as another threat to their lifestyle, economic pursuits, and property rights and express their concerns through the legislative or legal process.

Integrating Habitat Management with Species Management--FWP would expect support between conservation groups and nonhunters for this alternative's increased emphasis on ecosystem-based habitat management from alternative 1. Relationships between FWP and hunters would continue as they are currently with a continued focus on individual species or species groups among harvested wildlife.

Advocates for an ecosystem approach and those supporting aggressive management of T\&E species and conservation of their habitats would embrace the ecosystem-based habitat management. These 
groups and individuals might believe that this approach would prevent the need for listing additional species for protection under state and federal endangered species laws.

Compensating Local Governments for Lost Tax Revenue--FWP's policy of making payments to counties in lieu of taxes on real property under this alternative would remain unchanged from alternative 1. Local residents would continue to view these payments as partial compensation for public ownership of land in their counties. The relationship between FWP and county governments would not change nor would tax burdens on other landowners and residents change as a result of FWP's land acquisitions. Loss of personal property tax revenues might still cause some counties to oppose FWP purchases of land.

Setting Future Research Agenda--Research directed at regional and statewide priorities toward harvest and habitat issues, as proposed under this alternative, would provide a basis for decisions that maintain the social traditions of hunting and wildlife viewing. Those concerned about a wider variety of species, would view FWP's research as more broadly focused than alternative 1. FWP would remain part of a larger research community, including universities and other research organizations in which all parties benefit from an exchange of information and technology.

\section{Issue: Commercial Uses /Effects on Social Values}

This alternative would continue to review applications for a permit to construct and operate commercial game operations, such as game farms and shooting preserves. A reduced rate of growth would affect social values associated with many outdoor recreational activities. FWP's relationships with recreationists probably would be strengthened through new permitting criteria and clarification of existing laws to protect public wildlife. Community concerns about the effect of wildlife-borne diseases on humans and livestock might remain although the probability of their occurrence might decline.

\section{Issue: Landowner Relations/Effects on Social Values}

Predator Control--Hunters and trappers might view a redirection of emphasis of the monetary contribution to DOL as beneficial to preserving Montana's hunting and trapping traditions. Hunters and livestock producers might view FWP's contribution to predator control as benefitting both Montana's livestock industry and hunting traditions. Some livestock producers might perceive any change in the use of these funds as a minor threat to their livelihood and lifestyle.

Some nonhunting groups, particularly animal rights groups, would oppose any systematic harvest of predatory species. However, conservationists would support educational efforts that emphasize the role of predators in natural systems.

Game Damage--FWP's game damage policy would remain essentially unchanged from alternative 1 . Continued emphasis on hunting and public access to address game damage problems would be 
consistent with social traditions of hunting, and landowners would continue to be viewed as good neighbors and benefactors of wildlife recreation by the community.

By using hunting as a primary means of controlling game populations on private land and through coordination of harvest regulations with other jurisdictions, FWP would continue to maintain a working relationship with private landowners. Landowners that view unacceptably high game populations on their property as an infringement of private property rights might respond to assistance from FWP by allowing some public access for hunting. Others, however, would continue to view granting public access as a condition for FWP assistance as an infringement of private property rights.

Weed Control--This alternative's increased emphasis on weed control from alternative 1, which would incorporate weed control into all HM projects and explore collaborative opportunities to control weeds, could improve relationships among FWP, weed districts, and private landowners. FWP's assuming a leadership role in the control of weeds might increase tolerance of hunters by landowners who are concerned about hunters spreading weeds. Groups and individuals who oppose the use of chemicals to treat weeds would support this alternative's increased reliance on biological control but probably would still be dissatisfied with FWP's continuing use of chemicals.

Urban Wildlife--FWP would continue meeting its mandate to advise local governments about wildlife and habitat issues relative to local land use decisions and address wildlife conflicts on the urban interface that maintains public safety. Most local governments would view FWP as a resource for planning decisions and seek FWP participation. Urban residents would view FWP as concerned about wildlife problems and responsive to their needs.

This alternative's increased reliance on other entities to address wildlife/human conflicts and looking for alternative sources of funding to address urban wildlife issues could lead to more efficient resolution of conflicts. Most residents would welcome the services, but might resent having to pay for services that have traditionally been funded by revenue generated from the sale of hunting and fishing licenses.

\section{Issue: Access /Effects on Economic Values}

Overall Access--FWP's overall access policy would benefit participating landowners and local businesses that provide goods and services to recreationists. These benefits would increase with increased access to private land. If a new funding source is developed to provide access to private land for nonhunting recreation, economic benefits to local communities could increase from alternative 1 .

Block Management Policy--Acreage under BM/HEP agreements probably would increase over time as FWP enrolls new cooperators. Landowners enrolled in BM/HEP would benefit economically from reduced game damage and incentive payments for allowing hunting and managing hunters on their property. If FWP develops a funding source for nonhunting access, landowners would receive increased direct compensation for managing hunters and viewers on their property. Managing 
recreationists would consist of such duties as issuing permission slips, responding to inquiries, and other duties negotiated in agreements. This would increase indirect economic benefits to local businesses both from participating landowners and wildlife-related recreationists.

Access Through Lease, Purchase, or Easement--This alternative's emphasis on resource protection over access in HM projects might not significantly increase access to land under FWP's control. FWP would expect income to local businesses as a result of management of land under its control under this alternative to remain essentially unchanged from alternative 1.

Interaction with Other Agencies--The effect of FWP's response to land management proposals by other agencies under this alternative would be the same as under alternative 1. Land use decisions affecting public lands that are based on FWP's concerns could contribute to maintaining a stable economic situation for local businesses that rely on income from wildlife-related recreation. If FWP influences land management decisions to increase emphasis on habitat protection, income might be reduced for businesses relying on other activities on public land such as ranching and logging.

Closure of Large Private Blocks--Individuals and businesses that rely on public recreation for income might experience a loss of revenue where closures of private land occur. FWP programs under this alternative that increase public access to private land with increased local involvement might increase benefits from alternative 1 to the range of retail businesses that serve a hunter clientele.

Access Fees--Fees paid to local landowners by hunters also would benefit local economies, but the relative few participants would not provide the level of benefits to the local economy that would result from public access. Landowners participating in fee or leased hunting could expect higher levels of income than if they participate in HEP. The effect FWP programs have on local economies under this alternative would remain unchanged from alternative 1.

\section{Issue: Recreational Opportunity /Effects on Economic Values}

Providing Hunter Opportunities--Hunter expenditures among some hunter groups could increase under this alternative if opportunity for persons with disabilities were expanded above present levels. Local businesses and economies would benefit correspondingly. The outfitting industry would have an opportunity to expand its services to provide for hunters with disabilities or nonhunting recreationists wanting to view wildlife.

Emphasizing Conservation While Providing Recreation--This alternative's continued emphasis on hunting and trapping as management tools would continue to benefit businesses that provide goods and services to these groups. Increased emphasis on nonhunting recreation through I\&E efforts could provide offsetting economic benefits to local communities through equipment and travel expenditures by viewers and other recreationists.

Trophy Hunting--Providing opportunity to take large mature males under the present hunting season framework and application of regulations specifically to increase age class diversity in designated 
geographical areas would not change the mix of economic benefits from alternative 1. Huntingrelated expenditures resulting from diverse hunting opportunity probably would increase over time and with a corresponding increase in expenditures by trophy hunters.

Expenditures by hunters in designated geographical areas in which special regulations are implemented might decline because regulations intended to increase representation of older and larger animals could restrict hunter participation. However, such a reduction in expenditures might be small because "trophy" hunters tend to make larger expenditures than generalists or "meat" hunters (Duffield and Neher 1990 - see bibliography in Draft EIS).

Hunter Participation--FWP actions that maintain or increase participation in hunting, such as reducing barriers to participation, would maintain current economic benefits to businesses providing hunting-related goods and services. Expanded hunter education programs under this alternative probably would not affect local businesses any differently than under alternative 1 .

Resident Hunter Opportunity--Both resident and nonresident hunter numbers probably would remain stable over time. Numbers of resident hunters might fluctuate slightly with changes in big game populations, and nonresident numbers would adjust to market-based licenses. Although total numbers of nonresident hunters would not change from alternative 1, invoking Montana statute 87-1301 (4) (b) under this alternative could temporarily affect their geographical distribution. This might affect local economies while these rules were in force. Communities that receive decreased numbers of nonresident hunters would experience decreased hunter-related income.

\section{Issue: Species and Habitat Management/Effect on Economic Values}

Wildlife Introductions--Any increased recreational opportunity resulting from new or augmented populations of game and nongame would benefit local economies through increased demand for recreation-related services. Under this alternative, FWP would expect little change in economic benefits to local communities from alternative 1 .

Nongame and T\&E Species--Integration of nongame and T\&E species into habitat management programs could benefit local economies through sale of goods and services as a result of more viewing and hunting opportunities. FWP would expect a small gain in economic benefits from this alternative beyond those of alternative 1 .

Expanded efforts to recover and delist T\&E species and instate leadership in T\&E species management could reduce the overall economic burden that $T \& E$ species protection carries under state and federal statutes. Participating private landowners also could benefit from technical assistance and economic incentives under this alternative.

Integrating Habitat Management with Species Management--This alternative's increased emphasis on habitat protection could increase overall recreation opportunity. Such emphasis along with maintaining a focus on harvested wildlife would continue to benefit local communities economically 
through recreationists' purchase of goods and services. Individual landowners offering land or easements for sale to FWP also could benefit economically.

Compensating Local Governments for Lost Tax Revenue--Benefits to local governments from payments from FWP in lieu of taxes on real property to which FWP holds fee title would remain unchanged from alternative 1 . These payments would not compensate for revenues that would be paid to local governments for taxes on personal property if such land were in private ownership. FWP would expect the in-lieu payments to increase only slightly under this alternative because of heavy emphasis on conservation easements over outright purchase.

Setting Future Research Agenda-FWP's research program under this alternative would have a small effect within the state's economy. Overall benefits would remain unchanged from alternative 1 . Research focused primarily on harvest and habitat issues could indirectly increase or decrease revenues associated with hunting on a statewide basis through its influence on policy decisions. University communities funded by FWP's research efforts would continue to benefit. Some local economies would benefit from researchers' salaries.

\section{Issue: Commercial Uses /Effect on Economic Values}

Regulation of commercial facilities under this alternative, such as game farms and shooting preserves, might control proliferation of these operations from that which might occur under alternative 1 . This could reduce the rate of growth in the workforce of these businesses which also could affect the economic base of local communities. The long-range protection of wildlife habitats and the public recreational opportunities it offers, however, might offset this potential loss of income.

\section{Issue: Landowner Relations /Effect on Economic Values}

Predator Control--Under this alternative, FWP would continue its contribution to DOL for predator control to address predation on both wildlife and livestock. The program would continue to provide minimal localized income to predator control contractors. Economic benefits to producers from reduced livestock losses as a result of control efforts would remain essentially unchanged from alternative 1. The amount of FWP's contribution probably would remain stable or increase slightly over the next decade.

Game Damage--The mix of economic benefits resulting from FWP's response to game damage on private land would remain unchanged from alternative 1 . Harvest regulations designed to address game damage problems would benefit local service industries such as motels and restaurants. Actions to reduce game damage also would benefit agricultural producers. Purchases of materials such as fencing to reduce damage would benefit the local economy.

Weed Control--By increasing its involvement in weed control under this alternative, FWP could increase economic benefits to agriculture and local communities from alternative 1. Suppliers of weed control services and materials would benefit economically to some extent under all alternatives 
but less under this alternative because of reduced reliance on chemical control and increased reliance on biological control.

Urban Wildlife--By taking an active role in providing information to local decision makers, FWP could increase consideration of wildlife and habitat issues at the local level. This would prevent much of the need for design changes or delays in development, sparing developers lost time and money. FWP's involvement in planning could prevent future economic loss by subdivision residents, adjacent residents, and agricultural producers by considering such things as how the proposed development could influence game damage and lessen the potential for nuisance animals.

Consideration of wildlife viewing opportunities in local planning could help communities realize increased revenues from wildlife viewers. Increased reliance on other entities to address some human/wildlife conflicts and alternative funding sources to address wildlife issues on the urban interface would shift the burden of paying for these services from hunters and anglers to those receiving the services.

\section{Issue: Access /Effect on Other Agencies and Staff}

Overall Access--FWP would increase effort from alternative 1 to provide recreational access. The number of groups involved in recreational access under this alternative would expand to include conservation groups, private landowners, and land management agencies.

Integrating landowner/sportsmen and resource protection issues through expanded enforcement and I\&E efforts would require increased internal coordination. External coordination would emphasize educating landowners and the public about FWP's access programs and availability of land. Conflicting goals between agencies and differing needs among landowners, such as control of access and game populations, would continue to require significant staff time.

Block Management Policy--FWP's efforts to provide public access through BM/HEP would continue at the present rate of growth. Efforts directed toward providing nonhunting recreational opportunities under this alternative would expand the number of groups and organizations from alternative 1 with which FWP would coordinate to provide public access for both hunting and viewing and would include conservation and land preservation groups besides private landowners, sportsmen's groups, and land management agencies.

Internal coordination would maintain consistent services and compensation to landowners across the program.

Access-Through Lease, Purchase, or Easement--Maintaining a high level of commitment to habitat protection and quality of recreation on land under FWP control through dispersal of recreational use might require a small increase in internal and external cooperation and coordination from alternative 1. Internally, this would require coordination across administrative lines to identify and work toward statewide wildlife and recreation objectives. 
Interaction with Other Agencies--FWP. would continue to respond to other agencies' land management proposals affecting wildlife but increase emphasis on the ethical use of recreational vehicles on public land. Such responses would maintain current working relationships with agencies that manage public land. FWP responses could lead to decisions that favor wildlife conservation and recreation on public land over the long term.

Closure of Large Private Blocks--FWP programs that provide public access for hunting, such as HM, $\mathrm{BM} / \mathrm{HEP}$, and game damage assistance all have broadly different objectives, but their combined effect could increase the amount of private land that remains open for recreation especially with increased reliance on local involvement to implement these programs. Enrolling high priority land in $\mathrm{BM}$ agreements under this alternative would require increased internal coordination from alternative 1 between those who administer these programs at the statewide level and those who implement projects at the regional and field level. Actions to reduce the rate of closure of private land would require increased involvement of landowners, conservation groups and public land managers. Overall, these actions would result in a more focused approach to addressing public access to private land.

Access Fees--Efforts to maintain the current level of access to private land in light of some landowners charging fees would require increased cooperation from landowners and coordination with public land managers, sportsman groups, and local governments. FWP would continue to use programs, such as BM/HEP and game damage assistance, to discourage private landowners from charging recreationists a fee for access. These programs have broadly different objectives, but when implemented collectively, they could increase access to private land.

\section{Issue: Recreational Opportunity /Effect on Other Agencies and Staff}

Providing Hunter Opportunities--FWP would continue to offer special privileges to some groups of hunters although this alternative's proposal to encourage landowners to allow access for persons with disabilities, youth, and senior citizens would require increased coordination with landowners and other private organizations. Continuing to grant landowners preference for certain licenses could maintain a willingness to help provide opportunity for the public. Continued coordination with federal land management agencies would be necessary for access to federal land by persons with disabilities.

Emphasizing Conservation While Providing Recreation--Continued emphasis on hunting and trapping would require FWP to maintain, or even expand, coordination with private landowners, sportsmen, other public agencies, and conservation groups to manage both wildlife and habitats on public and some private land. Efforts to recover and delist T\&E wildlife by emphasizing habitat protection, while continuing to provide recreational opportunity, would require increased involvement with sportsman and conservation organizations to minimize conflicts.

Trophy Hunting--The overall effect of FWP actions and policies under this alternative would not change from alternative 1 . Special regulations under this alternative to increase representation of 
mature animals in designated geographical areas would continue to affect all major groups with which FWP must deal to set big game seasons. These groups include landowners, sportsmen's groups, guides and outfitters; and public land management agencies. Locally, sportsmen might sacrifice some hunting opportunity to increase numbers of mature males. This would continue to require compromise by the affected groups to reach an appropriate mix of benefits.

FWP would direct internal coordination at maintaining a diversity of hunter opportunity under this alternative. Education efforts would be required to inform affected parties of local regulation changes. Any local regulation change also would require enforcement effort to reduce any adverse impacts over a larger area than the area subject to the regulation change.

Hunter Participation--Effort to reduce barriers to participation would require substantial coordination of staff resources within FWP. Reduction of barriers, expanded educational programs, and working with communities to establish shooting ranges would require increased staff time to meet demands.

Resident Hunter Opportunity--The complex process of marketing and distributing nonresident licenses would continue to require continued coordination among divisions under this alternative. External coordination with private and public land managers would be required to maintain hunting opportunities. Issuing nonresident licenses under Commission rules if it invokes statute 87-1-301 (4) (b) as proposed in this alternative would require increased coordination between divisions and with administrative regions. Under those rules, FWP would issue licenses by allocation determined by the Commission.

\section{Issue: Species and Habitat Management/Effects on Other Agencies and Staff}

Wildlife Introductions--By developing a consistent statewide policy and expanding current effort to include T\&E species under this alternative, FWP would increase coordination with private landowners, the U.S. Fish and Wildlife Service and federal land management agencies. FWP would continue to work with private conservation groups, such as the Foundation for North American Wild Sheep, but under this alternative, also might collaborate with advocates of nongame and T\&E wildlife.

Nongame and $T \& E$ Species--This alternative would require increased internal and external coordination from alternative 1. FWP would coordinate with Canada, the U.S. Fish and Wildlife Service, and federal land management agencies that manage habitat for T\&E species. These alternatives propose technical assistance and incentives which would increase cooperation with private landowners and conservation organizations. Efforts to delist species or prevent new listings would increase the cooperation and coordination needed from both the public and the media.

Integrating Habitat Management with Species Management--FWP's coordination with federal agencies to protect habitat would increase from alternative 1 . Coordination would be required with private landowners and conservation organizations to protect and acquire high priority habitats. 
Compensating Local,Governments for Lost Tax Revenue--Internal coordination and cooperation with local governments would not change from alternative 1 .

Setting Future Research Agenda--The current level of assistance to research assistants and coordination between FWP researchers and Montana's University System would continue under this alternative. Any new funding for research on nongame and T\&E species could require increased cooperation with federal agencies. Continued internal cooperation would be required to identify research needs.

\section{Issue: Commercial Uses /Effects on Other Agencies and Staff}

Coordination and cooperation between FWP and other agencies, such as DOL, and within FWP would not change from alternative 1. Effort required to inspect facilities would increase.

\section{Issue: Landowner Relations /Effects on Other Agencies and Staff}

Predator Control--Redirecting emphasis from livestock to wildlife goals under this alternative might adversely affect FWP's working relationship with DOL because such action might not be consistent with DOL goals. However, this could expand opportunities for cooperation with private landowners and sportmen's groups.

Game Damage--Response to game damage under this alternative would require continued cooperation between FWP and private landowners as it would under alternative 1. Internal coordination would continue to maintain consistent services to landowners across the program. This alternative, however, would require increased cooperation between FWP and neighboring jurisdictions. Differing needs among individual landowners would require continued cooperation among FWP divisions.

Weed Control--FWP would increase collaborative efforts at the local level under this alternative to meet its statutory responsibilities on land that it controls and on other private and public land. Cooperation with public and private land managers would increase. FWP also would work closely with universities and extension services regarding biological controls and increased education.

Urban Wildlife--FWP personnel would continue to coordinate with local decision makers to minimize any adverse effects of proposed subdivisions on wildlife and habitat. FWP personnel could expect to work directly with planners, planning boards, city councils, and county commissioners to affect local land use decisions. Addressing wildlife/human conflicts that involve nuisance wildlife would require increased coordination with local governments and the private sector. Educational efforts about living with wildlife would require coordination and cooperation with schools, community groups, and the media. 
Overall Access--This alternative would continue to base priorities for funding on access needs and opportunities, landowner participation, and wildlife abundance. Earmarked and general license revenue and matching federal dollars would continue to fund hunter access programs. Overall funding for access-related programs, however, would be increased by a new funding source for nonhunting recreational access. Habitat sensitivity would determine program priorities. Viewers, hunters, and landowners would benefit from these programs. Any increases in the number of cooperators would require additional staff time to track and issue payments to landowners.

Block Management Policy--License fees and matching federal dollars would continue to fund $\mathrm{BM} / \mathrm{HEP}$ for hunter access to private land under this alternative. FWP would seek new funding sources to develop a similar program for nonhunting recreation. Overall funding for access-related programs would increase from alternative 1 as additional funding becomes available. Habitat sensitivity would determine program priorities. Beneficiaries would include hunters, viewers, and landowners. Increases in numbers of cooperators and development of a funding source for nonhunting recreational access would require redirection or increases in staff to track and issue payments to landowners. Program implementation would continue to be carried out by field personnel, and additional staff would be added or redirected as needed if legislative funding authority is granted.

Access Through Lease, Purchase, or Easement--HM projects would continue with funding from earmarked license revenue. Habitat protection would carry a high priority under this alternative with access acquired only on a case by case basis. The overall priority of access on FWP land might decrease from alternative 1 . Any increased access resulting from expanded habitat programs under this alternative would primarily benefit nonhunters. FWP would not expect staffing needs to appreciably change from alternative 1 .

Interaction with Other Agencies--General license revenue and matching federal dollars would continue to fund responses to land management agencies. Priority of responses to other agencies' travel management and habitat alteration proposals would vary with the scope of the proposal and the potential long-term effect of agency decisions. These efforts would affect recreationists and other users of public land. The responsibility for responding under this alternative would continue to fall on regional wildlife staff as part of its routine duties. Staff time required under this alternative would not change from alternative 1 .

Closure of Large Private Blocks--The funding for actions to discourage closures of private land would remain unchanged from alternative 1 . General and earmarked license revenue would continue to fund game damage, habitat, and access programs. Continued closure of large blocks of private land to hunting could appreciably decrease FWP's funding base over the long term through decreased resident license sales. 
Priorities for HM acquisitions, such as easements and leases, would be based primarily on habitat protection, but in such cases, the priority given access would increase. Efforts initiated to offset effects of land closures through both HEP and game damage programs at the FWP regional level might increase with time. Any increase in game damage associated with closures would increase staffing needs. Hunters would continue to receive most of the benefit from these actions as under alternative 1 .

Access Fees--The funding for actions to discourage landowners from charging access fees would remain unchanged from alternative 1 . Loss of public access to private land through fee hunting could adversely affect funding for these programs statewide through loss of license revenue.

Efforts initiated at the FWP regional level to offset effects of access fees through both game damage and access programs might increase with time. Any increase in game damage would increase staffing needs. Hunters would continue to receive most of the benefit from these actions as under alternative 1.

\section{Issue: Recreational Opportunity /Effects on Priorities, Funding, and Staffing}

Providing Hunter Opportunities--FWP does not expect priorities to change from those under alternative 1. Granting landowners preference for licenses or granting access exemptions and discounted licenses for persons with disabilities would not affect earmarked sources or general revenue from license sales. Granting discounted license fees to persons 62 years and older could adversely affect funding as an increasing number of hunters qualify for the discounts. Recreational opportunity and landowner willingness to provide access for special constituent groups of hunters would drive priorities. These special constituent groups would continue to benefit from these actions. Staffing needs would remain stable and unchanged from alternative 1.

Emphasizing Conservation While Providing Recreation--Revenues generated from license sales and matching federal dollars would continue to fund most conservation, recreation, and education programs as under alternative 1. FWP would maintain its program emphasis on hunting and trapping with anticipated periodic increases in license fees to meet rising program costs. Benefits to nonhunting recreationists might increase from alternative 1 , while those to hunters would remain unchanged. Staffing levels would increase slightly to implement new programs.

Trophy Hunting--FWP would continue a policy to increase representation of mature animals in big game populations in designated geographical areas. Such a policy would maintain a stable source of funding for FWP programs that depend on license revenue. Offering a diversity of hunting opportunity would continue to carry a high priority under this alternative. Staffing needs would remain unchanged from alternative 1.

Hunter Participation--General license revenue and matching federal funds would continue to fund I\&E efforts and this alternative's expanded hunter education program. Hunter education for youth and adults would carry a high priority under this alternative although these programs also would 
address interest of some nonhunters. Program implementation would continue with current levels of staffing. Hunters would benefit the most from these programs although nonhunting participants also would benefit by acquiring knowledge about wildlife and hunting traditions.

Resident Hunter Opportunity--Revenues from the sale of resident and nonresident licenses would continue to fund programs related to hunting under this alternative. Hunters would pay for and benefit most from these programs. Priorities would continue to emphasize resident hunting opportunities for big game. Staffing needs would not change from alternative 1.

\section{Issue: Species and Habitat Management /Effects on Priorities, Funding, and Staffing}

Wildlife Introductions--General license revenue and matching federal dollars would continue to fund introduction of harvested wildlife under this alternative. New funding sources would be developed to cover costs of introducing nongame and T\&E species. Recreational opportunity and minimizing conflicts with private landowners would carry a high priority under this alternative. Primary beneficiaries include hunters and nonhunting recreationists. Staff time would not change from alternative 1 .

Nongame and T\&E Species--General license revenue and matching federal dollars would continue to support the nongame and T\&E programs. FWP would need additional sources of funding to expand its efforts to delist species currently protected and to provide technical assistance to private landowners. T\&E wildlife would receive a higher priority than under alternative 1 . Viewers would be the primary beneficiaries of the additional emphasis on nongame and T\&E species. Priority of these programs could increase slightly among FWP programs from alternative 1 if alternative funding is developed. Required staff time might also experience a very small increase.

Integrating Habitat Management with Species Management--License revenue and matching federal dollars would continue to fund FWP's habitat and wildlife management programs. Harvestable wildlife would continue to carry a high priority under this alternative. Habitat programs would carry a higher priority than under alternative 1 . Hunters would continue to benefit, although landowners with property or easements to sell also could benefit. Staff requirements would continue at about current levels.

Compensating Local Governments for Lost Tax Revenue--General license revenue would continue to fund in-lieu of tax payments to local governments as under alternative 1. Costs of administering the program would increase only slightly over the next several years because of high emphasis on conservation easements over outright purchase. Priorities for this funding would vary among FWP regions based on the amount of FWP-controlled land. Staff time to administer these payments would not change from current levels. This program would primarily benefit local governments and communities.

Setting Future Research Agenda--General license revenue and matching federal dollars would continue to fund research on harvestable wildlife. Research on nongame and T\&E species would 
require a new funding source. Priorities would be aimed at filling information gaps related to high profile, harvest-related issues. Hunters and trappers would remain the primary beneficiaries.

Required staff time would continue at current levels.

\section{Issue: Commercial Uses /Effects on Priorities, Funding, and Staffing}

FWP would seek authority under this alternative to charge commercial operators for inspecting and licensing commercial facilities, develop new criteria to base permitting decisions, and clarify existing law regulating importation of wildlife and exporting animal parts. Monitoring and inspecting game farms, shooting preserves, and other commercial facilities would remain a high program priority. Staff time and expenses could increase from alternative 1. Passing the expenses of licensing and annual inspections to the operators would significantly reduce reliance on license revenue from alternative 1.

\section{Issue: Landowner Relations /Effects on Priorities, Funding, and Staffing}

Predator Control--Predator control would remain a low funding priority. FWP would continue to contribute to DOL's predator programs but would redirect the effort to address predation on both wildlife and livestock. General license revenue and matching federal dollars would continue to fund the program. Direct benefits to recreationists (in abundance of wildlife) would increase locally, whereas benefits to landowners could experience a small decline from alternative 1 .

Game Damage--The effects of FWP's response to game damage on priorities, funding, and staffing under this alternative would not change from alternative 1 . General license revenue would continue to fund game damage control. Overall program cost would remain low because public hunting would remain the primary tool to reduce depredations. License revenue could partially offset administrative costs generated by the program. FWP would base program priorities on levels of landowner complaints and populations of big game on private land. The program would continue to stress both abatement and prevention and would benefit hunters through increased opportunity. Landowners would benefit through reduced crop losses. Staff time to administer the program would continue at current levels.

Weed Control--License dollars would continue to support the control of noxious weeds on FWP land under this alternative. Funding levels and priorities would be established on the basis of statutory requirements for weed treatment and the 6-year weed plans of each FWP region. Under HEP agreements, landowners would continue to determine their own priorities for expenditures on weeds. Requirements for staff time might not change from alternative 1, but additional skills in biological control might be required.

Urban Wildlife--This alternative would decrease reliance on license revenue to manage urban wildlife issues from alternative 1 if new sources of funding are developed, and by increasing reliance on other entities to address conflicts involving nuisance wildlife. Priorities would be directed toward comprehensive land use decisions at the local level and maintaining public safety. Local 
governments and residents who value wildlife would benefit, as would agricultural producers for whom a game damage problem was averted. Workloads related to planning might increase but without additional staff time due to changed emphasis.

\section{Issue: Access /Effect on Licensing, Regulations, and Enforcement}

Overall Access--The effects of an overall access policy on licensing and regulations under this alternative would not change appreciably from those of alternative 1. Enforcement efforts would continue to concentrate on private land to improve sportsman/landowner relationships. This alternative's increased emphasis on resource protection might slightly increase enforcement workloads.

Block Management Policy--Levels of licensing under this alternative would not appreciably change from alternative 1. If additional funding similar to HEP is developed for a nonhunting access initiative, regulations might be implemented to protect those habitats. Enforcement workloads could increase from alternative 1 to enforce any new regulations.

Access Through Lease, Purchase, or Easement--This alternative's emphasis on resource protection would have no measurable effect on licensing. Any increased complexity of regulations from evaluating access on a case by case basis could increase enforcement workloads.

Interaction with Other Agencies-FWP's response to other agencies' land management proposals would have no measurable effect on licensing under this alternative but could affect regulations and enforcement. For example, efforts to reduce elk vulnerability to hunting on national forests might be accomplished through either restricting logging and associated road-building or restricting other users of public land such as hunters. Although travel restrictions on public land would remain the responsibility of the public agency managing the land, any cooperative effort to enforce restrictions on motorized recreation or motor-assisted hunting would increase enforcement workloads from alternative 1.

Closure of Large Private Blocks--FWP's efforts to discourage closure of large blocks of private land to hunting through game damage assistance, HM projects, and HEP would continue to minimally affect licensing, regulations, and enforcement under this alternative. A strong focus on private land issues and minimizing the potential for game damage by emphasizing annual harvests of big game over large blocks of private land could minimize the need to increase regulations and enforcement workload. However, a small increase in hunter access could correspondingly increase enforcement workload.

Access Fees--FWP would continue to apply game damage assistance and HEP to discourage private landowners from charging access fees. These actions probably would minimally affect licensing, regulations, and enforcement. Any new preference granted landowners for licenses might increase enforcement workload from alternative 1 . 


\section{Issue: Recreational Opportunity /Effect on Licensing, Regulations, and Enforcement}

Providing Hunter Opportunities--Offering some groups of hunters, such as persons with disabilities and others, special types of licenses or access exemptions would continue under this alternative. Complexity and number of license types, regulations and enforcement workload would would not change from alternative 1 .

Emphasizing Conservation While Providing Recreation--This alternative's proposal to continue emphasizing hunting and trapping, expand educational efforts directed at nonhunters, and expand efforts to recover and delist T\&E species would not affect licensing but would have a small effect on regulations and enforcement. An increased effort to delist T\&E species could increase complexity of regulations and enforcement workload from alternative 1.

Trophy Hunting--The effect of FWP's effort to increase representation of mature males among big game populations in designated geographical areas on licensing, regulations and enforcement would not change from alternative 1 . Special harvest restrictions would continue to require special licenses or permits. Harvest regulations intended to increase representation of mature animals, such as antler point restrictions, would require redirection of enforcement work loads. Any variation over time from one type of restriction to another might reduce effectiveness in deterring illegal harvest unless enforcement is coordinated with I\&E effort.

Hunter Participation--Effort to reduce barriers to participation that includes an expanded hunter education program would have a small impact on licensing, regulations, and enforcement. More informed hunters afield might decrease an enforcement workload from alternative 1.

Resident Hunter Opportunity--This alternative's proposal to invoke statute 87-1-301 (4) (b) would increase complexity of regulations while special rules were in effect. Enforcement workloads might be redirected as a result.

Issue: Species and Habitat Management /Effect on Licensing, Regulations, and Enforcement

Wildlife Introductions--Regulations could change in response to the need for managing new or larger populations. Protecting introduced T\&E species might require additional regulations. T\&E-related enforcement workload could increase even if additional regulations are not developed. Expanded efforts through hunter education programs could reduce the additional workload.

Nongame and T\&E Species--This alternative would not measurably impact licensing. Regulations could increase in number and complexity over the short term as a result of increased efforts to delist species currently protected by endangered species laws and prevent new species listings.

Enforcement would continue to support the U.S. Fish and Wildlife Service on T\&E issues and workloads could increase. 
Integrating Habitat Management with Species Management--This alternative's proposal to increase emphasis on habitat protection at an ecosystem level could initially increase complexity of regulations. Enforcement workloads might increase slightly to protect newly acquired habitats.

Compensating Local Governments for Lost Tax Revenue--No effect.

Setting Future Research Agenda--No effect.

\section{Issue: Commercial Uses /Effect on Licensing, Regulations, and Enforcement}

FWP would pursue major revisions in statutes and rules that regulate game farms, shooting preserves, and other commercial uses of game and nongame species and the funding for enforcement of those regulations. The need to license, inspect, and enforce regulations dealing with commercial operations would continue under these revisions. Enforcement workloads would not change under this alternative because FWP would not expect numbers of operations to expand at a rate greater than that under alternative 1.

\section{Issue: Landowner Relations /Effect on Licensing, Regulations, and Enforcement}

\section{Predator Control--No effect.}

Game Damage--FWP's response to game damage under this alternative would continue to influence regulations and law enforcement because hunter harvests would remain the primary tools to minimize the damage. Response to game damage requires special types of licenses, such as antlerless deer licenses, but fewer complex regulations than would be the case if damage were addressed outside the general big game hunting season. Enforcement workloads would not change from alternative 1 .

Weed Control--Additional regulations might be needed to prevent the spread of noxious weeds (such as for a weed seed free hay program). This would increase enforcement workloads.

Urban Wildlife--Continued real estate development might require increased numbers of regulations to protect public safety. This alternative's provisions for minimizing human-wildlife conflicts on the urban interface, however, would have only a small effect on licensing and regulations because hunting would not be a major factor in resolving urban wildlife issues. Enforcement workloads probably would remain unchanged from alternative 1 . 


\section{Wildlife Program Environmental Impact Statement (EIS)}

\section{SUMMARY OF PUBLIC COMMENT}

The draft EIS was released for public review and comment on April 1, 1998. The initial period for the public to review and comment on the draft EIS spanned from April 1 through July 31 . At the request of several individuals and groups, the comment period was extended through August 31 , 1998. The public had a total of 153 days to review and submit comments on the draft EIS. Overall, FWP received 825 comments on the draft EIS from 319 individuals and 23 organizations (see Appendix A), which included public hearings and meetings and comments submitted in writing.

During May 5-21, public hearings were held in each city (7) where FWP regional headquarters are located to take comment on the draft Wildlife EIS. The hearings spanned a period from 5 to 7 weeks following release of the document. On May 26, FWP took public comment at a meeting held in Libby, which was scheduled at the request of Lincoln County Commissioners. FWP received 94 comments from 36 members of the public who attended these facilitated gatherings. A second public meeting was held in Libby on July 20,1998, which was attended by 116 members of the public.

FWP received written comment on the draft EIS from 201 individuals and organizations. Of the written comment, 166 individuals and organizations returned the comment form (see Appendix B) sent out with copies of the draft EIS or executive summary; 35 individuals and organizations summarized their comments in letters to FWP of which several included a sixth alternative that would best reflect their concerns.

After reviewing public comment on the draft EIS, FWP, with the involvement of the Commission, identified a preferred alternative from among the alternatives analyzed in the draft EIS. The preferred alternative was sent out as a draft supplement for public review and comment for a 30-day period beginning on October 1,1998. This document also includes a summary of that comment and a list of those who responded (see Appendix C).

\section{Comment Form Accompanying Draft EIS}

Question 1: Do you believe the Wildlife Program should be guided by any of the alternatives as described?

Of the 166 returned comment forms, 93 (56\%) individuals favored alternative 3 (see Appendix D). Sixty-nine forms were from Flathead County for which a response was seemingly motivated by a local issue - a pending application for a permit to operate a game farm. Thirty-five individuals $(21 \%)$ stated a preference for alternative 1 (the current program), $17(10 \%)$ favored a $6^{\text {th }}$ alternative that incorporated parts of the five alternatives analyzed in the draft EIS, and $14(8 \%)$ did not indicate a preference among the alternatives. 
Question 2: ........which three [of the 21 issues] are the most important to consider within the Wildlife Program?

Of the 21 issues addressed in the alternatives, commercial uses of wildlife (e.g., game farms and shooting preserves) was cited more than any other single issue (see Appendix D). Eighty-six (51\%) of 166 respondents indicated that this was an important issue but again largely reflected the sentiments of those responding to a local issue in Flathead County. Other issues of high relevance to the public included overall access, resident hunting opportunity, protecting wildlife while providing recreational opportunity, and integrating habitat management with species management.

Individuals favoring alternative 1 indicated that issues dealing with access and resident hunting opportunity were most important (seeAppendix $D$ ). Those favoring alternative 3 were most concerned about commercial uses of wildlife and how FWP would protect the resource while providing recreational opportunity. Individuals urging FWP to develop a sixth alternative also were concerned about access, integrating habitat with species management, and commercial uses of wildlife.

\section{Question 3: ............ do you think anything is missing?}

Of 166 individuals returning the comment form, 61 (37\%) responded to question 3 indicating what they felt was missing from the document or what issues had not been emphasized to their satisfaction (see Appendix E). Of these comments, 14 were related to regulation of commercial activities such as game farms, 7 addressed recreational access, 5 dealt with relations between FWP and landowners/managers, and 16 comments were outside the scope of the decision. These comments did not raise any issues that were not already addressed in Chapters II and IV of the draft EIS.

\section{Question 4:} additional comments.

Additional comments were offered by 155 of 166 individuals returning the comment form (see Appendix F). Of those, 69 restated their opposition to game farms and shooting preserves primarily out of concern for public safety and for ethical reasons. Others expressed concerns about access (i7), relationships between FWP and its traditional constituencies (10), management of wildlife and habitat (6), and recreation (13). Nineteen comments centered on the process to develop the draft EIS and public involvement in the process. Eight comments were outside the scope of the decision. Here again, FWP believes that it addressed all concerns that were relevant to the decision. 


\section{.Letters and Public Hearings in Response to Draft EIS}

Of 354 comments submitted in letters and recorded at public hearings, $182(51 \%)$ were related to issues addressed among the five alternatives analyzed in the draft EIS. Another 90 comments were related to one or more of the alternatives. The process used to develop the EIS, funding and staffing for FWP wildlife programs, and the environment affected by implementing the alternatives received another 64 comments. Eighteen comments were outside the scope of the decision.

Issues receiving the most comment from letters submitted to FWP were policy and role of FWP in licensing and inspecting game farms and policies and actions that affect resident and nonresident hunter opportunity. The issue regarding commercial operations (e.g., game farms) public comment overwhelmingly favored FWP's continued involvement in regulation of commercial operations. FWP's involvement in predator control and hunter participation also were very important to the public.

Several parts of the draft EIS received significant scrutiny from the public including the process that FWP used to develop the document. These include:

- The respective roles of FWP and the Commission with respect to the decision and implementing it once it's made;

Policies and actions that affect access and recreational opportunity;

Impacts of FWP policies and actions on rural lifestyles; and,

FWP's funding source-- who pays and who benefits.

\section{SAMPLES OF COMMENTS RECEIVED ON DRAFT EIS AND FWP'S RESPONSE}

\section{Overall Access 8 comments.}

\section{ISSUE \#1}

\section{Summary}

Public comment overwhelmingly favors FWP involvement in obtaining public access for recreation on both public and private lands. Most comment on the issue advocates increased access for hunters. Those who would accommodate FWP securing access for nonhunting recreation desire that it be funded by a source other than license revenue.

\section{Samples of Comments}

- You must redeem your responsibility to allocate harvest opportunities. When any game population becomes so inaccessible that private owners are actually dictating who harvests animals, your agency must adjust the license structure so that the harvest allocation is done by your agency in a fair and equitable manner. This will often require large male animals being 
allocated by permit rather than an "A Tag" system where the landowner actually sells animals to clients.

- The Department should encourage good sportsman and landowner relations.

The Department should undertake an aggressive program to increase reasonable access to all game populations. While there is certainly a time and place for road closures, road closures can result in reduced hunting opportunities.

Response: Access to private land is at the discretion of the landowner and would remain so under any alternative. Under the preferred alternative FWP would continue working closely with landowners/managers and sportsmen to address landowners' concerns, recreational opportunity, and maintaining populations of harvestable species at desired levels.

\section{Access/Private Land-9 comments}

\section{ISSUE \#2}

\section{Summary}

Public comment strongly encourages FWP to actively pursue public access by recreationists to private land. Most comment expressed support for continuing the Block Management Program at current or increased levels of effort. Some expressed concern over experiencing quality hunting opportunity with continued administration of this program. Comment is supportive of FWP pursuing access for nonhunting recreation under the condition that funding for those efforts were linked to that user group.

\section{Samples of Comments}

- As I have read the 6 elements that deal with access, I see the constant fact that private land plays a very important role in the future management of our wildlife. Because of the importance of private land and wildlife, I feel that FWP should not hold back any efforts to continue to make private land available to the public. The funds generated by sale of license should continue to be used for this purpose. Remember that if the general public has no where to hunt, they will not have any need to buy a license.

- We support expansion of the Block Management Program, including some resident contribution to the funding. This program has expanded rapidly in the last three years, so future expansion should go slowly as we learn how to best manage the program.

- Block management has been strongly pushed. Nowhere does the document say there must be something to hunt when one arrives and the rancher laughs on his way to the bank.

- I strongly support the recommendation [alternative 3] that the department "actively pursue access for nonhunting recreation and develop a user-based source of funding." ............ Bird 
watchers and rock hounds use toilets as do hunters or fishermen - the "non- consumptive" user needs to pay his/her share.

Response: Comment recommends raising revenue from nonhunting recreationists to help fund wildlife management actions. Under the preferred alternative FWP would continue to negotiate block management agreements with private landowners and develop new sources of revenue to fund activities related to nonhunting recreation.

\section{Land Program/Access- 13 comments}

\section{ISSUE \#3}

\section{Summary}

Although a cross section of public comment was supportive of FWP efforts to acquire habitats through easement, lease or purchase, two opposing points of view emerged. The most common view is that FWP should not acquire habitat for wildlife without a guarantee of public access, particularly for hunting. If hunting access is not a condition of acquisition, then the acquisition should be funded by a source other than license revenue. Based on comment received, the minority view is that land acquired for wildlife by FWP should emphasize wildlife and habitat values over recreation; thus, these acquisitions should not be made contingent on availability of access.

Several individuals took issue with the statement in the document that Montana residents prefer easements and leases over fee title.

\section{Samples of Comments}

- The Issues, Access, 3 (p. S-2): Montana hunters DO NOT "favor the use of leases and easements over acquisitions."

- We favor alternative 1 plus the second paragraph of alternative 5 "consider public access a condition for acquiring an interest in land through easement, lease, or outright purchase."

- In all efforts to acquire property or property rights, highest priority should be given to the quality and value of the habitat. Public access and recreation should be secondary concerns.

- We strongly support continuation and expansion of state purchase of wildlife habitats, especially habitat for game animals.

We do not support purchase of conservation easements without public recreation and hunting rights. The exception to this is the purchase of key winter ranges, where deer and elk are available on adjoining public land during hunting season. Preserving elk habitats simply for the sake of preserving elk habitats, when the public cannot enjoy those elk through observation, photography or hunting is not a wise use of public money. 
Response: As proposed under the preferred alternative, FWP would stress habitat in its acquisitions and consider access on a case by case basis.

\section{ISSUE \#4}

\section{Response to Agency Requests-2 comments}

\section{Summary}

Public comment directed at this issue favored a FWP response emphasizing habitat protection over recreation and that recreational opportunity remains contingent upon maintaining habitat quality.

\section{Samples of Comments}

- Respond to all requests from an ecological perspective giving high priority to wildlife population stability, habitat security and individual hunter opportunity.

- Giving habitat protection a higher priority than recreation in all management decisions including road trail building and maintenance.

Response: FWP's preferred alternative would continue to consider benefits to wildlife, habitats, and recreational opportunity in its responses. Additionally, it would take the lead in promoting ethical use of recreational vehicles on public land.

\section{Private Land Closure 6 comments}

\section{ISSUE \#5}

\section{Summary}

Public comment expressed a primary concern that closure of large blocks of private land as a result of leasing to outfitters is diminishing hunting opportunity for resident hunters. Another concern is that such closures in some cases also limit public access to public land.

Suggested proposals for FWP to go beyond the package of actions addressed among the five alternatives. These included as a matter of policy, the Commission closing hunting seasons in districts where the public is denied access to private land as a result of leasing to outfitters. Another proposal would change the tax rate on land leased to outfitters from agricultural to commercial.

\section{Samples of Comments}

- Ranchers who lease their land to outfitters should be taxed at a recreational rate.

- Since wildlife belongs to the public, monies for game damage should only be given to landowners who allow free public access. On a broader note, the current nonresident licensing system is significantly contributing to this problem. 
- When large blocks of land are closed to public access, the Commission should use its authority to close the season until a plan for reasonable sharing of the public wildlife resources is developed and approved by the Commission.

Response: Closures of private land can preclude legal and physical access to some public land and would be the case under any alternative. FWP would continue to use game damage assistance, habitat, and access programs to counter the effects of closures. Under the preferred alternative, partnerships would be developed to apply these programs at the local level to improve hunter access.

\section{Loss of Access to Fee Hunting-3 comments}

\section{ISSUE \#6}

\section{Summary}

There was little direct comment on this issue probably because of some actions that FWP proposed among the alternatives (e.g., game damage assistance and incentives) were similar to issue number 5 .

One comment that addressed a response to the issue suggested at least partial agreement with alternative 3 .

\section{Samples of Comments}

- Concentrate all FWP attention, personnel and resources on those landowners who either do not charge fees or have sharing programs.

- A definite "no" on using hunter days to assess the value of BM or HEP contracts- too easily abused. The goal of these contracts should be not only to provide access for hunting but to provide quality hunting experiences and wildlife habitats. If all nonresident deer tags were drawn from the same pool, landowner preference may not need to be denied to landowners charging only a reasonable fee for access (a comment directed toward paragraph one of alternative 3).

Response: The Block Management program is intended to provide access to private land for resident hunters and NOT to enhance or acquire habitat for wildlife. FWP would continue to use hunter-days as a basis for payments and provide game damage assistance to landowners who allow public hunting. Under the preferred alternative, FWP also would explore opportunities for drawing or license preference for landowners who allow public hunting. 


\section{ISSUE \#7}

\section{Special Constituent Groups- 6 comments}

\section{Summary}

Public comment generally favored any exemptions offered to persons with disabilities, youth and seniors. Comment about special consideration given private landowners was mixed although more comment supported a viewpoint that it should be contingent on benefits they provide to public hunting. Providing licenses to landowners for resale as an inducement was opposed.

\section{Samples of Comments}

- Do not allocate licenses to landowners for resale or reissuance. Licenses must go directly from your agency to the individual receiving the license or permit.

- A landowner should be allowed to hunt for any huntable species on his land without drawing for special permits. Why let someone else hunt on your land if you are denied that privilege yourself?

- We support having reduced license fees for youth, disabled and the elderly. There should be no "free" licenses since it affects Federal funding.

Response: FWP proposes to continue providing some groups of hunters the current special privileges but additionally would encourage landowners to allow access for youth, seniors, and persons with disabilities.

\section{ISSUE \#8}

\section{Emphasize Wildlife \& Habitat/Recreation-10 comments}

\section{Summary}

Public comment endorsed FWP actions that protect or enhance habitat. How recreation opportunity is allocated with that endorsement, however, suggests a division in expectations among recreationists. Some individuals and groups believe that FWP should not involve itself in nongame wildlife and nonhunting recreation issues but remain committed to maintaining hunting and trapping as primary tools to manage wildlife. Others believe that FWP should increase emphasis on nongame and viewing. Public comment in those activities appears split about evenly on that issue.

\section{Samples of Comments}

- $\quad$ Continue to emphasize hunting and trapping as the primary tools to manage wildlife populations.

- We do not feel that it is necessary for the department, at this time, to be Montana's provider of nonhunter recreational activity, even though past director Dunkle envisioned the FWP as an "outdoor recreation leader." 
- In general, we feel that FWP should focus more attention on habitat protection and enhancement. The citizens of the state rely on FWP to maintain and enhance wildlands and habitats for all species of animals..........that are native to the state and nonnative species that are managed as game animals.

- $\quad$.........I actively support attention to nongame and threatened and endangered (T\&E) species. By statute, these concerns are the department's responsibility. These other species are all part of the ecosystem. Habitat- and the plant life with it - must be protected.

Response: As proposed under the preferred alternative, FWP would continue to emphasize hunting and trapping as tools to manage wildlife populations but expand efforts to recover and delist $T \& E$ species and increase I\&E efforts directed at nonhunters.

\section{Trophy Hunting - 10 comments}

\section{ISSUE \#9}

\section{Summary}

For various reasons, about half the public comment addressing this issue favorably view actions that would increase age class diversity or increase numbers of large mature males in big game populations. The other half attached a negative connotation to the term "trophy hunting." Some share the perspective that harvesting wildlife for trophy value is either unethical or that encouraging taking a trophy animal is not really a part of FWP's mission or mandates. Some people would just rather it be called something else such as managing for age diversity.

\section{Samples of Comments}

- Greater emphasis on trophy hunting - would help ecosystem management encourage maintenance of the herd to produce older-age males.

- I see the merit of restricting hunting of trophy big game "bucks" or "bull", which makes for better reproduction as well as attracting trophy hunters, and I support this goal.

- I do not agree with providing trophy hunting, as it is ego-driven, works hunting into the negative "hands" of anti-hunters, and does not recognize that hunting should only be performed if sustenance is gained. Even though you propose limiting trophy hunting to just a few hunters through quotas and permits, it implies that FWP condones trophy hunting, which is contrary to the purpose of FWP.

- $\quad$........ readers are very easily led to think that increasing the number of males to physical or phenotypical maturity is trophy management. I suggest there is a very clear distinction between these two concepts and the EIS does not adequately address age class distribution and physical maturity as a biological issue as opposed to trophy hunting as a social issue. I am not 
aware that any regulations have been implemented in Montana that would protect adult males beyond phenotypical maturity.

Response: Chapter III of the draft EIS provides a definition of a trophy animal and trophy hunter (pp. III-14 and -15). The biological consequences of implementing strategies to increase representation of older mature males are documented in Chapter IV of the draft EIS (pp. IV-49 and -51). The recreational, social, and economic consequences are documented on pp. IV-54, -59, and -62. FWP would continue to provide opportunity to harvest big game under the present big game season format. This format would strive to increase representation of large mature males in designated geographical areas while emphasizing a diversity of hunting opportunity throughout the state.

\section{Hunter Participation- 13 comments}

\section{ISSUE \#10}

\section{Summary}

Public comment endorsed expansion of hunter education programs that will continue to provide the revenue base to support wildlife management programs. Some comment targeted the allocation of nonresident licenses as a system that works against recruitment of young hunters.

\section{Samples of Comments}

- Hunters have built the resource and need to continue to be recognized as the department's primary constituents.

- Nonhunting attitudes should not be part of the hunter ed program.

- Again, your nonresident deer tag allocation system works against young hunter recruitment both on an instate and out-of-state basis. It is our belief that short of restructuring this system, no major strides will be accomplished by you in this area with the proposals in alternative 5 , although they are admittedly better than doing nothing.

- Regarding hunter education, I have a bias - what's wrong with hunting? Those who want to eliminate it don't come up with feasible alternative funding sources. Yes, educate our hunters to respect the land, landowners, each other, and different philosophies but go slow with this "anti-hunting" business! It has to be recognized, true enough!

Response: FWP would continue to use I\&E that reduces barriers to participation in hunting and develop shooting ranges to develop or improve skills. Under the preferred alternative, FWP also would expand hunter education programs to focus on Montana's hunting heritage. 


\section{ISSUE \#11}

\section{Nonresident/Resident Opportunities 19 comments}

\section{Summary}

Public comment, as among several other issues, was divided. This also was one of several issues in which respondents were primarily hunters.

Some comment recognized several contributions made by nonresident hunters that benefit wildlife management programs and hunting in general. Such comment also stressed the need to continue limiting numbers of nonresident hunters.

Other comments represent a point of view that the set-aside of nonresident combo (B-10) licenses for clientele of outfitters and market-based pricing are benefitting the outfitting industry at the expense of the resident hunter and even some nonresident hunters. Other comment suggested that license fees for both resident and nonresident licenses be increased; this was not addressed among the alternatives in the draft EIS.

The impact of anti-hunting sentiments and their effect on FWP programs also was tied to this issue. Some comment suggested that these sentiments should not influence FWP decision-making. Some comment maintained that support of nonresident hunters could help defend FWP programs from attacks from those with an anti-hunting philosophy.

\section{Samples of Comments}

- Market-driven license will phase average Montanans out of hunting - also reduces opportunity for nonresidents.

- Nonresident hunters should pay for the "right" to hunt in Montana; residents have a right under reasonable restrictions.

- Looks like several options are being considered to increase out-of-state dollars to increase FWP budget. Don't sell out to nonresidents for more money to the Department.

- I have problems with alternatives that provide outfitters with a guarantee for permits. By that you are guaranteeing them a living. I don't get that and they shouldn't either.

- Remember that there is a substantial amount of funds generated by the nonresident hunter that help support management here in Montana. More important, I think that we must remember that when the anti-hunting attack arrives here in Montana we will need the support of all nonresident hunters to battle this attack.

Response: FWP would continue to restrict numbers of nonresident big game combination licenses and charge nonresidents' higher fees for licenses. Under certain circumstances, the Commission would designate where nonresidents can hunt. Under 
the preferred alternative, FWP also would focus its I\&E programs on Montana's hunting heritage and set regulations encouraging the ethical use of Montana's wildlife resources.

ISSUE \#12

\section{Species Introductions -4 comments}

\section{Summary}

We did not receive much direct comment on this issue other than FWP should retain the option. Some concern was expressed about involving all affected parties. Other comment expressed concern that introducing some species may create problems with managing other species.

\section{Samples of Comments}

- The department should also keep its program of transplanting of wildlife to help build new populations in areas once lived in and also to keep dwindling populations from dying out.

- We support the capture and release of game animals to augment existing populations or start new populations. We do not think this will be a large program, but it may be useful from time to time to augment an existing game herd that has been decimated by weather or disease.

Response: The preferred alternative proposes developing a consistent statewide policy for species introductions and development of a new source of funding for transplants of nongame and $T \& E$ species.

\section{ISSUE \#13}

\section{Nongame and T\&E Species -7 comments}

\section{Summary}

Public comment indicated support for FWP to continue its nongame and T\&E efforts at least at current levels. Any expansion of or integration of these programs with other programs would require a new funding source.

\section{Samples of Comments}

- We do not support additional spending on these [nongame and T\&E] species without a new or additional revenue source. We suggest tapping the coal tax interest, the bed tax or establishing a nonhunting license of some kind for those wishing to visit or use our Wildlife Management Areas.

- $\quad$ Regarding threatened and endangered species, I think FWP should work together with federal agency employees, and not duplicate or work contrary to their work. When you say "assume instate leadership of individual T \& E species management..." it sounds like you are disagreeing with federal leadership in some species. 
- Rather than just being a hook and bullet club, the FWP has an obligation to nongame, native wildlife species. ......it is imperative that long-range plans that enhances native wildlife species be implemented. Many are considered sensitive or listed under the ESA as threatened or endangered.

Response: FWP would continue its efforts to recover T\&E species and influence reauthorization of the federal Endangered Species Act. Under the preferred alternative, FWP also would, contingent on new funding, expand its efforts to recover and delist protected species, assume an instate leadership role, and increase efforts on private land.

\section{ISSUE \#14}

\section{Integrate Habitat with Species Management- 3 comments}

\section{Summary}

Limited direct comment on this issue emphasizes a leadership role for FWP in wildlife habitat issues in the state. However, some of this comment emphasized that license revenues used in habitat projects should be directed at game species.

\section{Samples of Comments}

- Habitat is the key word for all fish and wildlife. The department should again be the leader in habitat issues, both by acquiring and protecting Montana's important areas, even if it means butting heads with other agencies, both Federal and Local. Many nongame species benefit from habitat and projects paid for by sportsmen.

- We believe that habitat purchased by and managed with hunting license revenues should concentrate on managing game species. As sportsmen, we also support nongame management, but believe nongame management should be funded by sources other than game license revenues.

Response: The preferred alternative proposes to increase emphasis on maintaining and protecting habitat at an ecosystem level, expanding its efforts to acquire habitat, and collaborating with organizations and landowners to protect important habitats.

\section{ISSUE \#15}

\section{Payments In-Lieu of Taxes- 6 comments}

\section{Summary}

Most public comment directed at this issue questioned the need to extend these payments to include those in-lieu of taxes on personal property. Most of these questions are addressed in Chapter IV of the draft EIS. 


\section{Samples of Comments}

- $\quad$ Alternatives 2-5 indicate local governments would benefit from expanded in-lieu tax payments. Could you explain how? I want to go on record as opposed to any changes in land use.

- Curiously, many landowners do not really pay the real and property taxes they should as it is.

We do not clearly understand your proposals to benefit local governments through expanded payments including those in-lieu of personal property taxes. Could you please address this concept in detail and explain it to us? What other kinds of payments in lieu of taxes are you considering?

Response: Under alternatives 3 and 5, FWP would make payments to local governments in lieu of personal property in addition to those on real property for which it holds fee title (see draft EIS, pp. II-10 and -17). Although use of the land could change if FWP purchased property, income to local governments could increase on land that FWP already owns from payments in lieu of taxes on personal property (pp. IV-62 and-108). FWP proposes to continue to only make payments in lieu of taxes on real property under the preferred alternative.

\section{Research- 4 comments}

\section{ISSUE \#16}

\section{Summary}

All comment directed at this issue supported continuing a wildlife research effort.

\section{Sample of Comments}

- Number 16 indicates relying on universities for short-term research needs. I don't think you should narrow this to short-term. Time frame should be irrelevant when finding the best solutions to wildlife management in Montana. ............. Combinations of employees and contracts with university faculties and students are both useful, regardless of time frame.

- I note that you are cutting back on research and data collection. Putting unqualified district supervisors in charge of research is a poor move.

Response: Under the preferred alternative, FWP would continue research with an emphasis on harvest and habitat issues. 


\section{Commercial Operations -19 comments}

\section{ISSUE \#17}

\section{Summary}

Public comment embraces the following points (received from a broad cross-section of groups and individuals).

FWP should be the lead agency responsible for inspecting and licensing of private game farms.

If FWP cannot prevent establishment of new game farm operations, then funding for administration that includes licensing, inspecting, and enforcement should come from a source other than license dollars.

The alternative point of view was that privately owned game animals should be treated as any other livestock and regulated by DOL.

\section{Sample of Comments}

- Who better than the FWP to do this; certainly NOT the DOL.

- Develop I\&E programs related to the detrimental impacts to Montana's wildlife heritage from wildlife domestication and game farming. Such impacts should include but not be limited to: disease transmittal, escaped exotic species, ethics of captive shooting, and the genetic integrity of Montana's wildlife.

- On the issue of game farms, I think that it is a big mistake for the department to be involved in this type of operation at all. I personally know the laws and regulations that game farm owners now face, and I feel that they should be treated as any other livestock operation and left at that.

Condoning commercial use of wildlife is in exact opposition to managing native wildlife populations in Montana. FWP should absolutely charge commercial operators for all expenses of inspecting their facilities. In fact, a moratorium on any new commercial operations should be immediately imposed.

- First and foremost Fish \& Game should be the leader in licensing and regulating game farms in Montana. These operations should bear the costs for all work done by Fish \& Game personnel and not sportsmen.

Response: Under the preferred alternative, FWP would provide oversight of game farming and other commercial uses of wildlife. This alternative also would seek legislation to provide funding for such oversight from a source other than license 
revenue, develop new criteria used in approval or denial of a permit, and clarify laws regulating importation of wildlife and exportation of animal parts.

\section{Predator Control- 15 comments}

\section{ISSUE \#18}

\section{Summary}

Public comment focused on abandoning the contribution to DOL for predator control. Some comments indicated redirection of funds to deal with predation on game animals and other wildlife or to other FWP programs.

The minority point of view was that some compensation or assistance to landowners experiencing depredation on livestock is warranted.

\section{Sample of Comments}

- Predators----look at other ways to handle predators, not just hunting and killing.

- Contributions by the department to the DOL for predator control was originally done because it was believed this donation might open more private land to the hunting public. We do not feel this is so any longer.

- Predation is also a volatile issue with me. DOL is responsible for depredation, and FWP has played a very minimal role in the depredation issue.

- Under current law, DOL is the only resource livestock growers here in Montana have available to them in the case of any losses that they experience. I think that a combined effort involving the FWP, DOL, and the private sector could effectively address this growing problem with not only better results, but also creating credibility in dealing with this problem for all of us involved.

- A review of the EIS indicates that none of the Alternatives address this issue very well. The definition of the terms management, control, and removal seem synonymous, but it is unclear. In addition, if the control of these animals is a DOL function, why should FWP fund these activities? If FWP is operating under the assumption that these animals are limiting game populations, some documentation should be added to the final version of the EIS.

Response: The biological, social, and economic impacts of FWP's contribution to DOL for aerial gunning of coyotes were summarized in Chapter IV of the draft EIS. FWP proposes to continue its contribution under the preferred alternative although with emphasis redirected to wildlife goals. Exploring incentives and alternative ways of reducing the impacts of predators also is part of the preferred alternative. 


\section{Game Damage -8 comments}

\section{ISSUE \#19}

\section{Summary}

Public comment supports providing game damage assistance to landowners that allow public access for hunting. Direct compensation to landowners in the form of cash payments or licenses received very little support and was limited to those directly involved in agriculture.

\section{Sample of Comments}

- Compensation to landowners will cost too much and take away from the rest of the program.

- We would definitely like to see the FWP (on a regional and statewide basis) become more involved in land use planning to prevent game damage situations from developing or worsening.

- The department should work with landowners in game damage problems, especially those providing access to their property. What is the definition of reasonable access and for whom?

Response: Under the preferred alternative, FWP would continue to investigate game damage complaints and provide assistance consistent with current state law and also use the general hunting season format to address game damage. Under this alternative, FWP would coordinate harvest regulations with adjacent jurisdictions and encourage cooperation among adjacent landowners in allowing hunting to minimize damage to crops.

\section{Noxious Weeds- 6 comments}

\section{ISSUE \#20}

\section{Summary}

Everyone agrees that something should be done about infestation of noxious weeds and most acknowledge FWP is a major player. Biological control has been endorsed by not only hunters and conservationists but also by one county commissioner suggesting relatively broad support for this method of control. Weed control is an issue where FWP should remain involved and would be supported in doing so.

\section{Sample of Comments}

- I feel that the department should aggressively treat the weed situation with all resources available. I realize that this can be an expensive proposition, but if we stay on top of this situation, we will prevail. We also must remember that not all of the weed problem is caused by the use of humans. 
- Weed control is a good use of wildlife management money. Money should be spent where long-term success is greatest. Biological control is the long-term answer. Annually spraying for weeds, year after year after year appears to be a waste of money.

- As a landowner and licensed outfitter, I am concerned about wildlife and habitat. ..weeds are of major concern to the landowner community..... We simply must stop the slow but persistent infestation of noxious weeds. Weeds are now commonly used as a reason (and justifiably so) for landowners to deny access to the hunting public. FWP must become a major statewide partner in weed control and eradication.

Response: FWP would continue to control weeds on its land at a level consistent with state law. Under the preferred alternative, FWP would increase emphasis on biological control of weeds and explore collaborative opportunities at the local level to control infestations of noxious weeds.

\section{ISSUE \#21}

\section{Urban Wildlife— 11 comments}

\section{Summary}

This is one of the most contentious issues addressed in the draft EIS. A broad cross section of public comment, including recreationists and conservationists from across the state support increased involvement by FWP in local land use planning and reducing human/wildlife conflicts on the urban interface.

The source of opposition to any FWP involvement in land use planning and managing wildlife on the urban interface came from Lincoln County. Many Lincoln County residents opposed the proposal under alternative 5 that would fund FWP's response to wildlife problems in residential areas with funds derived from a source other than with license dollars.

\section{Sample of Comments}

- The document says that FWP may propose legal changes to gain involvement in more issues such as subdivision review. If you go for legal changes, let local governmental officials know, mayors and county commissioners across the state. We need to know early in the process to provide an opportunity for informed input to state legislators before they vote. Public and local government officials are not at the table when it comes to these efforts for change.

- At a state level, the FWP needs to support the recommendations of its field staff. Urban wildlife control should NOT be paid with hunter dollars.

- Active participation in land use planning with an emphasis on reducing wildlife/human conflicts and habitat preservation. I think it's fair to charge impact fees to developers and/or homeowners. 
- Also assessing homeowners in rural subdivisions to pay for FWP services is an excellent idea. In that FWP is responsible for managing all wildlife, they cannot stick their heads in the sand and expect others to manage wildlife problems. Educating landowners about proper management of their subdivision properties is important.

Response: FWP would take a more active role in providing information to decisionmakers involved in land use planning under its preferred alternative. FWP would focus its effort on maintaining public safety and increase reliance on other entities to reduce other human/wildlife conflicts.

\section{Alternative $1-10$ comments}

\section{Summary}

Alternative 1 received substantial public support because of the familiarity of most actions identified under that alternative and many public comments expressed some satisfaction with the way things are now. Others believe that while many actions currently taken by FWP are satisfactory, some areas, such as nongame and T\&E management need more emphasis than they currently receive, or, believe that FWP may not be meeting its mandates in those areas.

\section{Sample of Comments}

- Do not support as changes are needed. Only strong point of this alternative is game damage assistance.

- From the limited time I have had to read the Wildlife Environmental Impact Statement, I feel that if the present program isn't broken, there is nothing to fix, in need of, or to change.

- It is not clear as to what extent the existing program meets the mandates. Given the language in the Introduction on page one, one must ask whether FWP is meeting its mandate for nongame and threatened and endangered species management when it directs most of its emphasis and financial and personnel resources to a limited number of game species, in comparison with the large number of nongame species that occur in the state. Alternative 1 seems to fall somewhat short of the agency's stated mission and goals of conservation and enhancement of terrestrial ecosystems and biodiversity.

\section{Alternative $2-5$ comments}

\section{Summary}

Public comment suggested strong opposition to alternative 2. Nearly all these comments favored a stronger leadership role for FWP in managing the states wildlife resource than what actions proposed under this alternative would imply. 


\section{Sample of Comments}

- Do not support this alternative as too much emphasis is being placed on wildlife statewide to reduce effort. One good point of Issue \#7 is including the big game combination for landowner sponsored licenses.

- The nature of this alternative seems to be an entirely inappropriate philosophical agency direction, given the existing pressures on natural resources. Despite the anti-government sentiment and the possibility that it will increase in the future, now is not the time for resource management agencies to fade into the background.

\section{Alternative 3-23 comments}

\section{Summary}

Alternative 3 received a mixed review in terms of public comment. One point of view favors FWP's habitat programs moving in a direction that considers a broader range of wildlife and more visibly meeting agency mandates. Those who oppose FWP moving in that direction do so because they believe that FWP does not control enough resources to reach any realistic objective or that it would not equate to making more game animals available to hunters.

\section{Sample of Comments}

- Need to manage/coordinate all goals to ecosystem framework to benefit fish and wildlife.

- Favors 3- outside pressures need to be addressed, and alternatives 1 and 2 ignore the realities of these pressures.

- This is not acceptable because FWP does not control all the resources needed to implement the alternative.

- With human populations continuing to grow especially in the rural areas, human encroachment in our "wild" lands is inevitable. Instead of reacting to the problems that arise from this encroachment, it has become more important than ever to be proactive in managing the wildlife.

- I favor Alternative III of the above EIS, in that I think the main mission of Montana Fish, Wildlife \& Parks (FWP) is to protect and enhance wildlife habitat for native wildlife species in Montana.

\section{Alternative 4-6 comments}

\section{Summary}

Nearly all public comment regarding this alternative suggested strong opposition to FWP implementing it in its entirety. Most opposition seemingly resulted from concern about increased 
privatization of wildlife and allowing private landowners and outfitters too much influence over resource decisions that could adversely affect public enjoyment of the resource.

\section{Sample of Comments}

- Alternative 4 will take much of the "public" out of the hunting picture.

- This alternative causes some concern about the viewpoint held by some that market forces direct natural resource management. It seems to open the door for privatization of public wildlife resources. This alternative includes an emphasis for programs on public lands, with the agency making only a minimal effort to discourage leasing and charging of access fees. This alternative would also reduce the agency's emphasis on habitat conservation.

- I object to Alternative IV because its central premise of reliance on "markets" to manage wildlife is anathema to the principle of public trust ownership of wildlife. It would eventually create a "European System" of wildlife management in Montana. This I consider to be a mild form of treason.

\section{Alternative 5-8 comments}

\section{Summary}

Public response to this alternative was mixed although comment focused on issues addressed in a way that individuals commenting on the alternative seemed to favor. Those opposed to implementing the alternative disagreed with the increased emphasis on management of wildlife for increased hunting opportunity.

\section{Sample of Comments}

- Again the wildlife program should not be in the "recreation business" (infer that FWP is in the business of game management for hunting).

- I prefer Alternative V in the Wildlife Program Draft Programmatic EIS dated March 1998. My first reaction was to choose Alternative I, the no action alternative, because I would prefer to continue hunting just as I have in the past. However, we should accept and accommodate change, and plan for a realistic, desirable future.

- I have to assume that alternative 5 , is the preferred alternative of the department. I come to this assumption, because this alternative combines several of the most important issues that are being considered, and allows for the dept. to maintain many of the programs that are currently in effect.

- The potential expansion and promotion of wildlife-related recreational opportunities (both consumptive and non-consumptive) on private lands is attractive. User preferences would be a driving force. Whereas, this alternative would broaden the support base for the agency and 
hopefully public interest in natural resource conservation, it would also expand the agency's role in of allocating recreational opportunity and resolving user conflicts.

\section{A Sixth Alternative- 18 comments}

\section{Summary}

Public comment that alluded to a $6^{\text {th }}$ alternative generally supported combining the more favorable elements of the five alternatives analyzed in the draft EIS. Most of this comment centered on developing an additional alternative that incorporated part of alternatives 1,3 , and 5 . Some organizations submitted their own alternative that addressed each of the 21 issues.

\section{Sample of Comments}

- No one alternative is fully acceptable and the final alternative should be a blend of the 5 offered.

- Alternative 3 holds the basic requirements to meet the future program challenges for the wildlife program. There are important and positive aspects within alternative 5 that should be melded into alternative 3 and some philosophical changes needed in alternative 3 .

We do not believe any one alternative is satisfactory. A combination of several alternatives would seem to be in order.

In considering the various alternatives along with their respective strengths and weaknesses, it would indeed be worthwhile to develop an additional alternative that combines portions of Alternatives 1,3 and 5. Philosophically, it would call on the agency to maintain much of its existing program, but to expand efforts above the current levels in management of nongame and threatened and endangered species management, wildlife viewing, land-use planning and research. 


\section{Summary of Public Response to the Preferred Alternative (Draft Supplement)}

Public response to the draft supplement included 63 individuals and seven organizations (see attachment 7). Of the response from the public, ten individuals indicated that the preferred alternative was the appropriate mix of actions and policies that should be implemented as FWP's wildlife program. Eight individuals agreed that it was acceptable but believe that FWP could have gone further to adequately address some issues important to them. Twelve individuals still preferred either alternative 1 or 3 . Nineteen letters from Lincoln County asked for an extension to the comment period. Ten letters focused on one or more of the 21 issues analyzed in the draft EIS and draft supplement. FWP believes that all these issues were adequately addressed in its analysis of the alternatives in the draft EIS and draft supplement.

\section{Response to Preferred Alternative}

\section{ISSUE \#1}

\section{Overall Access - 5 comments}

Public comment mainly centered on access to public land, road closures and motorized travel restrictions on public lands.

\section{Samples of Comments:}

- To have an effective and successful land management program you must have a transportation system. Roads are the only economical system we have today. Your plan must support these roads and not discourage them if you are going to provide for the recreational needs of the future.

- Continued reduction and control of motorized travel is going in the wrong direction.

- There are other questions we would like addressed .... managing motorized travel and other issues involving the Federal government.

- I would like to see the focus of access related to management gain more emphasis toward habitat protection, especially the habitat of sensitive and T\&E species, rather than an emphasis on increasing hunter harvest and opportunity.

Response: FWP does not regulate travel on public land under either federal or state jurisdiction. FWP does make recommendations on travel management to these agencies, who in turn may or may not follow those recommendations.

The preferred alternative does make provisions to increase emphasis on the protection of habitat for T\&E species, the effects of increased access for wildlife management 
purposes are discussed in the environmental effects portion of the draft EIS and are not expected to increase vulnerability of any species.

\section{ISSUE \#2}

\section{Access/Private Land - 2 comments}

\section{Summary}

Public comment indicated additional access was needed on federal land in order to reduce recreational pressures on private land and that additional incentives should be considered for private landowners.

\section{Sample of Comments}

- The plan must address how management of state and federal land will be changed so that current pressures for hunting and recreation opportunities on private land will be reduced.

Response: FWP does not regulate travel on public lands under either federal or state jurisdiction. FWP does make recommendations on travel management to these agencies, who in turn may or may not follow those recommendations.

Under the preferred alternative FWP would continue to emphasize block management and hunter enhancement programs with monetary compensation for participating landowners as well as the opportunity to obtain free sportsmen licenses.

\section{ISSUE \#3}

\section{Lands Program/Access - 2 comments}

\section{Summary}

Public comment did not differ substantially from those received on the Draft EIS.

\section{Sample of Comments:}

- We feel that public access should be mandatory, not merely encouraged on a case by case basis.

- Outright purchase within the Habitat Montana program should not be a first choice of the department. Easements provide a much more acceptable method of conserving habitat on private lands.

Response: By statute the Habitat Montana Program cannot make access a mandatory 
element of acquiring an easement. FWP will continue to use the most appropriate method of protecting these important habitats and leave the option of easement, lease, or purchase open to the Commission.

\section{ISSUE \#4}

\section{Response to Agency Requests - 3 comments}

\section{Summary:}

Commentors felt FWP should be more aggressive in discouraging the use of ATV's.

\section{Sample of Comments:}

- $\quad$ FWP should take an aggressive role in protecting wildlife habitat from the short and long term cumulative effects of both restricted and unrestricted motorized recreational vehicle travel.

Response: FWP does not regulate travel on public lands under either federal or state jurisdiction. FWP does make recommendations on travel management to these agencies, who in turn may or may not follow those recommendations. The preferred alternative, however, proposes working with land management agencies to promote ethical use of motor vehicles on public land.

\section{ISSUE \#5 - NO COMMENT}

\section{ISSUE \#6}

\section{Loss of Access to Fee Hunting - 1 comment}

\section{Sample of Comments}

Reasonable access fees that provide compensation to landowners for managing their public hunters should not restrict opportunities for assistance with game damage or other wildlife management expertise provided by the department.

Response: Under the preferred alternative FWP would continue to provide game damage assistance to landowners that provide "reasonable" access as mandated by state law. This may also include landowners that charge access fees. This does not constitute a change from current policy. 


\section{ISSUE \#7}

\section{Special Constituent Groups - 5 comments}

\section{Summary}

Public comment indicated that before any changes are made in the current program an analysis of data was needed to justify the change.

As one of the beneficiaries of the over 62 license discounts, I guess I'd suggest releasing some solid demographic and cash-total data to justify any proposed changes in this provision.

Response: FWP would provide both the public and the legislature, who would make such decisions, the reasoning behind any proposed change in license structure. FWP is not advocating the abolishment of the senior discount but used that as an example of what could be done to meet losses of funding in the future.

\section{ISSUE \#8}

\section{Emphasize Wildlife \& Habitat/Recreation - 2 comments}

\section{Summary}

One commentor felt FWP should emphasize recovering T\&E species, while the other felt trapping is not acceptable.

\section{Sample of Comments:}

- Emphasis should be on "Recovering" T\&E species then when recovered move to possible delisting.

- Trapping is an inhumane and unacceptable alternative in wildlife management.

Response: As proposed under the preferred alternative, FWP believes trapping is a tool that is compatible with wildlife management. The preferred alternative also places additional emphasis on the recovery of $T \& E$ species. 


\section{ISSUE \#9}

\section{Trophy Hunting - 4 comments}

\section{Summary}

As with the comments on the Draft, comments on this issue ranged from asking for more restrictions statewide to FWP not being involved with trophy management.

\section{Sample of Comments:}

- Hunters enjoy the privilege of harvesting animals from a natural population but Montana is not a game farm and MDFWP should not be involved in changing the natural biological makeup of our wildlife populations.

- I would remind you that Montana's "hunting heritage" includes the factor of quality as well as participation.

- MFWP needs to make more use of buck only seasons and bucks with certain size categories only.

Response: FWP believes that by emphasizing diversity of hunting opportunity most people will find an area to provide them with the type of animals they wish to hunt. We also know that because of the diversity of our hunters, these opportunities will not satisfy everyone everywhere. The preferred alternative would continue to emphasize the diversity of hunter opportunity across the state.

\section{ISSUE \#10/11}

\section{Hunter Participation/ Opportunity - 4 comments}

\section{Summary}

Public comment indicated some people had questions regarding the approaches FWP would take and the emphasis placed on hunter ethics. Others felt FWP should not be attempting to enlist new users.

\section{Sample of Comments}

- There are other questions we would like addressed in regard to nonhunting-public type people, social barriers programs, that include "Outdoor Woman", youth and advanced hunter skills programs, $\ldots$

- Hunter ethics certainly needs a lot more emphasis than this program promises. 
Response: Habitat protection may or may not result in increases in the numbers of game animals (see Issue 13). FWP will continue to emphasize habitat that is critical to game species but will also have the option to place more emphasis on the protection of high priority habitat important to nongame or T\&E species.

\section{ISSUE \#15}

\section{Payment In-Lieu of Taxes - 1 comment}

\section{Summary}

The commentor agreed with the position taken under the preferred alternative.

\section{Sample of Comments:}

- Make in-lieu payments to counties on real property

Response: Thank you for your support.

\section{ISSUE \#16}

\section{Research - 2 comments}

\section{Summary}

Comments supported a strong research program, however where the emphasis of the program should be placed differed.

\section{Sample of Comments:}

- Alternative \#6 does not place enough emphasis on long term research on management of ecological communities.

- $\quad$ Research projects utilizing MSU, or UM should be given a high priority for DFWP. Integration of advanced wildlife management practices within traditional family ranches should be given high priority, and should be so designed as to look at the economics of ranching, and how a wildlife conservation program can provide benefits for both livestock and wildlife.

Response: As stated in the preferred alternative FWP will direct research at regional and statewide priorities. This does not preclude an emphasis on ecological communities or conservation programs that would benefit both livestock and wildlife. It emphasizes habitat and harvest issues which encompass the stated concerns. 


\section{Commercial Operations - 5 comments}

\section{Summary}

Public comment indicated FWP has more than a legal obligation to fulfill concerning this issue, called for the prohibition of game farming in Montana and supported passing on costs incurred by FWP in dealing with game farms to the owners.

\section{Sample of Comments}

- Despite a stated intention to meet legal obligations, the FWP response to game farming remains the weakest, least defensible, and most disappointing responses to all wildlife issues in Montana. What about moral obligations to the wildlife resources of this state?

- One answer - ban game farms.

- All costs relating to game farms must be borne by game farm owners.

Response: FWP's mission statement declared we will "... provide for the stewardship of fish, wildlife, parks and recreational resources of Montana..", by statute we are also obligated to abide by and uphold the laws of the state of Montana, which regulate the existence of game farming in the state. The preferred alternative would also seek authority to charge commercial operators for expenses incurred for inspecting and licensing facilities.

\section{ISSUE \#18}

\section{Predator Control - 8 comments}

\section{Summary}

Public comment ranged from opposition to FWP contributing to DOL for predator control to support for the program where it involved primarily protection of livestock as well as wildlife.

\section{Sample of Comments}

- We remain opposed to the contribution of hunter dollars to Montana DOL for coyote control under the guise of benefits to game populations and Montana hunters.

- Many of us remain pretty much unconvinced that DOL is in the predator control business to “...address wildlife goals...", but I assume there must be some situations that justify whatever 
monetary contribution is involved. I particularly favor the exploration of incentives and alternative methods.

- I urge FWP to stop all monetary contributions to DOL and use these funds to research ways to limit livestock depredation without destroying or harming any predators.

- Trapping is inhumane and an unacceptable alternative in wildlife management.

- Is the evidence for the need for this effort strong enough to justify it? While the Preferred Alternative seems to move toward more of an ecosystem approach toward management, this issue seems solidly grounded in a single-species approach.

Response: Under the Preferred Alternative FWP would retain control of where contributions made to DOL for coyote control are expended. Efforts would be directed toward areas that would be most beneficial to wildlife and secondarily benefitting livestock. FWP expects this to remain a contentious issue in the future.

\section{ISSUE \#19 - NO COMMENTS}

ISSUE \#20

Noxious weeds -2 comments

\section{Summary}

Comments asked FWP to look at our own actions, and to be sure biological controls do not result in additional problems.

\section{Sample of Comments:}

- Again look down the hall at the boys in Parks division ATV bureau. They are sponsoring and funding weed spreading by promoting ATV use.

- Lets be sure that biological controls aren't worse than initial problem.

Response: FWP will assess our programs and any control method used on noxious weeds prior to initiating any actions. 


\section{ISSUE \#21}

\section{Urban Wildlife - 3 comment}

\section{Summary}

Comments indicated it was unlikely that other entities would be willing or able to deal with nuisance urban wildlife, and a tax to fund such actions was in order.

\section{Sample of Comments}

- $\quad$ The FWP response to the urban wildlife issue appears tho address only the presence of large predators. This is just the tip of an iceberg involving habituation of ungulates, where the FWP action seems far too dependent on hoping other entities will address the conflicts. It would be nice if someone else could take this responsibility, but it is unlikely that anyone will.

- I support Alt. \#6. In addition to stated goals MDFWP should aggressively seek legislative funding through urban wildlife control districts which would assess a tax on rural subdivisions to fund FWP services.

Response: Under the Preferred Alternative FWP would continue to deal with those situations that pose a threat to public safety but would not relinquish its authority to deal with nuisance ungulates. We would rely more heavily on the private sector to deal with problems involving other species, and possibly seek new funding sources to deal with these situations. 



\title{
Organizations, Groups, or Individuals That Reviewed and Responded to the Draft EIS
}

\author{
ORGANIZATIONS AND GROUPS
}

Big Sky Country Trail Preservers

Billings Rod \& Gun Club

Dawson County Commission

East Sanders County Sportsman Club

F.H. Stoltze Land \& Lumber Co.

Five Valley's Audubon

Flathead Audubon Society

Flathead Wildlife, Inc.

Friends of the Wild Swan

Gallatin Wildlife Assoc.

Headwaters Fish \& Game Assoc.

Intermountain Forest Industry Assoc.
Lincoln County Commissioners

Montana Audubon

Montana Bowhunters Assoc.

Montana Stockgrowers Assoc.

Montana Wildlife Federation

Orion, The Hunters Institute

Ravalli County Fish \& Wildl. Assoc.

Russell Country Sportsmans Assoc.

Skyline Sportsmen's Assoc., Inc.

The Wildlife Society, Montana Chapter

Western.Mont. Fish \& Game Assoc.

\section{INDIVIDUALS}

Robin Aasheim

Torleif Aasheim

Lori Adams

Rick Adams

Mark Ahner

Elaine Allestad

Jerry Ambrose

William Anderson

Dwayne Andrews

Cyril Appel

Myra Appel

Andy Apple

Holly Apple

Maria Armstrong

Bea Arroe

Carvel Artley

Doug Artley

Jack Atcheson Sr.

Howard Baker

Bill Ballard
Steven Barkley

Rebecca Barkley

Kandis Barrie

Dale Becker

Arlyne Beito

Stacey Bengston

Paul Berg

Michael Bergman

Gary Bintz

Larry Birge

Velma Birge

Lee Black

L. Blatter

John Blonquist

Brad Borden

Tom Bowe

Rick Bragg

Barb Brant

Kurt Breithaupt
Kenneth Breitousteno

Richard Brogg

Ron Brown

Mary Bruce

Billie Jo Brue

Mary Brue

Vernon Brue

Donna Clark

R.W. Blair

Andrea Breu

R. Brus

Ronald Buentemeier

Mary Burgess

Robert Burgess

Tom Burson

Ryan Busse

Dale Byrer

Deanna Byrer

Mary Campbell

Rauch Campbell 
Irene Carlson

Maynard Carlson

Jim Carney

Les Castren

Frederick Cerra

Mark Chase

Rev. H. Christiansen

Paul Clark

LaVern Clark

Trent Clark

Gail Cleveland

John Cleveland

Ty Cobb

Mike Conto

Michael Copple

Shirley Copple

Marie Cripe

N. Crismore Jr.

Karen Crittenden

James Cross

Aubyn Curtiss

Donna Davis

Stanley Davis

Dr. D. Delise

J. Diemert

Lawrence Dolezal

Herman Dolezal

Peggy Dolezal

Mary Downey

Ron Downey

Daniel Doyle

Craig Drynan

Andrea Dunn

Wendell Dunn

Charles Eanes

Ettalee Eanes

Robert Evans

Helen Farbert

Kevin Feist

John Feldenzer

Jane Fellows

Chris Ferlune

M. Ferguson
Nick Fergusen

Bill Fett

Barry Fitzgerald

Carl Florey

Mayne Flowers

Keith Fogle

Stan Frasier

Frank Friend

Lucia Friend

Harlan Galbraith

John Gibson

James Gray

Steve Haarsteck

Martin Hale

Vicky Hall

Ron Halvorson

Darrell Harris

Hugh Hollyday III

Ted Hardgrove

Perry Harrk

Lois Harvey

Nancy Hayes

William Hayes

Judy Hering

Sharon Hesselgesser

Larry Hilderman

Jack Hinkle

Ruth Hill

Melvin Hoff

Jeff Hoff

Ira Holt

Linda Hosek

Greg Houska

Steve Huarstick

Mary Huff

Gary Iacoluvd

Warren Illi

Michael Ivinsn

Cheryl Jo Jackson

Mitchel Jackson

Sandra Jackson

Dale Jantz

Roger Jensen
Royal Johnson

Casey Johnston

Brian Jones

Dan Jones

Jack Jones

Kurt Jones

Lisa Jones

Gayle Joslin

James June

Bob Kamena

Gregory Kasper

Raymond Keeler

Evelyn Kelch

Deborah Knox

Arnold Kelly

Daniel Kelly

Doug Kelly

Marilyn Kelly

Vela Kelly

Ray Kenny

Tom Kilmer

Sam Kitzenberg

Ralph Klawitter

William Konie

Scott Lampshire

Larry Lampton

Robert Lance

Ernest Landert

Valerie Larimore

LaVerne Larimore

Marshall Larimore

Karen Larsen

Barbara Lewis

Susan Lindberg

Ron Litostansky

Kathy Lloyd

Becky Lomax

Curtis Lord

Bob Lovegrove

Jeremy Lugibihl

Pattie Luz

Jack Lyon

Keith Mack 
Anthony Madonna

Michael Makieve

Gary Marbut

Bok Markeberg

Lawrence Markeberg

Sarah Markeberg

D. Matott

Scott McCollough

Fran McCully

Marcus McCully

Jim McDermand

Bill Meadows

Brent Mitchell

Georgia Mcghee

Robert Mcghee

Jimmie McKay

Dawn Melcer

Gerry Mercer

Bob Miars

Duane Millett

Arlene Montgomery

Wayne Moser

Ron Moody

Jerry Murphy

Jonathon Nelson

Tim Neville

Harmon Olbekson

Loren Olbekson

Bridgett O'Leary

Douglas Oliver

Geraldine OliverJ. O'Neill

D. Orr

Scott Orr

Judy Owsowitz

Ron Pagel

Sara Parr

David Patterson

William Pattie

Charles Peek

Phyllis Peek

Barbara Penner

Steve Penner

Mary Lou Peterson
James Phelps

Jim Pierce

Carolyn Pitman

Shannon Podruzny

Jim Posewitz

Kathryn Posten

Bob Potter

Ethna Prook

Vito Quatraro

Julie Raine

Casey Rankin

Julie Rathlsun

Timothy Ravndal

Jim Rector

Tom Reilly

Chuck Rein

John Resch

Martin Riedlinger

J. Rodichr

Douglas Rhodes

Arlen Roll

Allen Ross

Karen Ross

James Rostorfer

Sally Roy

Marianne Rozar

Bruce Ruckman

Ross Savage

Joy Savage

Dario Scarabosio

Allen Schallenberger

Joe Schnackenberg

Steve Schnackenberg

Kim Schwenk

Franklin Schroeter

Peggy Sebrowsky

Bob Seidel

Wally Shamanski

Josh Sherwood

Greg Shildwachter

Patricia Siddall

Pat Simmons

Don Slusher
Bill Smith

Cynda Smith

Jean Smith

Zane Smith

Seath Snelson

George Snyder

John Sparks

Kurt Spencer

Francis Stanton

Harold Stanton

Roy Stanton

Bob Stevenson

Ida Stewart

Ellis Stewart

Ray Stout

Patrick Sullivan

Joseph Tandy

Stacy Tandy

Bob Teagarden

John Tidwell

Dave Trumbo

Richard Trumbo

Dwight VanBrunt

Kellie VanBrunt

Mike Vinion

Lew Wallace

Sarah Walter

Kendall Ward

Betty Ward

Larry Weeks

John Weigand

ChallenWells III

Patricia Westhauer

Peter Westhauer

Scott Westphal

Bonny White

Wesley White

Jerry Whitmer

George Wideuer

Brian Williams

Mike Williams

Rita Windom

Robert Windom 
Jean Winn

Leslie Winn

Jeff Witbrod
Kevin Witbrod

Mary Witbrod

Trish Wolf

Chester Wolter
Ed Yonally

Phyllis Yonally 


\section{Appendix B.}

\section{WILDLIFE ENVIRONMENTAL IMPACT STATEMENT \\ RESPONSE FORM}

This response form is being provided for your convenience in commenting on Fish, Wildlife \& Parks' Wildlife Environmental Impact Statement (EIS). Please respond to the questions listed and provide any additional comments you may have. It would be most helpful to receive your completed response form by June 30, 1998.

Name:

Address:

Organizational affiliation (if any)

1. Do you believe the Wildlife program should be guided by any of the altematives as described?

2. In your opinion, of the 21 issues used to develop the EIS, which three are the most important to consider within the Wildlife program?

3. Recognizing that the EIS goals represent long-term priorities to guide our efforts, do you think anything is missing?

4. Please add any additional comments.

After completing this form, please fold it so that FWP's return address is on the outside, add a stamp, and seal with scotch tape. (Do not use staples). Thanks for your help! 
Appendix C.

\title{
Organizations, Groups, or Individuals That Reviewed and Responded to the Draft Supplement
}

\author{
ORGANIZATIONS AND GROUPS
}

F.H. Stoltze Land \& Lumber Co.

Flathead Wildlife, Inc.

Headwaters Fish \& Game Assoc.

Intermountain Forest Industry Assoc.
Lincoln County Commission

Montana Chapter, The Wildlife Society

Montana Stockgrowers Assoc.

\section{INDIVIDUALS}

$\begin{array}{lll}\text { Jerry Ambrose } & \text { Myrtle Feldenzer } & \text { Arlen Roll } \\ \text { Dale Becker } & \text { Nick Fergusen } & \text { Marianne Roose } \\ \text { Arlyne Beito } & \text { Lois Harvey } & \text { Bruce Ruckman } \\ \text { Velma Birge } & \text { Hugh Halyden III } & \text { Dario Scarabosio } \\ \text { Ron Brown } & \text { Jack Hinkle } & \text { Mary Ann Scarabosio } \\ \text { Billie Jo Brue } & \text { Greg Housla } & \text { Greg Schildwachter } \\ \text { Ronald Buentemeier } & \text { Steve Huarstick } & \text { John Sparks } \\ \text { Jason Campbell } & \text { Warren Illi } & \text { Francis Stanton } \\ \text { Irene Carlson } & \text { Tom Kilmer } & \text { Ellis Stewart } \\ \text { Maynard Carlson } & \text { Robert Lance } & \text { Ida Stewart } \\ \text { Jim Carney } & \text { Karyn Larsen } & \text { Graham Taylor } \\ \text { Mark Chase } & \text { Bob Lovegrove } & \text { Diana Trumbo } \\ \text { Marie Cripe } & \text { Jack Lyon } & \text { David Trumbo } \\ \text { James Cross } & \text { Scott McCollough } & \text { Richard Trumbo } \\ \text { Herman Dolezal } & \text { Jerry Murphy } & \text { Dwight VanBrunt } \\ \text { Lawrence Dolezal } & \text { Norman Olbekson } & \text { Kellie VanBrunt } \\ \text { Peggy Dolezal } & \text { Loren Olbekson } & \text { Mike Vinion } \\ \text { Kristi DuBois } & \text { Scott Orr } & \text { Rita Windom } \\ \text { Ettalee Eanes } & \text { Kathryn Posten } & \text { Jerry Whitmer } \\ \text { John Feldenzer } & \text { Vito Quatraro } & \end{array}$




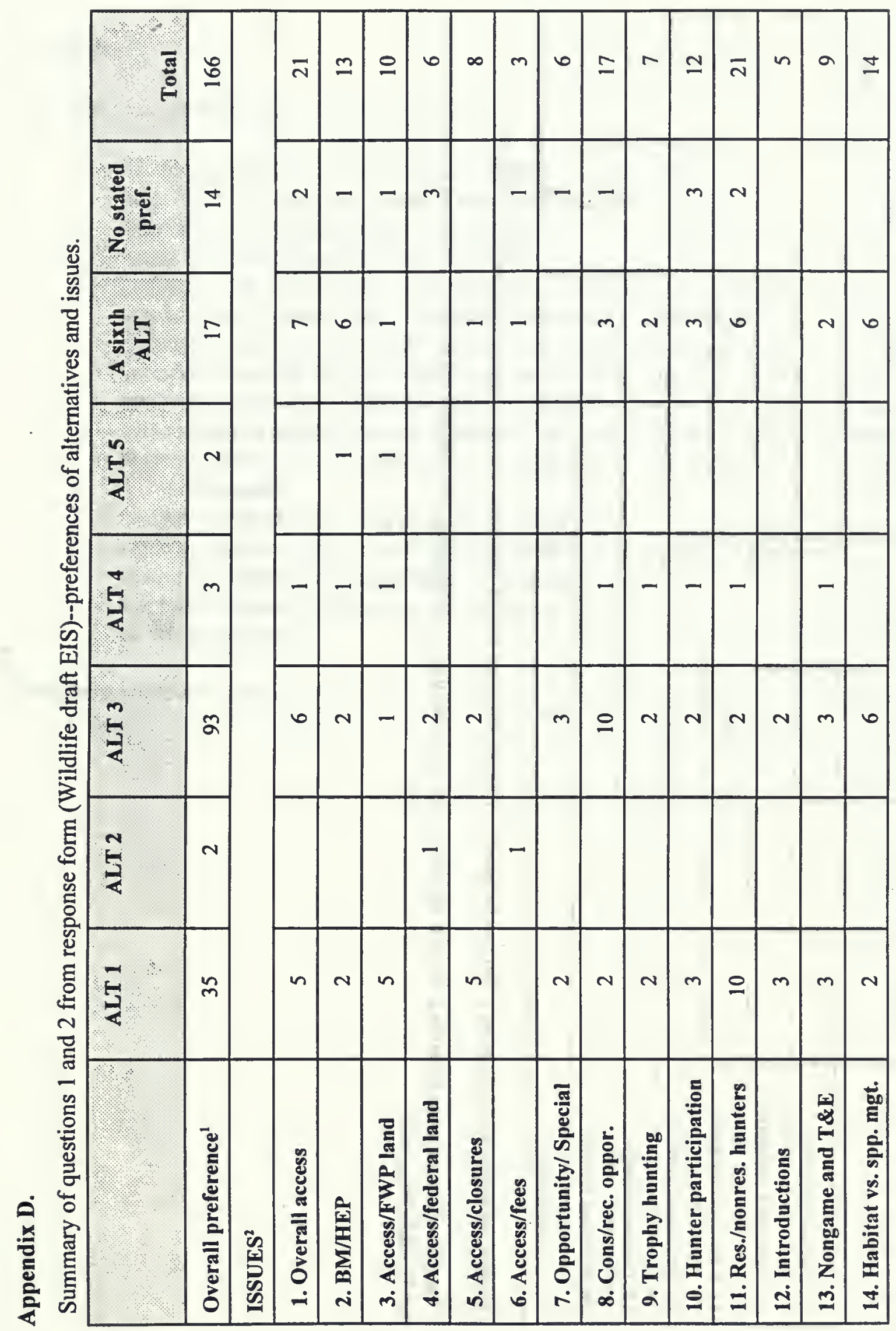



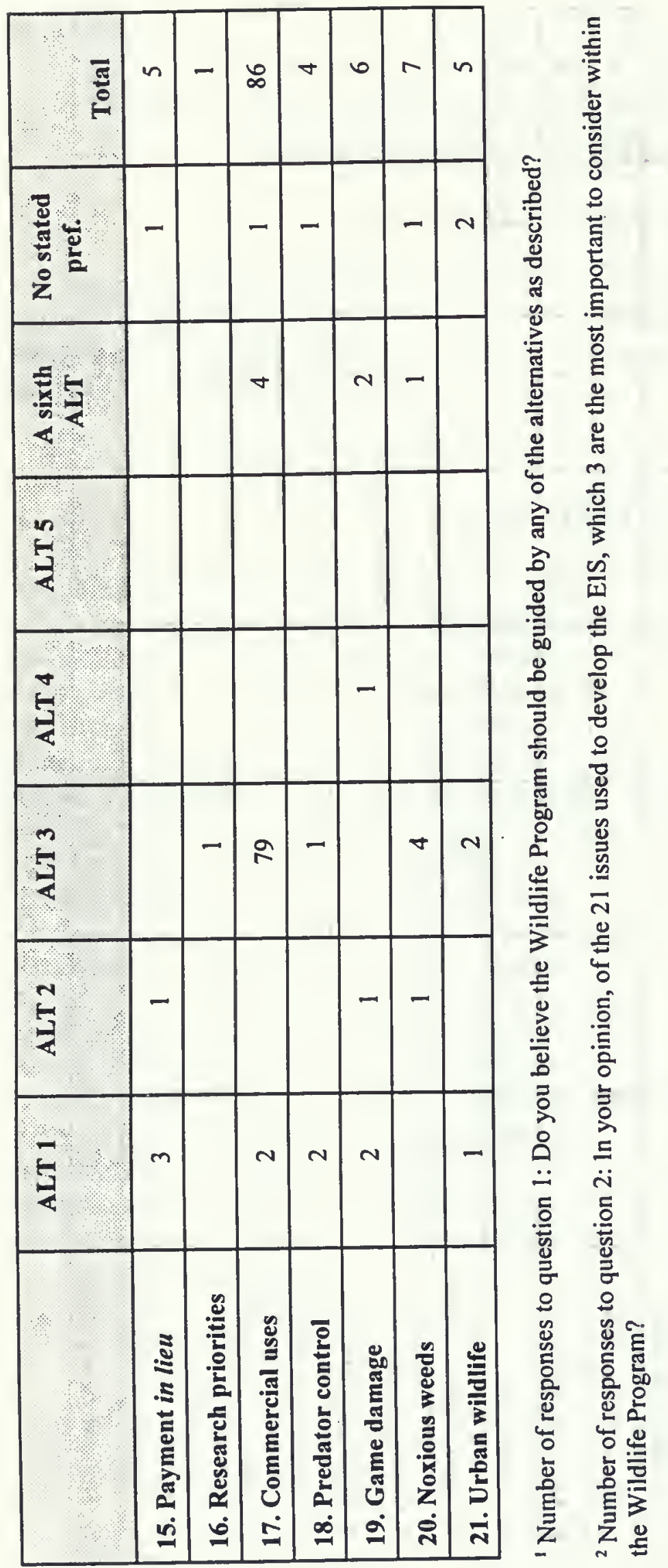


\section{Appendix E.}

Question 3: .....do you think anything is missing?

- adequate emphasis on private property rights. 1 comment

- local control of decisions related to land and wildlife. 2 comments

- innovation or common sense. 3 comments

- emphasis on habitat acquisition. 1 comment

- gaining access to corporate timber land and federal land. 2 comments

- emphasis on managing motorized access/recreation. 5 comments

- managing wildlife in areas with diverse land ownership. 4 comments

- specificity, e.g., funding, predator/prey relationships, population trends. 5 comments

- emphasis on managing T\&E species. 3 comments

- data to support implementation of alternatives analyzed in the draft EIS. 1 comment

- decrease quality and abundance of wildlife resources from commercial activities.

4 comments

- analysis of the effects of trapping. 1 comment

- working relationships between major stakeholders in hunting. 1 comment

- adequate regulation of game farms. 10 comments

- emphasis on control of noxious weeds. 2 comments

-16 other comments

Total number of comments -61 


\section{Appendix F.}

Question 4: ..... additional comments.

- opposition to commercial activities such as game farms and shooting preserves. 69 comments.

- favor FWP's traditional role of emphasizing game species and hunting. 2 comments.

- role of access in land acquisitions. 2 comments.

- concern about loss of access to private land because of leasing to outfitters or serving nonresident hunters. 7 comments.

- predation on harvestable species. 2 comments.

- FWP/hunter relationships and program funding. 7 comments.

- FWP/landowner relationships. 3 comments.

- motorized access and recreation. 3 comments.

- relative emphasis on hunting/nonhunting recreation. 4 comments.

- access to federal land. 5 comments.

- access to private land. 1 comment.

- terminology used in draft EIS. 1 comment.

- opportunities for special consitituent groups. 1 comment.

- conflicting mandates within FWP. 1 comment.

- enforcement of FWP laws and regulations. 3 comments.

- hunter ethics. 2 comments.

- EIS process. 5 comments.

- a desire for continuing involvement in the process. 11 comments.

- general comments about the issues and alternatives (collectvely). 8 comments.

- T\&E policy. 2 comments.

- hunting and trapping seasons. 7 comments.

- other topics. 8 comments.

Total number of comments -155 
; 